\title{
Studying synaptopathies using Mecp2 transgenic mouse models
}

\author{
Dissertation \\ zur Erlangung des Doktorgrades \\ der Mathematisch-Naturwissenschaftlichen Fakultäten \\ der Georg-August-Universität zu Göttingen \\ von \\ Chiranjeevi Bodda \\ aus Etikoppaka, Indien
}

Göttingen, 2013 
Referent: Prof. Dr. med. Dr. h. c. Wolfgang Engel Korreferent: Prof. Dr. rer. nat. Sigrid Hoyer-Fender Tag der mündlichen Prüfung: 
Dedicated to

o science \& tech' and my family 


\section{Table of Contents}

Table of Contents.

List of Figures iii

1. Zusammenfassung. iv

1. Summary vii

2. Introduction. .1

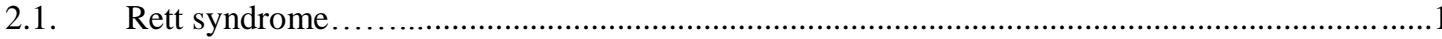

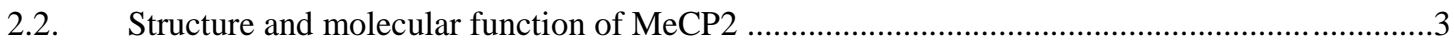

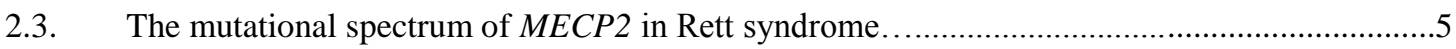

2.4. $\quad M E C P 2$ gain-of-function mutations cause neurological disorder...........................................

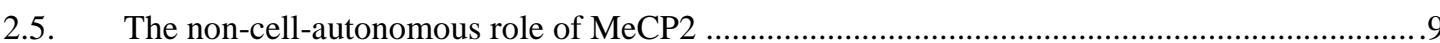

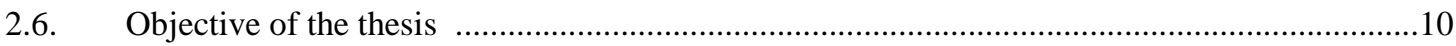

3. Results.

3.1 $\mathrm{MeCP} 2{ }^{270}$ Mutant protein is expressed in astrocytes as well as in neurons and localizes

in the nucleus.

3.2 Mild overexpression of Mecp2 in mice causes a higher susceptibility toward seizures .23

4. Discussion

4.1 Functional characterization of Mecp2 mutant mouse models .41

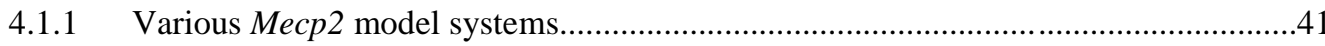

4.1.1.1 Mecp $2^{\text {tm1.1Bird }}$ knockout mouse model....................................................4

4.1.1.2 Reversal of neurological defects in Mecp $2^{\text {lox-stop }} / y$ mouse model ..................42

4.1.1.3 Mecp $2^{\mathrm{R} 308 \mathrm{X}}$ mutant mouse expressing a truncated

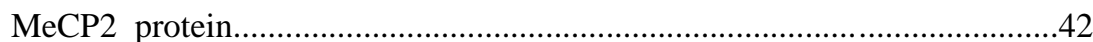

4.1.1.4 Mecp $2^{\mathrm{T158A}}$ mutant mouse model...............................................................43

4.1.1.5 Mecp $2^{\mathrm{R} 168 \mathrm{X}}$ nonsense mutation mouse model..............................................43

4.1.2 Functional characterization of $M e c p 2^{\text {R270X_EGFP }}$ mutant mouse model.........................45

4.1.2.1 Generation of Mecp $2^{R 270 X_{-} E G F P}$ mutant mouse model....................................46

4.1.2.2 Evaluation of neuronal parameters of Mecp2 $2^{R 270 \_E G F P}$ mutant mice

4.2 Phenotypical consequences of mild Mecp2 overexpression and estimation of gene-doses 
effects in a mouse model. .50

4.2.1. Mild overexpression of Mecp2 has negligible effect on differential regulation of target genes .52

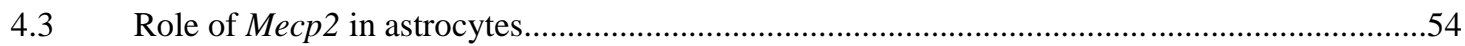

4.3.1 Establishment of astrocyte culture …..................................................................5

4.3.2 Proteomics approach to identify the MeCP2 target proteins in astrocytes....................56

4.3.3 Validation of differential expression of selected MeCP2 target proteins by Western blot.

4.3.4 Exploring therapeutic intervention by down/up-regulation of astrocyte factors in

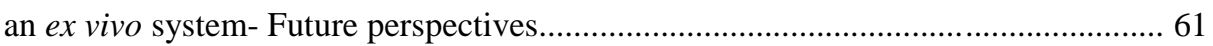

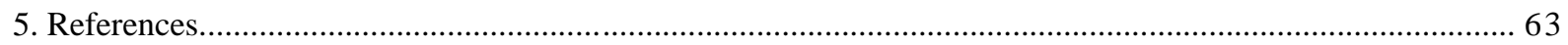

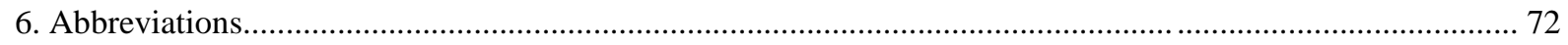

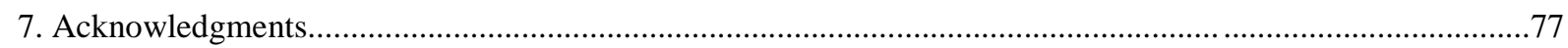

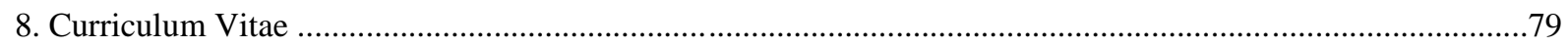

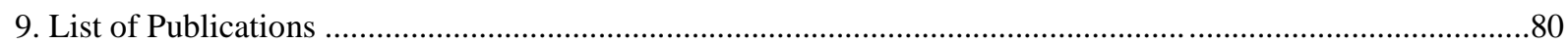




\section{List of Figures and Tables}

Figure 2.1. Schematic diagram outlining the beginning and progression of phenotypes in RTT patients....2

Figure 2.2. Schematic representation of the $M E C P 2$ gene and its splice variants .......................................

Figure 2.3. The graphic representation of $\mathrm{MeCP} 2$ protein and its functional domains...................................

Figure 2.4. Schematic diagram showing the multifunctional role of MeCP2 during development................5

Figure 2.5. Representative diagram showing the frequency of the eight most recurrent de novo mutations in $M E C P 2 / \mathrm{RTT}$ syndrome

Figure 2.5. Schematic representation of the survival of R270X mutation carrying patients compared to other mutations.

Figure 2.7. Schematic diagram showing the toxic effect of Mecp2-null astrocytes in neuronal culture..... 10

Figure 4.1. Spectrum of phenotypes of various mouse models with different types of Mecp2 mutations.. 45

Figure 4.2. Schematic diagram of mouse breeding and validation of MeCP2 protein expression............ 46

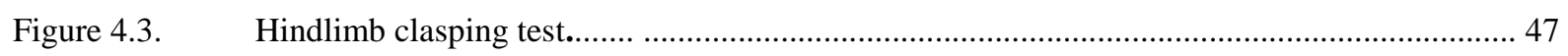

Figure 4.4. Evaluation of hippocampus neuronal parameters................................................................. 48

Figure 4.5. Evaluation of spine density in Mecp2 mouse models. ……................................................ 49

Figure 4.6. Schematic diagram showing consequence of loss and gain of MeCP2 function. ......................50

Figure 4.7. To determine the effect of mild Mecp2 overexpression ( 1.5X) on target genes regulation.... 53

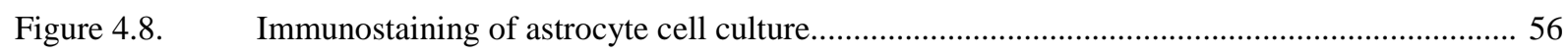

Figure 4.9. Summary of functional groups of differentially expressed Mecp2 target proteins in

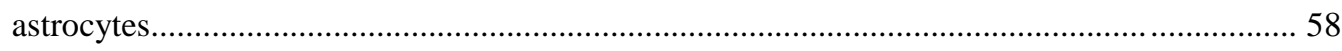

Figure 4.10. A histogram representation of selected proteins which showed significant changes in proteomic analysis.

Figure 4.11. Validation of MeCP2 target protein expression by Western blot.

Table 4.1. Summary of different mouse models of RTT with molecular defects and behavioral characteristics 44

Table 4.2. Mouse models of $M E C P 2$ duplication syndrome with their behavioral studies. 51 


\section{Zusammenfassung}

Das MECP2-Gen ist auf dem X-Chromosom in der Region Xq28 lokalisiert und kodiert für das Methyl-CpG-Bindeprotein 2. Mutationen im MECP2-Gen sind die primäre Ursache für die postnatale neuronale Entwicklungsstörung, das Rett-Syndrom (RTT, Verlust der Funktion). Im Gegensatz dazu führt die Überexpression von MECP2 zum Duplikationssyndrom (Zugewinn von Funktion). In beiden Fällen, Zugewinn und Verlust von $M E C P 2$, kommt es zu neurologischen Erkrankungen.

Im ersten Teil der Arbeit war es mein Ziel, den Pathomechanismus zu charakterisieren, der mit der humanen Mutation R279X assoziiert ist. Dies ist die am häufigsten vorkommende Mutation in RTT-Patientenkollektiven. Die R270X-Mutation ist in der TRD-NSL (transcriptional repression domain-nuclear localization signals) des MeCP2Proteins lokalisiert. Diese nonsense Mutation ruft im Vergleich zu anderen Mutationen einen schweren Phänotyp mit hoher Mortalitätsrate hervor. Um die funktionelle Rolle der R270XMutation zu evaluieren, haben wir mittels BAC-Rekombinationstechnologien eine transgene Maus generiert $\left(\right.$ Mecp $\left.2^{R 270 \_E G F P}\right)$, die equivalent zur humanen Mutation ist. Die $M e c p 2^{R 270 \_E G F P}$ zeigte ähnliche Expression wie das endogene MeCP2. Weiterhin haben wir die männliche transgene Maus Mecp2 $2^{R 270-E G F P}$ mit weiblichen Mecp2 knockout Mäusen verpaart, um $M e c p 2^{R 270}$ knockin (KI) Mäuse zu generieren. Leider konnten wir keine neurologischen Beeinträchtigungen in den Mecp $2^{R 270 \_E G F P}$-transgenen Mäusen beobachten, aber die KI Mäuse waren positiv für „hindlimb clasping“. Des Weiteren haben wir keinen Unterschied in der Neuronenlänge, der Somafläche und der Dendritendichte zwischen Wildtyp und transgenen Mecp $2^{R 270-E G F P}$ Neuronen erkennen können, aber dafür in KI Neuronen. Ausgehend von unseren experimentellen Daten schließen wir, dass das $\mathrm{MeCP} 2^{\mathrm{R} 270 \_ \text {EGFP }}$ Protein einen negativen Effekt auf die neuronale Morphologie hat und die Dendritendichte beeinflusst. 
Im zweiten Teil meiner Arbeit habe ich ein Mecp2 transgenes Mausmodell generiert, um den Dosiseffekt von MECP2 beim Duplikationssyndrom $\mathrm{zu}$ bestimmen. Die generierte $M e c p 2^{W T_{-} E G F P}$ transgene Maus zeigt eine 1,5 fache Überexpression. Auf Grund unserer intensiven Verhaltensanalysen können wir zeigen, dass eine gesteigerte Aggressivität und eine höhere Verletzungstoleranz nach Behandlung mit epileptogenen Komponenten wie Pentylenetetrazole (PTZ) in transgenen Mäusen bestehen. Weiterhin führte die Induktion von kultivierten Neuronen der transgenen Maus mit PTZ zu einer gesteigerten Calcium-Amplitude mit einer höheren Frequenz. Zusätzlich zeigten in $M e c p 2^{W T_{-} E G F P}$ transgenen Mäusen die ex vivo und in vivo Evaluationen der neuronalen Parameter von hippokampalen Neuronen eine vergrößerte Somafläche, reduzierte tertiäre Verzweigungsstellen und größere Dendritendichte. Zusammenfassend weissen unsere Ergebnisse darauf hin, dass eine milde MeCP2Überexpression in Mäusen zu epileptischen Anzeichen als einem ersten Symptom führt. Es ist eine fein regulierte Dosierung von $\mathrm{MeCP} 2$ nötig, um eine normale neuronale Entwicklung in Mäusen zu gewährleisten.

Im dritten Teil meiner Arbeit habe ich gezeigt, dass die MeCP2-Expression nicht auf Neurone beschränkt ist, sondern dieses Protein auch in Astrocyten exprimiert wird. Neueste Studien heben die Rolle von MeCP2 in Astrocyten hervor. Das Co-Kultur System mit Mecp2 Null Astrocyten mit Wildtyp Neuronen zeigte weniger sowie kürzere Dendriten. Dieses Ergebnis deutet daraufhin, dass unbekannte Faktoren von Mecp2 defizienten Astrocyten einen toxischen Effekt auf benachbarte Neurone haben. Um die MeCP2 Targets in Astrocyten zu bestimmen und zu charakterisieren, haben wir eine Proteomanalyse durchgeführt und ca. 5000 verschiedene Proteine in Astrocyten in drei unabhängigen technischen Replikaten charakterisiert. Unsere Analyse offenbarte im Vergleich zu Wildtyp Astrocyten 69 rauf- und 29 runterregulierte Proteine in KI sowie 50 rauf- und 32 runterregulierte Proteine in KO. Die identifizierten Mecp2 Targetproteine aus der Proteomanalyse zeigten, dass MeCP2 in Zelladhäsionen durch desmosomale Proteine (Dsp und Pkp1), in der Regulation der ROS 
(Reactive Oxygen Species) und der Glutamathomöostase via Slc25a18 in Astrocyten involviert ist. Wir konnten die differentielle Expression mittels Western Blot bestätigen, wobei die Proteine wie Dsp und Pkp1 eine geringere Expression in Mecp2 KO Astrocyten im Vergleich zu Wildtyp Astrocyten aufwiesen. Nach Validierung der Proteomdaten kann zukünftig ein ex vivo Assay etabliert werden, um den Effekt von non-cell autonomen Faktoren durch Proteomics zu identifizieren. Die Aufklärung der Rolle von glialer Dysfunktion in RTT kann das Verständnis von RTT verbessern und uns helfen, eine neue Therapie für diese Krankheit zu entwickeln 


\section{Summary}

The MECP2 gene is located in the $\mathrm{Xq} 28$, which encodes for methyl-CpG binding protein 2 (MeCP2). Mutations in $M E C P 2$ gene is the primary cause of postnatal neurodevelopmental disorder, Rett syndrome (RTT) (loss-of-function). In contrast the over expression of $M E C P 2$ leads to duplication syndrome (gain-of-function). In both cases, gain and loss-of function of $M E C P 2$ leads to neurological disorders.

In the first part of the thesis, we attempted to characterize the pathomechanism associated with human $\mathrm{R} 270 \mathrm{X}$ mutation in $M E C P 2$, which is one of the most frequent mutation in RTT cohorts. The R270X mutation is located within the transcriptional repression domain- nuclear localization signals (TRD-NLS) of MeCP2 protein. This nonsense mutation exhibits severe phenotype with higher mortality rate as compared to the other mutations in RTT cohorts. To evaluate the molecular and functional role of R270X mutation, we generated a Mecp $2^{R 270 \_E G F P}$ transgenic mouse by BAC recombineering technology, which is equivalent to human R270X mutation. The Mecp $2^{R 270 \_E G F P}$ transgenic mouse showed similar pattern of expression as compared to the endogenous MeCP2. Further, we bred the Mecp $2^{R 270-E G F P}$ transgenic male mouse with Mecp 2 knockout female to obtain $M e c p 2^{R 270}$ knockin (KI) mouse. Phenotypical evaluation revealed no neurological impairment in Mecp2 $2^{\text {R270_EGFP }}$ transgenic mice, but KI mice were positive for hindlimb clasping. In addition, we observed no difference in neurite length, area of soma and spine density between wildtype and Mecp2 $2^{R 270 E G F P}$ neurons, but detected reduced neurite length, soma size and spine number in KI neurons. From our experimental data, we conclude that $\mathrm{MeCP} 2^{\text {R270_EGFP }}$ protein has a deleterious effect on neuronal morphology and alters the spine density.

In the second part of the thesis, we generated a Mecp2 transgenic mouse model to determine the $M E C P 2$ dosage effect on duplication syndrome. The generated Mecp $2^{W T_{-} E G F P}$ transgenic mice mildly overexpressed MeCP2 ( 1.5X) (MeCP2 transgenic with endogenous). 
From our extensive behavioral analyzes, we observed increased aggressiveness and higher seizures in Mecp $2^{W T_{-} E G F P}$ transgenic mice propensity after treatment with epileptogenic compound pentylenetetrazole (PTZ). Furthermore, induction of Mecp $2^{W T_{-} E G F P}$ transgenic cultured neurons with PTZ caused increase calcium amplitude with a higher frequency. Additionally, the ex vivo and in vivo evaluation of neuronal parameters of hippocampal neurons revealed an increased area of soma, reduced tertiary branching sites and increased spine density in Mecp $2^{W T_{-} E G F P}$ transgenic mouse. Collectively, our results suggest that mild $\mathrm{MeCP} 2$ overexpression in mice leads to epileptic seizures as a first symptom. Furthermore, precise MeCP2 dosage is necessary for proper neurodevelopment in mice.

In the third part of the thesis, we reported that the MeCP2 expression is not restricted only in the neurons but also expressed in astrocytes. Recent studies highlighted the role of MeCP2 in astrocytes. The co-cultured assay system with Mecp2 null astrocytes together with wild type neurons displayed shorter and small number of dendrites. These findings suggested the unknown secreted factor(s) from Mecp2 deficient astrocytes cause toxic effect to the neighboring neurons in non-cell-autonomous manner. In order to determine and characterize the $\mathrm{MeCP} 2$ targets in astrocytes, we performed proteomic analysis and characterized $~ 5000$ different proteins in astrocytes with three independent technical repeats. Our proteomic analysis revealed 69 up-regulated and 29 down-regulated proteins in knockin (KI) and 50 upregulated and 32 down-regulated proteins in knockout (KO), when compared to wildtype astocytes. The identified Mecp2 target proteins from proteomic analysis revealed that MeCP2 is involved in cell adhesions through desmosomal proteins (Dsp and Pkp1), regulation of reactive oxygen species (ROS) (Txn2) and glutamate homeostasis via Slc25a18 in astrocytes. We could validate the differential expression of Mecp2 target proteins such as Dsp and Pkp1 in Mecp2 knockout astrocytes compared to wild type astrocytes through Western blot analysis. After validating the proteomic data, in future an ex vivo assay can be established to test the effect of non-cell autonomous astrocytes factors identified through proteomics 
approach. Establishing the role of glial dysfunction in RTT pathogenesis could provide a new avenue for understanding RTT and will assist us in developing novel therapy for this disease. 


\section{Introduction}

\subsection{Rett syndrome}

The postnatal neurodevelopmental disorder, Rett syndrome (RTT, MIM \#312750) was first reported by Andreas Rett in 1966 (Rett et al., 1966). It is an X-linked dominant neurodevelopmental disorder that primarily affects girls at a frequency of $1: 10,000$ to 15,000 live female births (Rett et al., 1966; Hagberg et al., 1985; Laurvick et al., 2006; Neul et al., 2010). Although RTT infants develop normally up to the age of 6-18 months, thereafter they show developmental stagnation followed by rapid regression of phenotypes (Figure 2.1). Subsequently, these patients fail to meet psychomotor milestones and fall into regression (Amir et al., 2000; Francke et al., 2006; Chahrour et al., 2007; Samaco et al., 2011). Affected RTT individuals develop stereotypic hand movements and autistic features during the regression period followed by difficulties in social behavior (Zappella et al., 1998; Glaze et al., 2004). Recent studies have reported few additional symptoms such as anxiety, seizures, breathing abnormalities, sleep disturbances, and autonomic dysfunction in RTT patients (Chahrour et al., 2007). The subsequent screening of candidate genes in familial RTT cases revealed mutations in $M E C P 2$ gene (Amir et al., 1999). Mutations in MECP2 gene are found in $95-97 \%$ of patients showing classical Rett syndrome symptoms (Neul et al., 2008). Majority of RTT patients display classically defined (typical) phenotypes, however some RTT individuals display mild or more severe clinical phenotypes with a late age of onset, which appears between 1 to 3 years and is known as atypical RTT (Amir et al., 2000). The most atypical RTT patients manifest the 'forme fruste' phenotype with less severe regression, milder mental retardation, congenital hypotonia, loss of hand skills and develop seizures (Amir et al., 2000). About 10\% of atypical RTT cases are caused by mutations in the cyclin dependent kinase like 5 (CDKL5) gene (Guerrini et al., 2012). In addition, mutations in the 
forkhead box G (FOXG1) gene cause a congenital variant of RTT with severe cognitive impairment, early epilepsy and dyskinetic movement disorders (Guerrini et al., 2012).

Due to random $\mathrm{X}$-chromosome inactivation (XCI), females are mosaics for $M E C P 2$ mutations, justifying a spectrum of phenotypes ranging from classic RTT to asymptomatic individuals (Wan et al., 1999). Conversely, male patients carrying MECP2 mutations manifest very severe phenotype, including neonatal encephalopathy and lead to early childhood death (Kriaucionis et al., 2003).

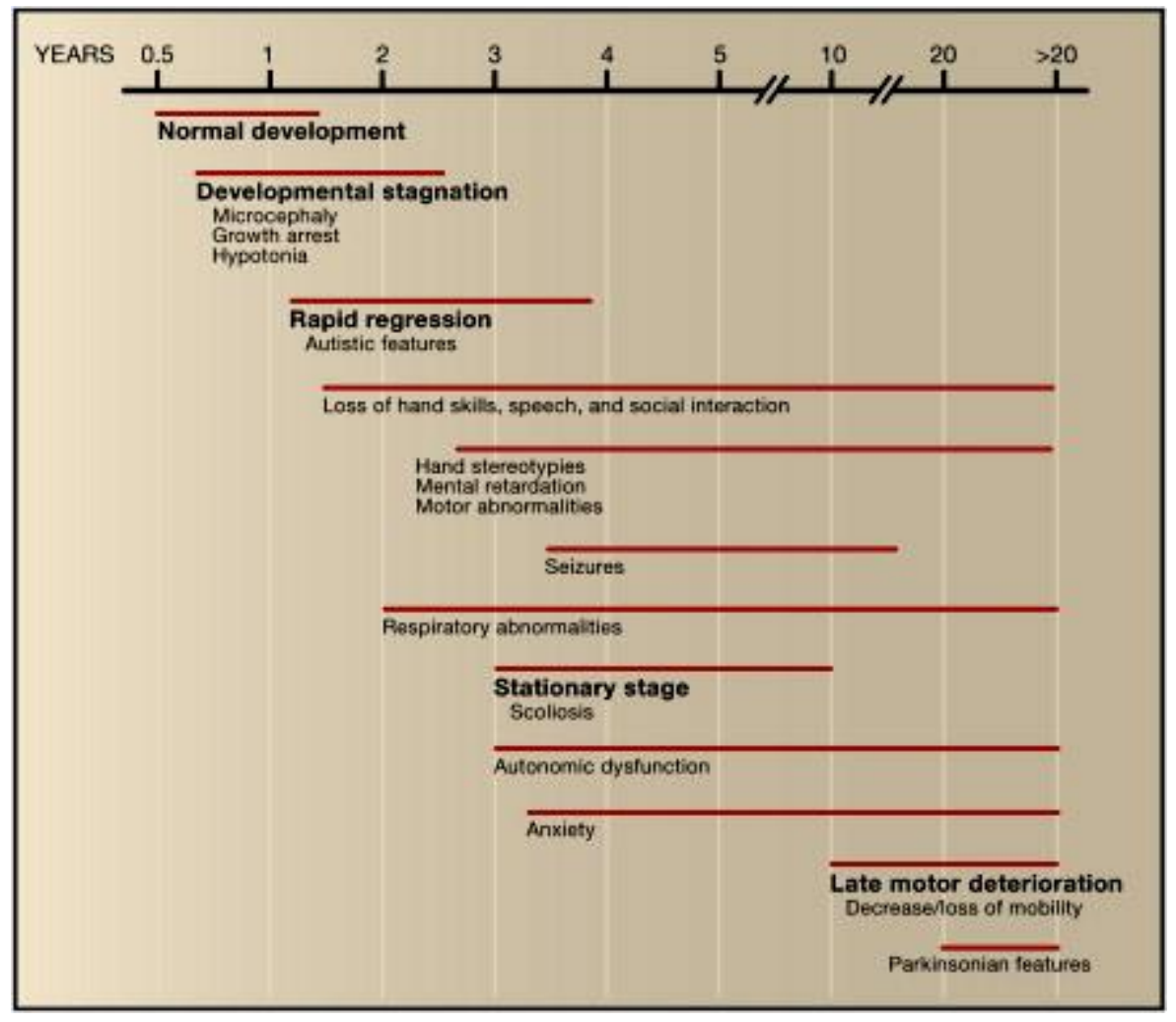

Figure 2.1. Schematic diagram outlining the beginning and progression of phenotypes in RTT patients. A healthy looking RTT infant shows normal development after birth and falls into developmental stagnation, rapid regression and develops autistic features, followed by loss of hand skills and abnormalities in respiration. The patients also suffer from motor abnormalities, autonomic dysfunction, seizures and undergo to stationary stage and anxiety (Figure adapted from Chahrour et al., 2007). 


\subsection{Structure and molecular function of MeCP2}

The MECP2 gene (OMIM:*300005) is located on the $\mathrm{X}$-chromosome and encodes for Methyl-CpG-binding Protein 2 (MeCP2), that recognizes methylated $\mathrm{CpG}$ dinucleotides and binds symmetrically to target DNA sequences (Meehan et al., 1992; Nan et al., 1993). To date over 700 mutations causing RTT (HGMD database; https//:portal.biobaseinternational.com/hgmd/pro/all.php) have been reported which include missense, nonsense, splice site, deletions and insertions (Amir et al., 1999). The MECP2 gene consists of 4 exons and transcribes into two different isoforms of $M E C P 2$ (MECP2-e1 and $M E C P 2-\mathrm{e} 2)$ through the alternative codon usage and splicing of exon 2 (Figure 2.2). These two isoforms differ only in their N-terminal sequence. The protein product of MECP2-e1 isoform consists of 21 additional amino acids encoded by exon 1, and is abundantly expressed in the brain (Dragich et al., 2007). The translation of $M E C P 2-e 2$ isoform starts at exon 2 and the protein product consists of 9 amino acids encoded by exon 2 (Esposito et al., 1996; Kriaucionis et al., 2004; Dragich et al., 2007). No unique function has been described to the MeCP2 (e1 and e2) isoforms (Mnatzakanian et al., 2004; Dragich et al., 2007).

The MECP2 have multiple polyadenylation sites in $3^{\prime}$ untranslated region, which generate several transcript variants (Chahrour et al., 2007). The MeCP2 protein encoded by $M E C P 2 e 1$ and $M E C P 2 e 2$ transcript belong to the methyl-CpG binding protein family (Hendrich et al., 1998). The MeCP2 protein consists of two conserved functional domains, namely a methyl-CpG-binding domain (MBD, 90-174 amino acids location in protein) and a transcriptional repression domain (TRD, 219-322 amino acids location in protein) (Quaderi et al., 1994; Esposito et al., 1996) (Figure 2.3). The function of MBD protein is to bind the methylated CpG sequences symmetrically (Lewis et al., 1992; Meehan et al., 1992; Nan et al., 1993). While, the TRD recruits transcriptional corepressors such as Sin3A and histone deacetylases (HDAC1 and HDAC2) at the target promoter sites. The histone acetyl groups 
will be removed by HDACs thus leading to a chromatin compaction structure, which suppresses the gene expression (Nan et al., 1997, 1998; Jones et al., 1998; Samaco et al., 2011). The MeCP2 also harbors two nuclear localization signals (NLS) embedded within the TRD. The C-terminal region of $\mathrm{MeCP} 2$ comprises a proline-rich region named as C-terminal domain (CTD, 376- 405 amino acids) (Adams et al., 2007), which might facilitate the binding of MeCP2 to the DNA (Shahbazin et al., 2002; Chahrour et al., 2008).

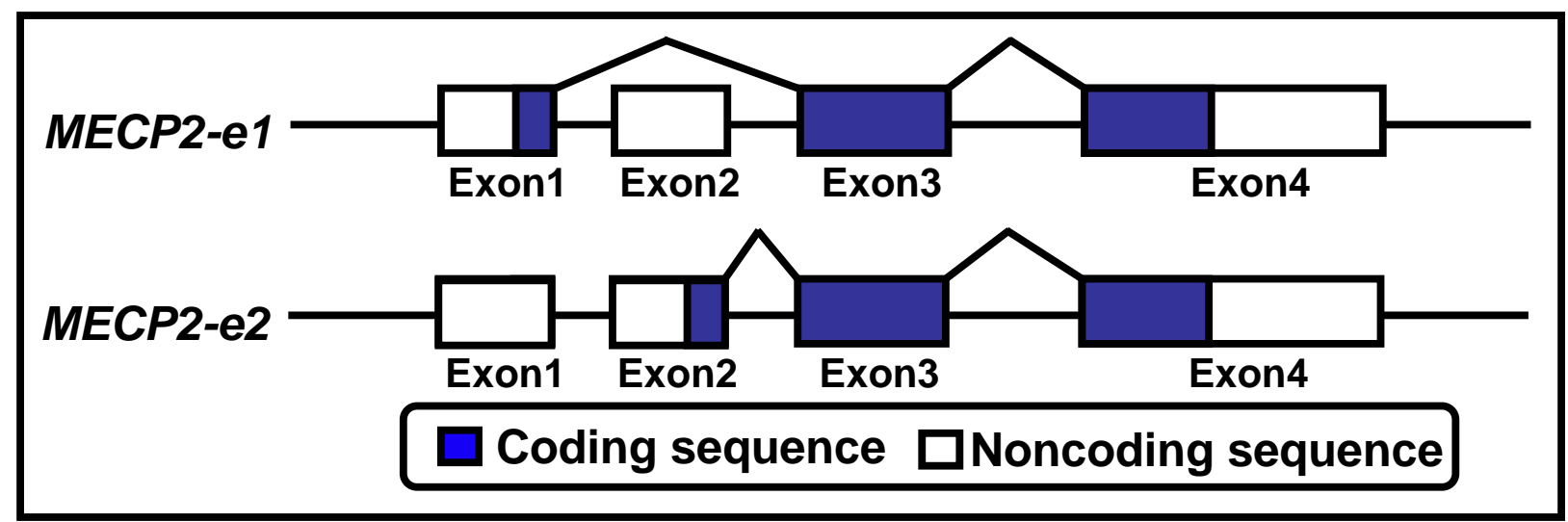

Figure 2.2. Schematic representation of the $M E C P 2$ gene and its splice variants. The $M E C P 2$ gene contains of four exons and the alternative splicing and codon usage produce two isoforms: MECP2-e1 and MECP2-e2. The coding sequence of each isoform is highlighted in blue color.

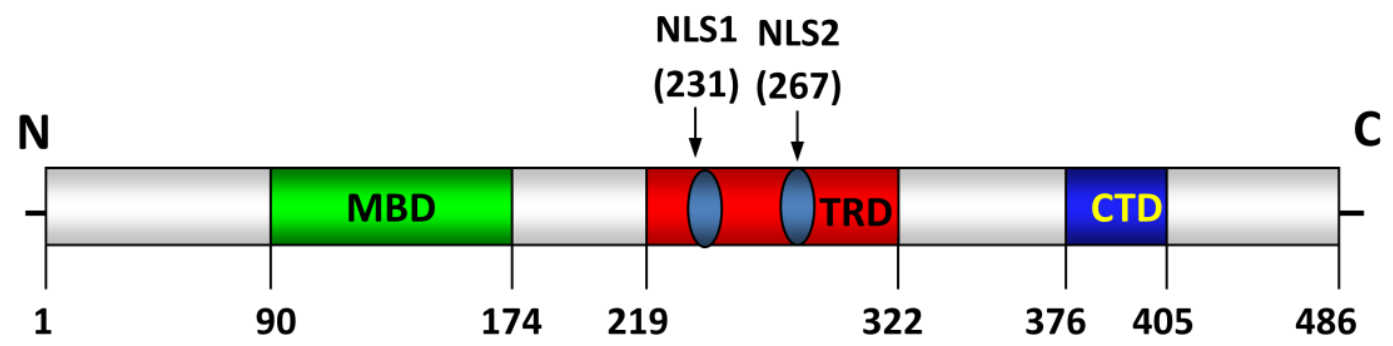

Figure 2.3. The graphic representation of MeCP2 protein and its functional domains. The methyl binding domain (MBD), transcriptional repression domain (TRD), two nuclear localization signals (NLS1 and NLS2) located within the TRD and the C-terminally located proline-rich domain (CTD) are highlighted. The amino acid numbering corresponding to each domain is indicated below. 
Although, $\mathrm{MeCp} 2$ was regarded as a transcriptional repressor for a long time, recent studies have shown the role of MeCP2 in various cellular processes, hence it has been recognized as a multifaceted protein (Chahrour et al., 2008). Various experiments evidenced that $\mathrm{MeCP} 2$ is actively involved in RNA splicing and chromatin compaction (George et al., 2003; Young et al., 2005). An elegant study by Chahrour and colleagues showed that MeCP2 also functions as an transcriptional activator by associating with transcriptional activators such as CREB1 (cAMP responsive element binding protein 1) (Chahrour et al., 2008). The various functions of $\mathrm{MeCP} 2$ are summarized in Figure 2.4.

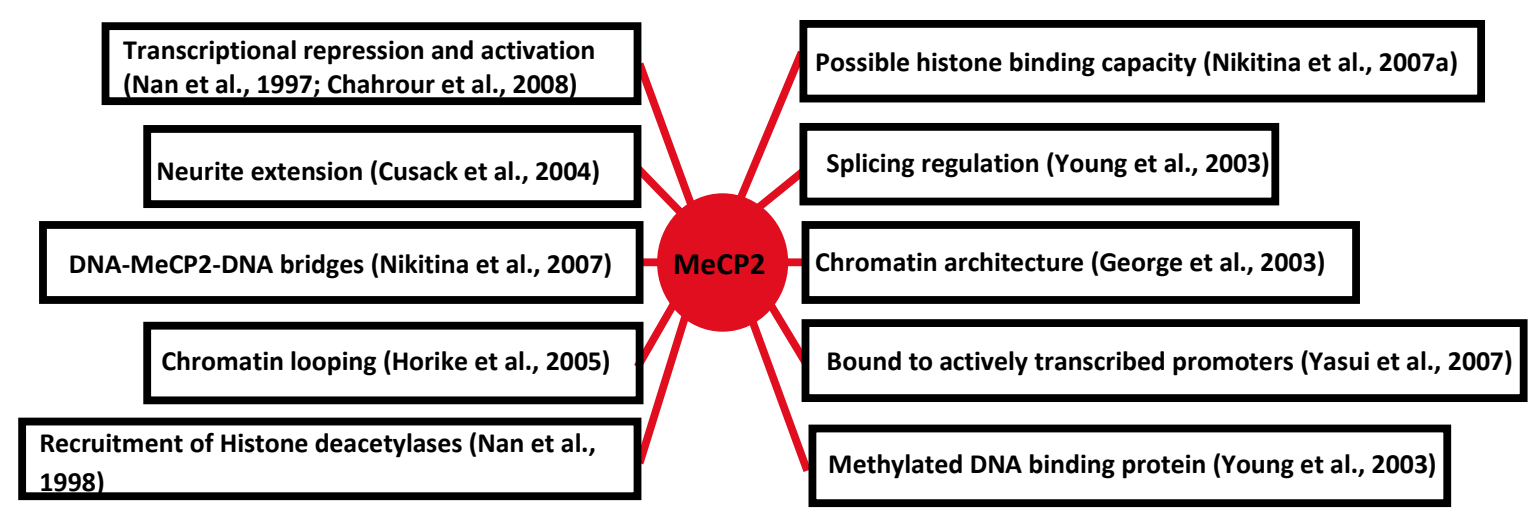

Figure 2.4. Schematic diagram showing the multifunctional role of MeCP2 during development. The $\mathrm{MeCP} 2$ protein plays a role in neurite extension, chromatin architecture and looping, binding to the methylated DNA and it contributes to both activation and repression of transcription.

\subsection{The mutational spectrum of $M E C P 2$ in Rett syndrome}

It is interesting to note that over 700 different types of mutations in the $M E C P 2$ gene causing RTT have been reported (https//:portal.biobase international.com/hgmd/pro/all.php). However, 8 recurrent missense and nonsense mutations (R106W; R133C; T158M; R168X; R255X; R270X; R294X; and R306C) account for up to two thirds of total RTT cases (Figure. 2.5) (Dragich et al., 2000; Chahrour et al., 2007; Bebbington et al., 2008). Among the different classes of mutations, the missense mutations manifest milder phenotypes as 
compared to truncated mutations (Amir et al., 2000; Huppke et al., 2002; Colvin et al., 2004). Similarly, the mutations in MBD exhibit milder clinical phenotype in comparison to mutations in the TRD domain (Colvin et al., 2004). Further studies have revealed that the truncated mutations in TRD-NLS region (R255X; R270X) manifest a significantly more severe phenotypes as compared to the rest of mutations located in other regions of the $\mathrm{MeCP} 2$ (Huppke et al., 2002; Colvin et al., 2004). In this context, the R294X, R306C mutations that are situated after the TRD-NLS domain manifest milder phenotypes (Colvin et al., 2004).

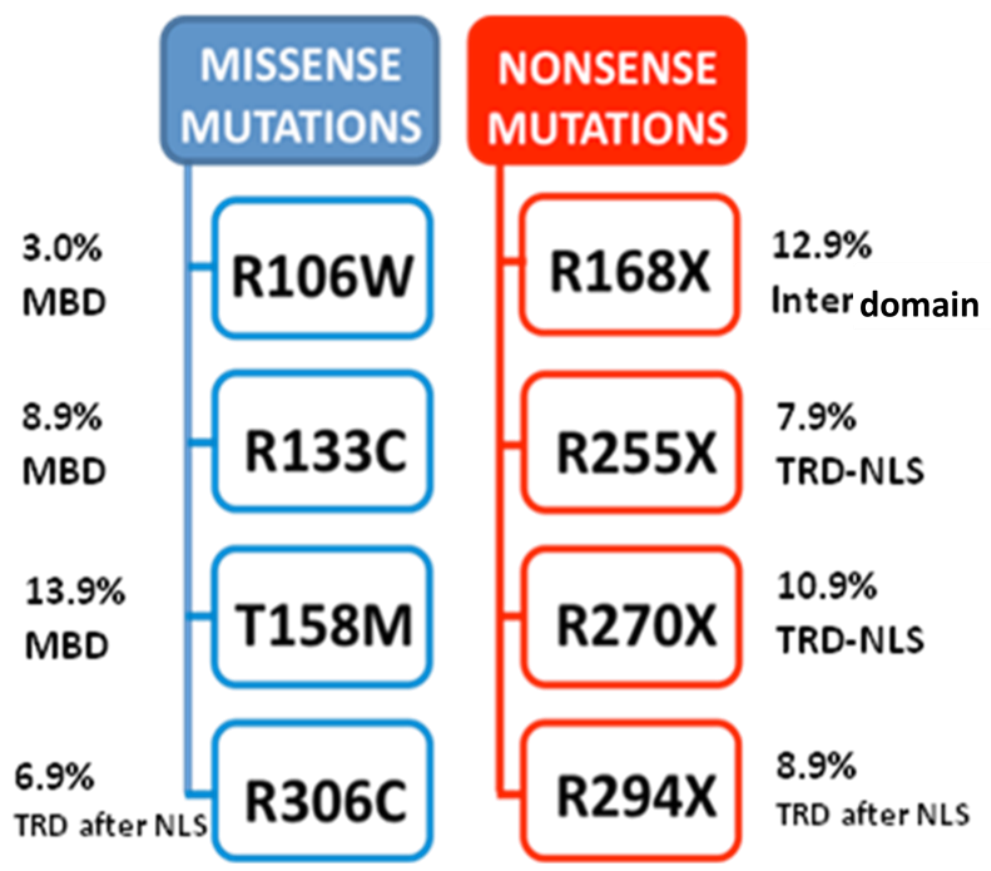

Figure 2.5. Representative diagram showing the frequency of the eight most recurrent de novo mutations in MECP2/ RTT syndrome. The R106W, R133C and T158M mutations are located in the methyl binding domain (MBD). The R255X and R270X mutations are situated in the nuclear localization signal (NLS2) is located within the transcriptional repression domain (TRD) while the R294X and R306C mutations are located after the NLS2 region. The R168X mutation is present in between the MBD and TRD and is termed as interdomain mutation.

Interestingly, the R270X mutation results in one of the most severe phenotypes among the other mutational cohort (Dragich et al., 2000; Bebbington et al., 2008). According to recent reports, the R270X represents $10.9 \%$ of the pathogenic mutations that are recorded in 
RettBase (Christodoulou et al., 2005; Jain et al., 2005). The phenotypic characteristic features of the R270X mutation include epilepsy, loss of social interactions and motor skills, stereotypical hand movements, and breathing abnormalities resulting in a higher mortality rate (Figure 2.6) (Colvin et al., 2004; Jian et al., 2005). Truncating mutations in the TRD-NLS region were predicted to result in failure of the truncated $\mathrm{MeCP} 2$ protein (presuming if structurally stable protein) to be moved to the nucleus. These assumptions were further supported by a remarkable reduction in the $\mathrm{MeCP} 2$ specific transcription, which could possibly lead to a more severe phenotype (Colvin et al., 2004). In addition, the truncated protein resulted from mutations in the TRD, but distal to the NLS, could still be translocated into the nucleus and displayed a partial effect on transcriptional activity with a milder phenotype (Colvin et al., 2004). However, to our knowledge no functional in vitro studies of mutations in the TRD-NLS have been performed.

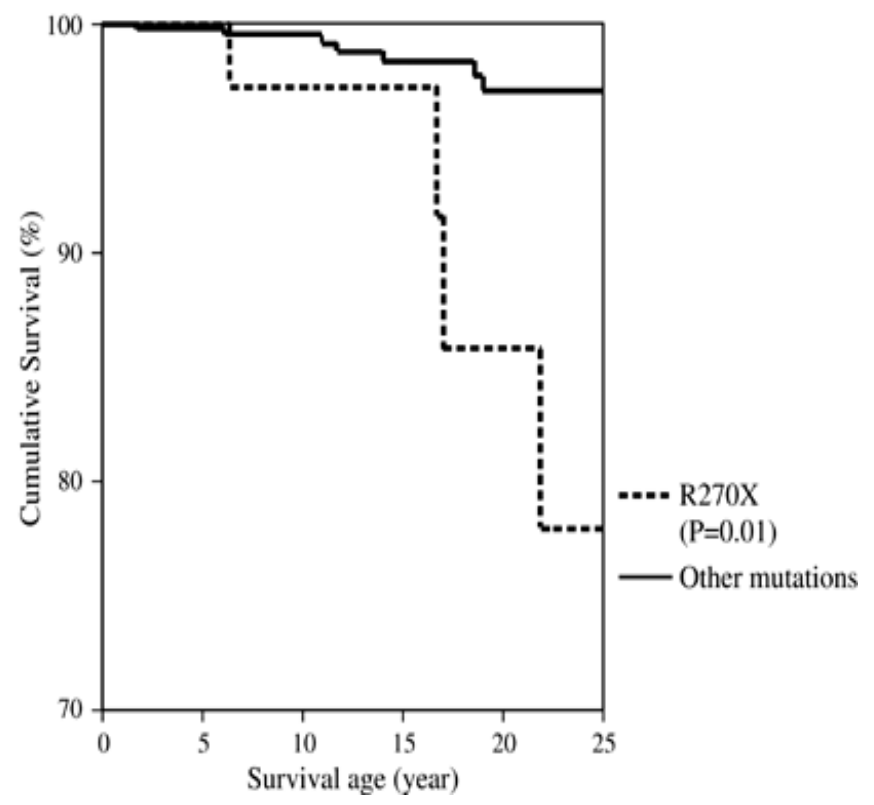

Figure 2.6. Schematic representation of the survival of R270X mutation carrying patients compared to other mutations. The R270X mutation within the TRD - NLS2 region showed higher mortality as compared to other types of mutations $(n=524)$. (Figure adapted from Jain et al., 2005). 


\section{4. gain-of-function mutations cause neurological disorder}

Loss-of-function mutations in $M E C P 2$ causes RTT syndrome, whereas duplication of the $M E C P 2$ gene causes another neurological disorder termed as $M E C P 2$ duplication syndrome (Carvalho et al., 2009; Ramocki et al., 2010; Carvalho et al., 2011). It primarily affects boys and the incidence rate is 1-4 in 50,000 live male births and 1 in 600,000 live female births (http://mecp2.wordpress.com/2012/02/06/how-many-children-and-adults-havemecp2-duplication-syndrome/\#more-868). The major symptoms of MECP2 duplication syndrome include severe mental retardation, hypotonia, epileptic seizures, progressive spasticity, autistic features, anxiety and severe respiratory infections (Ramocki et al., 2010; Van Esch et al., 2012). The severity of symptoms increases in patients who have the triplication of MECP2 locus as compared to the duplication syndrome (Van Esch et al., 2005; Velinov et al., 2009; Prescott et al., 2009; Samaco et al., 2011). To elucidate the pathomechanism of the $M E C P 2$ duplication syndrome, several different mouse models were generated. The MECP2 transgenic mouse model expressing $\mathrm{MeCP} 2$ at double the normal protein level (MeCP2-2X) displayed motor defects, stereotypies, seizures, spasticity and ataxia (Collins et al., 2004; Samaco et al., 2011). In addition, the MeCP2-2X mice showed heightened anxiety, less interest in new partners, decreased activity and premature death between 20 weeks to 1 year of age (Collins et al., 2004). Interestingly, the transgenic mice expressing in excess of threefold MeCP2 protein expression (MeCP2-4X) exhibited very severe phenotypes as compared to MeCP2-2X transgenic mice and die within 3 weeks of age (Collins et al., 2004; Na et al., 2012). 


\subsection{The non-cell-autonomous role of MeCP2}

The predominant expression of MeCP2 in neurons (Shahbazian et al., 2002; Kishi et al., 2004) led to the speculation that the loss of MeCP2 function in neurons is solely responsible for the majority of the observed RTT phenotypes. In addition, it has been shown that the deficiency of MeCP2 causes abnormalities in neuronal structure and function such as abnormal dendritic arborization (Kishi et al., 2004; Armstrong et al., 2005), and spine density (Belichenko et al., 1994), reduced basal synaptic transmission (Moretti et al., 2006), excitatory synaptic plasticity (Moretti et al., 2006; Chao et al., 2007), and spontaneous cortical activity (Dani et al., 2005). In summary, these studies pointed out that the neuropathology is the underlying cause for RTT. Interestingly, several lines of evidence showed that MeCP2 expression is not only restricted to neurons, but is also detected in astrocytes, microglia, oligodendrocyte progenitor cells (OPCs) and oligodendrocytes (Ballas et al., 2009; Maezawa et al., 2009). Astrocytes are the major component as glial population in the central nervous system (CNS) (Molfsky et al., 2012). They mainly regulate the brain microenvironment, such as guidance of neuronal migration, synaptic transmission and neuronal excitability, energy metabolism, detoxification, free radical scavenging, and immune function (Davalos et al., 2005; Markiewicz et al., 2006; Barres et al., 2008). Recently, a number of elegant experiments showed that the wild type as well as MeCP2-deficient neurons displayed lesser and shorter dendrites, when co-cultured with $M e C P 2$-null astrocytes (Figure 2.7). These findings suggested that some unknown secreted factors from MeCP2-deficient astrocytes inhibit the maturation of neurons (Ballas et al., 2008; Maezawa et al., 2009; Zoghbi et al., 2009). Furthermore, conditioned media from the $M e C P 2$-null astrocytes phenocopied the astrocytic effect, suggesting that unknown secreted factor(s) by the mutant astrocytes contribute to the neuronal damage thereby to developmental defects in a non-cell-autonomous manner (Ballas et al., 2009). 
a

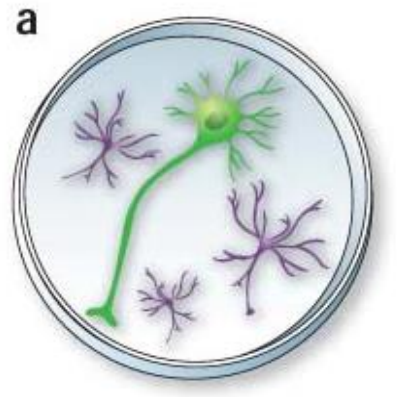

d

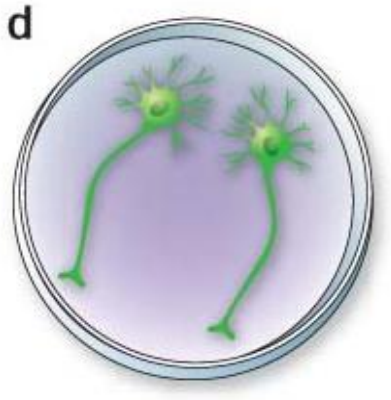

b

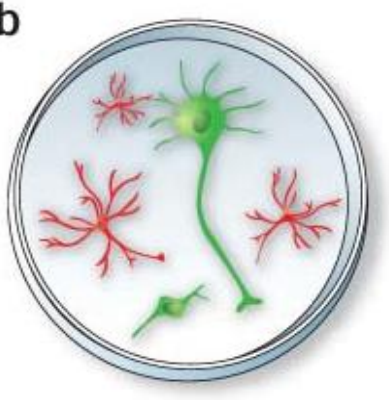

e

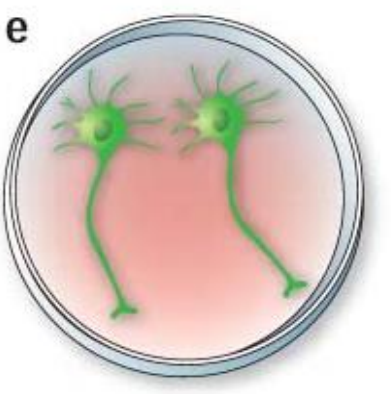

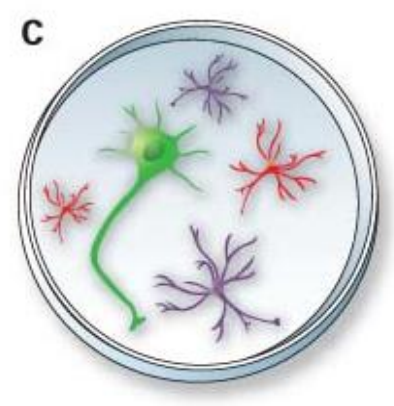

f

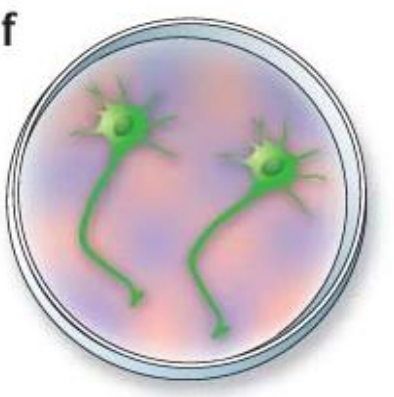

Figure 2.7. Schematic diagram showing the toxic effect of Mecp2-null astrocytes in neuronal culture. (a)

Wild type neurons (green) show normal dendrite structure in presence of wild type astrocytes (purple). (b) In the presence of Mecp2-null astrocytes (red), the adjacent neurons exhibit decreased dendrite structure. (c) Wild type astrocytes failed to rescue the neuronal abnormalities from the toxic effect from the Mecp2-null astrocytes. (d) Conditioned media from wild-type astrocytes support neighboring neurons. (e) Conditioned media from Mecp2null astrocytes are toxic to neuronal growth. (f) Astrocyte conditioned media from both wild type and Mecp2null showed toxic effect on neuronal growth (Figure adapted from Zoghbi et al., 2009).

\subsection{Objective of the thesis}

To elucidate the molecular mechanism leading to a severe phenotype due to R270X mutation in RTT patients, we generated a mouse model expressing the human R270X equivalent mutation $\left(\mathrm{MeCP} 2^{270}\right.$ EGFP $)$ and utilized it for a comprehensive functional analysis of mutant MeCP2.

To study the pathomechanism associated with $M E C P 2$ duplication syndrome, we generated a transgenic mouse model with a mild (1.5X) overexpression of MeCP2 using BAC transgenesis. The generated mouse model was used to identify and characterize the earliest pathologies manifested due to MeCP2 gain of function. 
Further, a proteomic approach was employed to identify and characterize MeCP2 target proteins in astrocytes. This study will help us to establish the role of glial dysfunction in RTT pathogenesis, hence, could provide not only a new avenue for understanding RTT pathogenesis but to develop novel therapies for this disease. 


\section{Results}

3.1 MeCP2 $2^{270}$ Mutant Protein Is Expressed in Astrocytes as well as in Neurons and Localizes in the Nucleus

3.2 Mild overexpression of Mecp2 in mice causes a higher susceptibility toward seizures

Each chapter in results part starts with a brief description with aim of the specific manuscript and the author's contribution to the work. 


\section{1 $\mathrm{MeCP2}^{270}$ Mutant Protein Is Expressed in Astrocytes as well as in Neurons and Localizes in the Nucleus}

In the first part of the thesis, we characterize the function of most frequent human associate mutation $\mathrm{R} 270 \mathrm{X}$ in $M E C P 2$. To evaluate the molecular and functional role of nonsense mutation $\mathrm{R} 270 \mathrm{X}$, we generated a Mecp2 $2^{\text {R270_EGFP }}$ transgenic mouse. The $M e c p 2^{R 270-E G F P}$ transgenic mouse showed similar pattern of protein expression as compared to the endogenous MeCP2. However, we didn't observe any neurological impairment in $M e c p 2^{R 270-E G F P}$ transgenic mice and these mice were phenotypically normal up to 1 year of age. Further studies, in ex-vivo system showed no difference in neuronal growth and differentiation. Interestingly, we observed the Mecp $2^{R 270-E G F P}$ expression in astrocytes as well as neurons.

L.A. Kifayathullah*, J.P. Arunachalam*, C. Bodda*, H.Y. Agbemenyah, F.A. Laccone, A.U. Mannan

*L.A.K., J.P.A. and C.B. contributed equally to this work.

Status: Published in Cytogenetic and Genome Research (Impact factor: 1.729), Volume 129 (2010), Page: 290-297.

Author contributions to the results:

L.A. Kifayathullah: Generation of the Mecp2 $2^{270 \_E G F P}$ transgenic mouse and immunohistochemistry.

J.P. Arunachalam: Generation of the transgenic construct.

C.Bodda: Primary cell culture of neurons, Immunocytochemisty and analysis. Phenotypical analysis of $\mathrm{MeCP} 2^{270}$ transgenic mouse. Involved in manuscript preparation.

H.Y. Agbemenyah: Primary cell culture of neurons and immunocytochemistry.

F.A. Laccone: Generation of the transgenic construct. 
Ashraf U. Mannan: Designed the experiments. Interpretated the data and prepared the manuscript. 


\title{
MeCP2 270 Mutant Protein Is Expressed in Astrocytes as well as in Neurons and Localizes in the Nucleus
}

\author{
L.A. Kifayathullah ${ }^{\text {a }} \quad$ J.P. Arunachalam ${ }^{a} \quad$ C. Bodda ${ }^{a} \quad$ H.Y. Agbemenyah ${ }^{a}$ \\ F.A. Laccone ${ }^{a, b}$ A.U. Mannan ${ }^{a, c}$ \\ ${ }^{a}$ Institute of Human Genetics, University of Goettingen, Goettingen, Germany; ${ }^{b}$ Department of \\ Medical Genetics, Medical School of Vienna, Vienna, Austria; 'DFG-Research Center Molecular Physiology of \\ the Brain, Goettingen, Germany
}

\section{Key Words}

$\mathrm{MeCP} 2 \cdot \mathrm{R} 270 \mathrm{X}$ mutation $\cdot$ Rett syndrome $\cdot$ Transgenic mice

\section{Abstract}

The MECP2 gene, located at Xq28, encodes methyl-CpGbinding protein 2 (MeCP2), which is frequently mutated (up to $90 \%$ ) in Rett syndrome (RTT). RTT is a progressive neurodevelopmental disorder, which affects primarily girls during early childhood and it is one of the most common causes of mental retardation in females. R270X is one of the most frequent recurrent $M E C P 2$ mutations among RTT cohorts. The R270X mutation resides within the TRD-NLS (Transcription Repression Domain-Nuclear Localization Signal) region of $\mathrm{MeCP} 2$ and causes a more severe clinical phenotype with increased mortality as compared to other mutations. To evaluate the functional role of the R270X mutation, we generated a transgenic mouse model expressing MeCP2 ${ }^{270 \_E G F P}$ (human mutation equivalent) by $\mathrm{BAC}$ recombineering. The expression pattern of MeCP2 $2^{270}$ EGFP was similar to that of endogenous MeCP2. Strikingly, MeCP2 ${ }^{270 \_E G F P}$ localizes in the nucleus, contrary to the conjecture that R270X could cause disruption of the NLS. In primary hippocampal cells,
\end{abstract}

L.A.K., J.P.A. and C.B. contributed equally to this work.

\begin{tabular}{ll}
\hline KARGER & (2010 S. Karger AG, Basel \\
Fax +41 61 306 12 34 & Ac4-8581/10/1294-0290\$26.00/0 \\
$\begin{array}{l}\text { E-Mail karger@karger.ch } \\
\text { www.karger.com }\end{array}$ & $\begin{array}{l}\text { Accessible online at: } \\
\text { www.karger.com/cgr }\end{array}$
\end{tabular}

we show that MeCP2 ${ }^{270 \_E G F P}$ was expressed in astrocytes by colocalization with the astrocyte-specific marker glial fibrillary acidic protein. Our data showing expression of $M e C P 2^{270 \_E G F P}$ in transgenic mice astrocytes further reinforce the recent findings concerning the expression of $\mathrm{MeCP} 2$ in the glial cells.

Copyright $\odot 2010$ S. Karger AG, Basel

Rett syndrome (RTT) is a progressive neurodevelopmental disorder, which affects primarily girls during early childhood and it is one of the most common causes of mental retardation in females. RTT was first identified and described in 1966 by Andreas Rett in the Wiener Klinische Wochenschrift [German literature; Rett, 1966]. However, RTT was relatively unknown until the mid 1980s when Bengt Hagberg and his colleagues reported 35 cases of RTT in an English language journal [Hagberg et al., 1983]. The characteristic features of the disease include postnatal microcephaly, hand dyspraxia, stereotypic hand movements, ataxia, abnormal breathing, and growth retardation. In addition, tendency to develop social withdrawal and loss of the ability to speak were also

Dr. Ashraf U. Mannan

Institute of Human Genetics, University of Goettingen

Heinrich-Dueker-Weg 12, DE-37073 Goettingen (Germany)

Tel. +49 551397 522, Fax +49551399 303, E-Mail amannan@gwdg.de

Dr. Franco A. Laccone

Department for Medical Genetics, Medical School of Vienna

Waehringer Strasse 10, AT-1090 Vienna (Austria)

Tel. +43 142 776 0614, Fax +43 1422779606

E-Mail franco.laccone@ meduniwien.ac.at 
observed; furthermore, many girls develop seizures and anxiety [Hagberg et al., 1983; Trevathan and Moser, 1988].

The gene MECP2 (OMIM: *300005) encodes methylCpG-binding protein 2 (MeCP2), a nuclear protein that recognizes methylated $\mathrm{CpG}$ dinucleotides and binds symmetrically to target DNA sequence [Meehan et al., 1992; Nan et al., 1993]. Mutations in MECP2 are the main cause of RTT [Amir et al., 1999]. MECP2 located at Xq28 is comprised of 4 exons that code for 2 different isoforms of $\mathrm{MeCP} 2$ protein (el and e2) through alternative splicing of exon 2 . The 2 isoforms differ only in their $\mathrm{N}$-terminal sequence; the MeCP2-el isoform contains an additional 21 amino acids encoded by exon 1 but lacks 9 amino acids encoded by exon 2. In the MeCP2-e2 isoform, translation initiates from exon 2 [D'Esposito et al., 1996; Kriaucionis and Bird, 2004; Dragich et al., 2007]. The 3' untranslated region of $M E C P 2$ contains multiple polyadenylation sites, which can further produce several transcript variants [Chahrour and Zoghbi, 2007].

The MeCP2 protein contains 2 conserved functional domains, a methyl-CpG-binding domain (MBD) and a transcriptional repression domain (TRD) with a 17-amino-acid nuclear localization signal (NLS) embedded within the TRD. The $\mathrm{C}$-terminal residues of $\mathrm{MeCP} 2$ also comprise a domain named CTD [Adams et al., 2007]. Initial studies implicated $\mathrm{MeCP} 2$ as a transcriptional repressor, which silences target genes by recruiting co-repressors and histone deacetlyases [Razin, 1998; Ng and Bird, 1999]. Recent advancements in the molecular function of $\mathrm{MeCP} 2$ suggest that it is a multifaceted nuclear protein. In terms of target gene regulation, $\mathrm{MeCP} 2$ acts both as a transcriptional activator as well as repressor [Chahrour et al., 2008; Ben-Shachar et al., 2009]. It also plays a prominent role in the modulation of global chromatin architecture by directly binding to chromatin fibers and facilitating its compaction by folding the chromatin [Georgel et al., 2003]. Moreover, MeCP2 also functions as a gene-specific splice regulator [Young et al., 2005].

To understand the underlying molecular mechanisms leading to symptoms of the RTT disease, several animal models have been generated. MeCP2-deficient mice recapitulate the pathological hallmarks of RTT symptoms. Mecp2 null mice are phenotypically normal until 3-6 weeks of age; thereafter male mutant mice show stiffness, gait abnormalities, hypoactivity, tremor, hindlimb clasping and irregular breathing. The symptoms are progressive in nature leading to severe weight loss and eventually death [Chen et al., 2001; Guy et al., 2001]. The female mice manifest a milder and delayed age of onset of the symptoms.

Mecp2 270_EGFP Transgenic Mice
It is interesting to note that recent meta-analyses of MECP2 mutations from several published and unpublished cases revealed that 8 recurrent missense and nonsense mutations (R106W, R133C, T158M, R168X, R255X, R270X, R294X, and R306C) accounted for up to 2 thirds of the pathogenic mutations identified in RTT [Dragich et al., 2000; Bebbington et al., 2008]. Among MECP2 mutations, R270X (c.808 C > T) is one of the most frequent recurrent $M E C P 2$ mutations among various cohorts irrespective of ethnic background [Dragich et al., 2000; Bebbington et al., 2008]. Further studies revealed that mutations in the NLS region within the TRD domain manifest a significantly more severe phenotype as compared to mutations located in other regions of the protein, particularly the region after the TRD-NLS including the C-terminal region [Huppke et al., 2002; Colvin et al., 2004]. R270X, located in the NLS of the TRD, manifests the most severe phenotype among the mutations, in contrast to R294X, which was also found in the TRD domain but after the NLS and had a much milder phenotype [Colvin et al., 2004]. In the epidemiological context, patients harboring R270X are prognosed to lose skills such as motor function, hand use and social interaction much earlier than their counterparts with the R294X. Patients with the latter type of mutation, on the other hand, are likely to be mobile and less likely to have growth or nutritional problems [Colvin et al., 2004].

The molecular mechanism leading to a severe phenotype by R270X mutation is still elusive. To dissect the effect of R270X, we generated a mouse model expressing the R270X mutant fused with green fluorescent protein $\left(\mathrm{MeCP} 2^{270 \_G F P}\right)$ under the control of the endogenous promoter.

\section{Material and Methods}

Generation of Mecp2 270_EGFP Transgenic Mouse Line

To generate the Mecp2 $2^{270 \_E G F P}$ transgenic mouse line, a BAC (Bacterial Artificial Chromosome) clone B22804 (kindly gifted by Dr. M. Platzer, Jena, Germany) consisting of the murine Mecp2 gene and its flanking regulatory regions was used to generate a transgenic construct by inserting an enhanced green fluorescent protein/kanamycin-resistant gene (EGFP/Kan) cassette into exon 4 of $M e c p 2$ by BAC recombineering (recombination-mediated genetic engineering) via the pGET recombination system [Orford et al., 2000]. The EGFP/Kan cassette was amplified by a primer pair consisting of 50-bp sequence flanking Mecp2 exon 4 on either side of amino acid 270. Furthermore, 2 glycine residues were inserted between the truncated $\mathrm{MeCP} 2$ protein and the EGFP protein inframe to facilitate the 2 proteins to fold and function independently. The correct insertion of EGFP/Kan cassette after the recombination event into the BAC DNA was confirmed by sequenc-

Cytogenet Genome Res 2010;129:290-297 
ing. The BAC clone B22804 also contained transcriptional units of Opsin1 and part of Irakl genes upstream and downstream of the Mecp2 gene. The sequences of both genes were deleted from the BAC clone by additional GET recombination steps using the zeocin selection cassette (containing the homology arms and Zeocin antibiotic marker gene driven by EM7 promoter from pSELECT vector) (InvivoGen).

The final BAC construct pBAC_Mecp2 $2^{270 \_E G F P}$ was linearized with $M l u$ I enzyme and micro-injected into the male pronuclei of the fertilized mouse oocytes derived from the $\mathrm{FVB} / \mathrm{N}$ strain. Next, the injected oocytes were transplanted into the uteri of the foster mothers. The newborn pups were screened for the presence of the transgene by PCR analysis on genomic DNA isolated from tail biopsies. The transgenic product of $632 \mathrm{bp}$ was amplified by primer pair Ctrl Mecp2_F1 (5'-TCCAGTTTGTTCCTTGTTCACTTA- ${ }^{\prime}$ ) and EGFP_Rev1 (5'-CCGTTTACGTCGCCGTCCAGC- $3^{\prime}$ ) under the following conditions: $95^{\circ} \mathrm{C}$ for $30 \mathrm{~s}$ (denaturation), $55^{\circ} \mathrm{C}$ for $40 \mathrm{~s}$ (annealing), $72^{\circ} \mathrm{C}$ for $55 \mathrm{~s}$ (extension) for 35 cycles. To amplify the endogenous Mecp 2 allele (398 bp), we used the primer pair oIMR1436 (5'-GGTAAAGACCCATGTGACCC- $\left.3^{\prime}\right)$ and oIMR1438 (5'-GGCTTGCCACATGACAA-3').

Western Blot Analysis

Proteins were extracted from fresh or frozen mouse tissues by homogenization in the tissue lysis buffer $(62 \mathrm{mM} \mathrm{Tris} / \mathrm{HCl} \mathrm{pH} 6.8$, $2 \%$ SDS, $5 \mathrm{mM} \beta$-2-mercaptoethanol, $0.15 \mathrm{mM} \mathrm{NaCl}$ ) containing protease inhibitors (Sigma). Lysates were sonicated on ice and centrifuged at $12,000 \mathrm{~g}$ for $10 \mathrm{~min}$ at $4^{\circ} \mathrm{C}$. Supernatant consisting of total protein extract was used for further analysis. In brief, 50 $\mu \mathrm{g}$ protein lysates were denatured by boiling in a buffer containing sodium dodecyl sulfate and dithiothreitol, which was resolved by SDS-PAGE using a NuPage $4-12 \%$ Bis-Tris precast gel in MES buffer (Invitrogen). The resolved proteins were electro-transferred to a polyvinylidene difluoride membrane (Macherey-Nagel). The membrane was blocked in 5\% dried milk in PBS and then incubated with either anti-MeCP2 antibody (dilution 1:5,000) raised in rabbit using $\mathrm{MeCP} 2$-strep tag fusion protein as antigen (Eurogentec) or anti-GFP antibody (dilution 1:4,000) at $4^{\circ} \mathrm{C}$ overnight. Next, the immunoblot was incubated with secondary antibodies conjugated with alkaline phosphatase (dilution 1:30,000) (Sigma) for $1 \mathrm{~h}$ at room temperature (RT). The resolved proteins were visualized using nitroblue tetrazolium, 5-bromo-4-chloro3 -indolyl phosphate.

\section{Immunohistochemistry}

The mice were transcardially perfused with $4 \%$ paraformaldehyde in PBS. The whole brain was dissected and immersed in 30\% sucrose solution for 3 days and then cryosectioned to 7-10 $\mu \mathrm{m}$ thickness. The brain sections were washed 3 times with PBS for $5 \mathrm{~min}$ each and then permeabilized with $0.2 \%$ Triton-X for $30 \mathrm{~min}$ at $4^{\circ} \mathrm{C}$. Then slides were again washed 3 times with PBS for $5 \mathrm{~min}$ and incubated in 5\% BSA for $1 \mathrm{~h}$ at RT. The brain sections were then incubated with anti-MeCP2 antibody (1:200; Eurogentec), anti- $\beta 3$-tubulin (1:400, Abcam), anti-GFAP (1:500, kind gift from Dr. T. Manzke, Goettingen, Germany) or anti-GFP (1:200, Abcam) at RT for $2 \mathrm{~h}$ in $2 \%$ BSA solution, which was followed by incubation with secondary antibody conjugated with $\mathrm{Cy} 3$ or FITC (Sigma) for $1 \mathrm{~h}$ at RT in 2\% BSA solution. After final washing, the slides were mounted with coverslips and were observed using a BX60 fluorescence microscope (Olympus).
Primary Cell Culture and Immunocytochemical Analysis

Mice were decapitated and the whole brain was isolated and put into dissection solution $(0.72 \mathrm{~g}$ bovine albumin, $0.347 \mathrm{~g}$ $\mathrm{MgSO}_{4}$ in $240 \mathrm{ml} \mathrm{Hanks} \mathrm{medium)} \mathrm{on} \mathrm{ice.} \mathrm{Hippocampi} \mathrm{were} \mathrm{care-}$ fully dissected and cut into small pieces in dissection solution. The tissue samples were then digested at RT for $5 \mathrm{~min}$ with $6 \mathrm{mg}$ trypsin and $60 \mu \mathrm{g}$ DNAase $(2 \mathrm{~K}$ units $/ \mu \mathrm{l})$ in $2 \mathrm{ml}$ of digestion solution $\left(0.8 \mathrm{~g} \mathrm{NaCl}, 35 \mathrm{mg} \mathrm{NaHCO} 3,37 \mathrm{mg} \mathrm{KCl}, 99 \mathrm{mg} \mathrm{Na} \mathrm{HPO}_{4}\right.$ in $100 \mathrm{ml} \mathrm{H}_{2} \mathrm{O}$, pH adjusted to 7.3-7.4). The reaction was stopped by addition of trypsin inhibitor (Invitrogen). The tissues were then incubated at RT in a solution of $0.5 \mathrm{ml}$ horse serum and 2.5 $\mathrm{ml}$ dissection solution for $10 \mathrm{~min}$, and afterwards washed 3 times with dissection solution. The hippocampal cells were triturated with 3 different pore sizes of pipettes coated with Sigmacote (Sig$\mathrm{ma}$ ). The homogenate was centrifuged at $1,400 \mathrm{~g}$ at $4^{\circ} \mathrm{C}$ for $5 \mathrm{~min}$. The cells were resuspended in $1 \mathrm{ml}$ dissection solution. The cell suspensions were seeded (2,000-3,000 cells per well) in pre-incubated culture plates with coverslips coated with poly-D-lysine and laminin in dissection medium and incubated at $37^{\circ} \mathrm{C}$ for $30 \mathrm{~min}$ in $5 \% \mathrm{CO}_{2}$, thereafter, culture medium A ( $0.5 \mathrm{~g} \mathrm{D}$-glucose, $0.2 \mathrm{ml}$ $(12.5 \mathrm{mg} / \mathrm{ml})$ insulin, $1 \mathrm{ml}(200 \mathrm{mM})$ glutamax, $50 \mu \mathrm{l}(10 \mathrm{mg} / \mathrm{ml})$, gentamicin, $10 \mathrm{mg}$ transferrin and $10 \mathrm{ml}$ horse serum up to 100 ml DMEM) was added to the cultured neurons. After overnight incubation with culture medium $\mathrm{A}$, the cells were washed with PBS to remove cell debris. After 4 days, medium A was replaced with culture medium B ( $50 \mu$ l gentamicin, $125 \mu \mathrm{l}$ bFGF, $250 \mu \mathrm{l}$ L-glutamine, $2 \mathrm{ml} \mathrm{B27}$ supplement, $125 \mu \mathrm{l}$ cytosine arabinoside (4 mM) up to $100 \mathrm{ml}$ neurobasal medium) and cultured until day 7. Medium was changed every 2 days until the day of neuronal cell analysis, when cells were fixed and immunostained with anti- $\beta 3$ tubulin (dilution 1:500) (Abcam). The evaluation of neuronal parameters such as cell soma volume and neurite length was performed by Image J software (http://rsb.info.nih.gov/ij/).

\section{Results}

\section{Establishment of the Mecp2 $2^{270 \_E G F P}$ Transgenic Mouse Line}

The founder mice obtained by microinjection of linearized pBAC_Mecp2 $2^{270 \_E G F P}$ into the fertilized mouse oocytes derived from the $\mathrm{FVB} / \mathrm{N}$ strain were tested for the integration of the transgene into the genomic sequence by PCR genotyping using a primer pair specific for the transgene (fig. 1B). As can be seen from the PCR genotyping, the transgenic mice in addition to endogenous Mecp2 allele also carry the Mecp2 $2^{270 \_E G F P}$ transgene (fig. 1B). The mice which were positive for the transgene were bred with $\mathrm{FVB} / \mathrm{N}$ mice to set up a stable Mecp $2^{270-E G F P}$ transgenic mouse line. To determine whether the Mecp $2^{270 \_E G F P}$ is expressed in the transgenic mice, we performed Western blot analysis with total protein extracted from brain biopsies from the transgenic mice. The immunoblot with antibody against MeCP2 revealed expression of $2 \mathrm{MeCP} 2$ proteins, in addition 
Fig. 1. Schematic diagram illustrating the generation of the Mecp $2^{270 \_ \text {EGFP }}$ transgenic construct using GET recombination in the BAC clone. An EGFP/Kan cassette was inserted in-frame at amino acid 270 of Mecp 2 in exon 4 and an arginine was replaced with 2 glycine residues in the BAC clone by homologous recombination (A). PCR genotyping of mice. The transgenic allele was amplified by the primer pair Ctrl Mecp2_F1 and EGFP_Revl, yielding a PCR product of $632 \mathrm{bp}$. The endogenous Mecp2 allele of $398 \mathrm{bp}$ was amplified using primer pair oIMR1436 and oIMR1438. $\mathrm{T}^{270} /$-, transgenic; -/-, wild-type; $\mathrm{N}$, negative control $\left(\mathrm{H}_{2} \mathrm{O}\right)(\mathbf{B})$. Western blot analysis using MeCP2 antibody on the total protein extract isolated from brain samples revealed in addition to the endogenous $\mathrm{MeCP} 2(70 \mathrm{kDa})$ an additional $\mathrm{MeCP} 2$ protein corresponding to $\mathrm{MeCP} 2^{270}$ EGGFP $(65 \mathrm{kDa})$ in the transgenic mice. Further immunoblots with anti-GFP antibody confirmed that the $65-\mathrm{kDa}$ size protein was indeed $\mathrm{MeCP} 2^{270}$ EGFP $($ C).

A

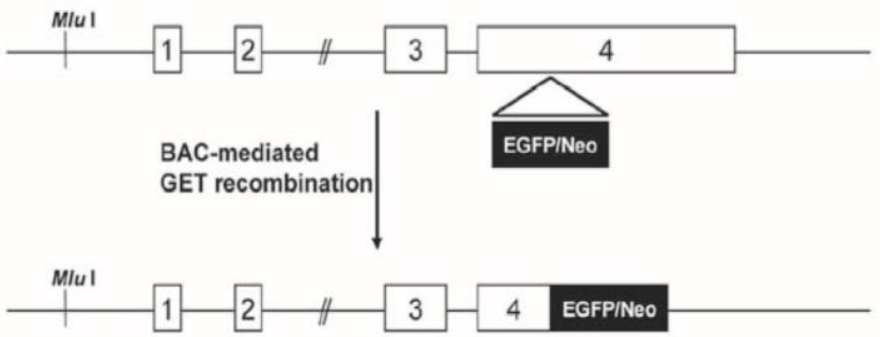

B

\% $\%$ T270/- T270/- N

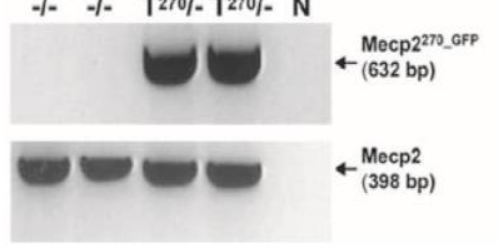

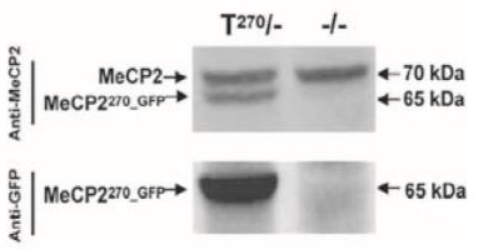

to the endogenous $\mathrm{MeCP} 2(70 \mathrm{kDa})$, a transgenic MeCP2 $270 \_$EGFP $p r o t e i n$ of $65 \mathrm{kDa}$ was detected in the total protein extract isolated from the brain of transgenic mice (fig. 1C). In contrast, in the total protein extract isolated from the brain of wild-type mice, only endogenous MeCP2 was detectable (fig. 1C). Furthermore, immunoblot analysis with GFP antibody detected the same 65$\mathrm{kDa}$ transgenic MeCP2 ${ }^{270 \_E G F P}$ protein, which was identified by MeCP2 antibody (fig. 1C).

\section{Transgenic MeCP2 270_EGFP Protein Shows a Nuclear}

\section{Expression Pattern}

The transgenic pBAC_Mecp2 $2^{270 \_E G F P}$ construct consists of a mouse genomic fragment of $\sim 150 \mathrm{~kb}$, which contains all 4 exons of Mecp2, including the entire regulatory regions necessary for temporal and spatial expression of MeCP2. To determine the expression pattern of

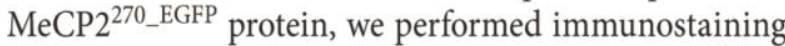
on brain sections derived from transgenic mice $\left(\mathrm{T}^{270} /-\right)$ (note: $\mathrm{T}^{270}$ refers to the transgenic allele and - corresponds to the wild-type allele) with GFP antibody. The expression of MeCP2 ${ }^{270 \_E G F P}$ was widespread throughout different regions of the brain with predominant expression in the hippocampus, cerebellum and olfactory bulb (data not shown). Next, the hippocampal sections from the transgenic mice were stained with $\mathrm{MeCP} 2$ and GFP

Mecp $2^{270 \_E G F P}$ Transgenic Mice antibodies to evaluate the expression of $\mathrm{MeCP} 2$ from the transgene as compared to the endogenous protein. The MeCP2 $270 \_$EGFP protein revealed a similar expression pattern as shown by the endogenous $\mathrm{MeCP} 2$ (fig. 2B-D; see online supplementary figure S1, www. karger.com/doi/10.1159/000315906). In the primary structure of MeCP2, the NLS spans 267-283 amino acids, therefore in the trans genic MeCP2 ${ }^{270}=$ EGFP protein the NLS is likely to be abolished. To determine the intracellular localization of MeCP2 $2^{270}$ EGFP protein, we analyzed the hippocampal sections at a higher magnification $(60 \times)$, immunostaining with GFP antibody, which revealed MeCP2 270 EGFP protein localized in the nucleus (fig. 2E) as confirmed by counterstaining the cells with DAPI (fig. 2F). Furthermore, staining the cells with MeCP2 antibody showed MeCP2 ${ }^{270 \_E G F P}$ protein co-localized with the endogenous $\mathrm{MeCP} 2$ (fig. $2 \mathrm{G}$ ) predominately at the heterochromatin foci of the nuclei (fig. $2 \mathrm{E}-\mathrm{G}$ ).

\section{Phenotypic Analysis of Mecp2 270_EGFP Transgenic}

Mice

Quantification of expression of MeCP2 ${ }^{270 \_E G F P}$ in the transgenic mice revealed that the level of transgenic protein was comparable to that of endogenous MeCP2 suggesting that a single copy of the transgene was integrated into the genome of the transgenic mice (data not shown). 
Fig. 2. Schematic diagram showing structural domains of the $\mathrm{MeCP} 2$ protein. $\mathrm{N}, \mathrm{NH}_{2}$-terminal; C, COOH-terminal; MBD, methyl binding domain; TRD, transcription repression domain; CTB, proline-rich C-terminal domain; NLS, nuclear localization signal (A). Expression analysis of $\mathrm{MeCP} 2$ in the hippocampus showed a similar expression pattern for the transgenic MeCP2 $2^{270}$ EGFP protein as compared to endogenous MeCP2 (B-D). Analysis of the cryosection at the higher magnification revealed that both transgenic MeCP2 $270 \_$EGFP as well as endogenous $\mathrm{MeCP} 2$ proteins localize in the nucleus (E-G). Scale bar, $50 \mu \mathrm{m}$ (B-D), $10 \mu \mathrm{m}$ (E-G).

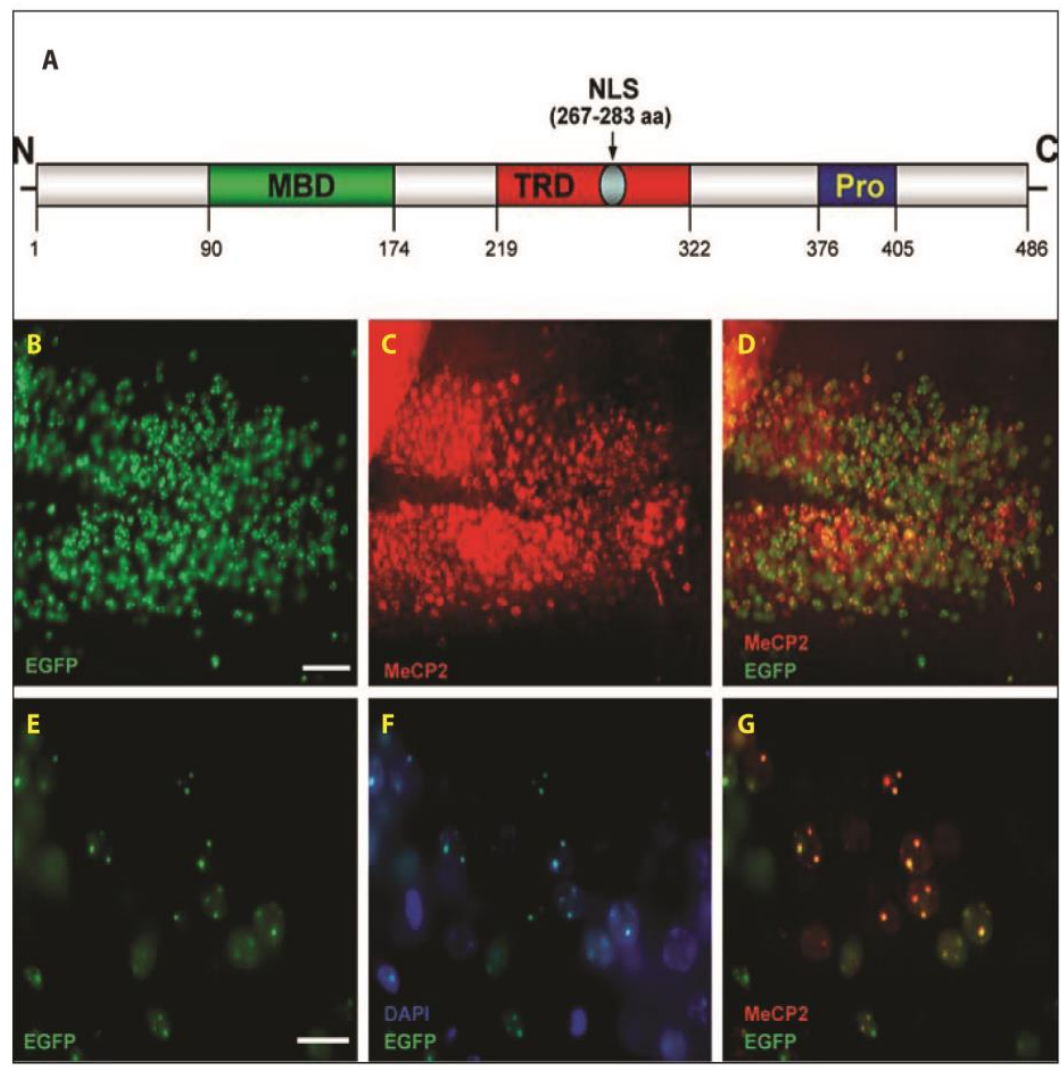

To maintain the transgenic mouse line, the heterozygous $\mathrm{T}^{270}$ /- mice were backcrossed with FVB/N mice. From such breeding, we obtained 50\% T $\mathrm{T}^{270} /$ - mice and 50\% wild-type littermates, thus excluding the possibility of prenatal lethality. Furthermore, we obtained equal numbers of male and female mice, which suggests that integration of the transgene was in an autosomal chromosome. Postnatally, the transgenic mice appeared normal with no obvious abnormalities. To assess neurological abnormalities, hind-limb clasp tests were performed on 5 adult (6-month-old) mice; however, the transgenic mice did not show clasping of their hind-limb when suspended by their tails (fig. 3A).

To determine any defect in the process of neuronal development and differentiation, hippocampal neurons from the transgenic mice (P7 stage) were cultured for 7 days and stained with neuronal marker $\beta 3$-tubulin (fig. 3B). For evaluation of neuronal parameters, the stained primary neurons were analyzed by Image J software. There was no significant change in neurite length as well as in cell soma size in the Mecp2 $2^{270}$ EGGF transgenic neurons as compared to the wild-type neurons (fig. 3C, D).
Expression of MeCP2270_EGFP in Astrocytes

In the primary hippocampus culture of transgenic mice, when cells were stained with neuronal marker $\beta 3$-tubulin, we observed that several cells expressing MeCP2 ${ }^{270}{ }^{\mathrm{EG} F P}$ were negative for expression of $\beta 3$ tubulin (fig. 4A). When these hippocampal cells were stained with astrocyte marker GFAP, co-expression of $\mathrm{MeCP} 2{ }^{270}{ }^{20 G F P}$ with GFAP was observed in the astrocytes (fig. 4B).

\section{Discussion}

Mutational spectrum analysis of MeCP2 in RTT shows that mutations are distributed throughout the structural architecture of the protein. However, certain point mutations occur recurrently and account for up to 2 thirds of the pathogenic mutations identified in RTT [Dragich et al., 2000]. R270X is one of the most frequent recurrent MECP2 mutations amongst different cohorts irrespective of ethnic background and accounts for $6.4 \%$ of all reported mutations [Dragich et al., 2000; Laccone et al., 

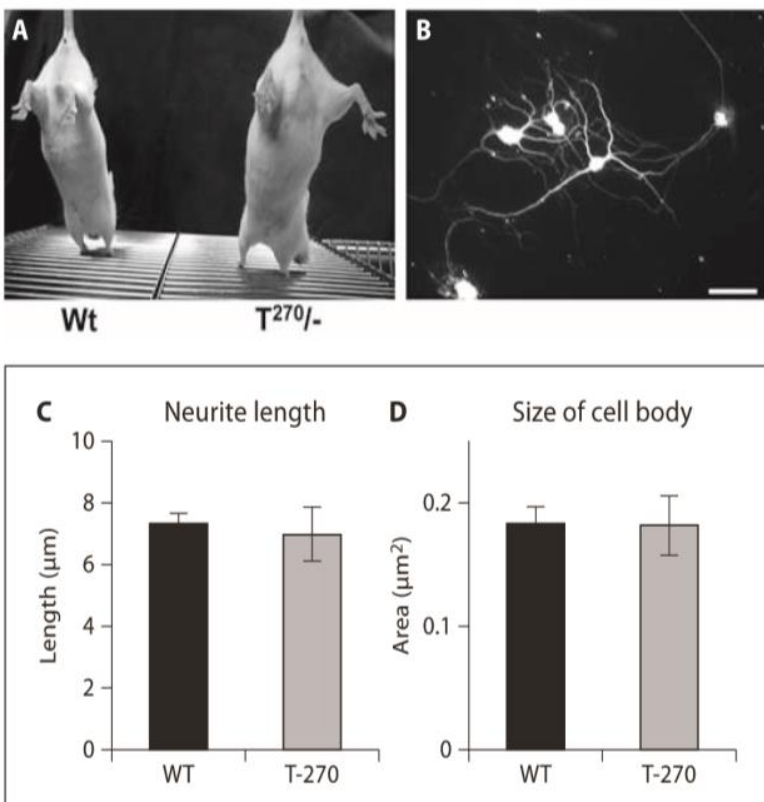

Fig. 3. Image showing both Mecp $2^{270}{ }_{-}^{E G F P}$ transgenic as well as wild-type $\mathrm{FVB} / \mathrm{N}$ mice were negative for hind-limb clasp test. Both mice, when they were held by the tail, showed normal spreading of hind-limbs. $\mathrm{T}^{270} /-$, transgenic; -/-, wild-type (A). Immunostaining of the transgenic Mecp2 $2^{270}$ EGFP primary neuronal cells with the neuronal marker $\beta 3$-tubulin. The stained neuron images were analyzed by Image J software. Scale bar, $50 \mu \mathrm{m}$ (B). Image J analysis of the neuronal parameters; neurite length and cell soma size. Measurement of neurite lengths of the transgenic and wild-type neurons after 7 days of ex vivo culture showed no significant difference (C). Evaluation of cell soma size of the transgenic and wild-type neurons also failed to detect any difference, which was statistically significant. WT, wild type; T-270, Mecp $2^{270-E G F P}$, transgenic mice (D).
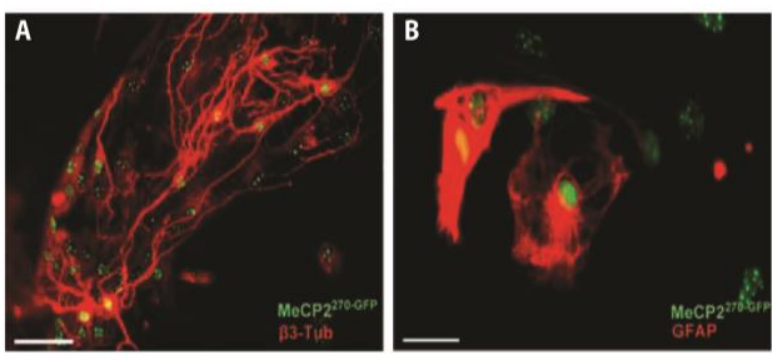

Fig. 4. Immunocytolochemical analysis of Mecp2270_EGFP hippocampal cell culture. Staining of cells with neuronal marker $\beta 3$ tubulin revealed several MeCP2 $2^{270}$ EGFP - expressing cells were negative for the $\beta 3$-tubulin (A). Immunostaining with astrocyte marker GFAP confirmed expression of MeCP2 $2^{270}$ EGFP in astrocytes (B). Scale bar, $50 \mu \mathrm{m}(\mathbf{A}), 10 \mu \mathrm{m}$ (B).

Mecp2 $2^{270 \_E G F P}$ Transgenic Mice
2001; Colvin et al., 2004; Jian et al., 2005]. The R270X mutation resides within the TRD-NLS region of MeCP2. Individuals with mutations in the TRD-NLS region manifest a more severe clinical phenotype than those with mutations in other domains [Huppke et al., 2002; Colvin et al., 2004; Jian et al., 2005]. Moreover, it is suggested that the R270X mutation is associated with increased mortality [Jian et al., 2005]. Mutations in the TRD region appeared to have a less severe influence on the phenotype [Huppke et al., 2002; Colvin et al., 2004]. A representative mutation in this group is R294X [Colvin et al., 2004]. Mutations involving the TRD-NLS region might result in failure of the truncated $\mathrm{MeCP} 2$ protein (assuming a stable protein) to be imported into the nucleus of the cell, thus resulting in a dramatic reduction in the $\mathrm{MeCP} 2$-specific transcription activity, which could lead to a severe clinical phenotype [Colvin et al., 2004]. On the other hand, proteins with truncating mutations occurring distal to the NLS in the TRD could still be translocated into the nucleus, where the mutation could exert a partial effect on transcription activity thus rendering a milder effect [Colvin et al., 2004]. However, to our knowledge, no functional studies of mutations involving the TRD-NLS have been performed so far.

To evaluate the functional role of the R270X mutation, we generated a transgenic mouse model expressing $\mathrm{MeCP} 2^{270}$ EEGFP, which is equivalent to the human mutation. The BAC construct, which was used for generation of the transgenic mice, consist of an $\sim 150-\mathrm{kb}$ genomic fragment with $\sim 50 \mathrm{~kb}$ upstream and downstream of the Mecp2 locus, which is supposed to contain along with the promoter also further regulatory elements necessary for the spatio-temporal expression pattern of $\mathrm{MeCP} 2$ [Collins et al., 2004]. The BAC clone also contained a transcriptional unit of Opsinl and Irakl genes upstream and downstream of the Mecp2 gene, which we deleted, thus ensuring expression of the Mecp2 locus only from the $\mathrm{BAC}$ construct. When expression of MeCP2 2 270_EGFP from the transgene was compared with endogenous $\mathrm{MeCP} 2$ in the wild-type as well as transgenic mice, we observed a similar expression pattern thus confirming that the BAC transgene mimics the endogenous $\mathrm{MeCP} 2$ expression. Previously, Collins and colleagues reported that expression of a transgenic MeCP2 from a human PAC containing a $90-\mathrm{kb}$ fragment of $M E C P 2$ was similar to that of endogenous MeCP2 [Collins et al., 2004], which is consistent with our finding.

Strikingly, MeCP2270_EGFP localizes in the nucleus, although it was speculated that R270X could cause disruption of the NLS within the TRD-NLS region [Colvin 
et al., 2004]. In silico analysis using the PSORT II Prediction program (http://psort.ims.u-tokyo.ac.jp/form2. html) [Horton et al., 1997] revealed several bipartite NLS preceding the R270 amino acid. It is likely that the NLS at region R270 is not critical for translocation of MeCP2 into the nucleus and other NLS in the N-terminal region are sufficient for the nuclear localization of MeCP2 270 EGGPP protein.

The nuclear localization of transgenic MeCP2 270 EGFP, particularly at the heterochromatic foci, suggests that the methyl-cytosine-specific binding property of $\mathrm{MeCP} 22^{270}=\mathrm{EGFP}$ is still intact. It is likely that the human $\mathrm{MeCP}_{2}{ }^{\mathrm{R} 270 \mathrm{X}}$ also localizes in the nucleus. Therefore, manifestation of clinically severe phenotype by patients harboring the R270X mutation could be due to either a gain of function or a loss of functional domain. Although in principle both proteins can localize in the nucleus, interestingly, there is a striking difference in the phenotype between $\mathrm{MeCP}^{\mathrm{R} 270 \mathrm{X}}$ and $\mathrm{MeCP}^{\mathrm{R} 294 \mathrm{X}}$ [Colvin et al., 2004], which suggests perhaps an important functional domain/motif of MeCP2 located within the 270-294 residues region is disrupted in $\mathrm{MeCP} 2^{\mathrm{R} 270 \mathrm{X}}$.

The transgenic mice expressing MeCP2 270 EGFP were phenotypically normal. There were no symptoms of neurological abnormalities as these mice were negative for hind-limb clasping, which is indicative of neurological impairment [Dietrich et al., 2005]. Evaluation of neuronal parameters, such as neurite length and cell soma size of the MeCP2 270 EGFP neurons, revealed no significant difference as compared to wild-type neurons. Overall, our data from transgenic mice do not support a gain of function or a dominant negative effect of the MeCP2 270 EGGP on the endogenous protein. Further investigation of the transgenic mice including neuro-physiological tests and behavioral analyses to assess cognitive learning and motor performance of mice will assist us in dissecting the role of the MeCP2 $2^{270 \_E G F P}$ protein. This issue is of particular relevance for the development of therapeutic strategies for the Rett syndrome aimed at reintroducing a wild-type MeCP2 protein in the diseased cells.

Previous studies reported that MeCP2 was highly expressed in mature neurons but was absent in the glial cells [Shahbazian et al., 2002; Kishi and Macklis, 2004]. In the primary hippocampal cell culture derived from $M e c p 2^{270}{ }_{\text {EGFP }}$ transgenic mice, staining with neuronal marker $\beta 3$-tubulin revealed that several cells expressing $\mathrm{MeCP} 2^{270}{ }^{27 G F P}$ were negative for $\beta 3$-tubulin. Furthermore, staining hippocampal cells with astrocyte marker GFAP showed MeCP2 270_EGFP was expressed in astrocytes. Recently, 2 studies reported that MeCP2 expres- sion in the brain was not limited only to the neurons, but also was expressed in all types of glia, including astrocytes, oligodendrocyte progenitor cells and oligodendrocytes [Ballas et al., 2009; Maezawa et al., 2009]. Our data showing expression of MeCP2 $2^{270}$ EGFP in astrocytes of the transgenic mice further reinforces these recent findings concerning expression of $\mathrm{MeCP} 2$ in the glial cells.

These recent studies showed that loss of MeCP2 in the astrocytes causes abnormalities in neighboring neurons probably by a non-cell-autonomous mode of action [Ballas et al., 2009; Maezawa et al., 2009]. MeCP2-deficient astrocytes interfere with proper development and maturation of neurons; both wild-type and Mecp2 null neurons develop fewer and shorter dendrites and only a few neurons can survive beyond 6 days when co-cultured with MeCP2-deficient astrocytes [Ballas et al., 2009]. However, MeCP2 target proteins in the astrocytes still remain unknown. An appropriate mouse model is needed to evaluate the role of $\mathrm{MeCP} 2$ in the astrocyte dysfunction contributing to RTT pathogenesis. Towards this end, our Mecp $2^{270 \_E G F P}$ transgenic mice can serve as a valuable model-system.

\section{Acknowledgements}

The authors would like to thank H. Huehn for excellent technical assistance, K. Pantakani and P. Kempaiah for intellectual contribution and W. Engel for support and critical suggestions. The authors would also like to thank M. Platzer, Jena, Germany for kindly providing the BAC clone B22804 and P.A. Ioannou, Melbourne, Australia for kindly providing pGET plasmid. This work was funded by the DFG-Research Center for Molecular Physiology of the Brain Grants.

References Adams VH, McBryant SJ, Wade PA, Woodcock CL, Hansen JC: Intrinsic disorder and autonomous domain function in the multifunctional nuclear protein, $\mathrm{MeCP} 2$. J Biol Chem 282:15057-15064 (2007).

- Amir RE, Van den Veyver IB, Wan M, Tran CQ, Francke U, et al: Rett syndrome is caused by mutations in X-linked MECP2, encoding methyl-CpG binding protein 2. Nat Genet 23:185-188 (1999).

- Ballas N, Lioy DT, Grunseich C, Mandel G: Noncell autonomous influence of MeCP2 deficient glia on neuronal dendritic morphology. Nat Neurosci 12:311-317 (2009).

- Bebbington A, Anderson A, Ravine D, Fyfe S, Pineda $M$, et al: Investigating genotype-phenotype relationships in Rett syndrome using an international data set. Neurology 70:868875 (2008).

Kifayathullah/Arunachalam/Bodda/

Agbemenyah/Laccone/Mannan 
- Ben-Shachar S, Chahrour M, Thaller C, Shaw $\mathrm{CA}$, Zoghbi HY: Mouse models of MeCP2 disorders share gene expression changes in the cerebellum and hypothalamus. Hum Mol Genet 18:2431-2442 (2009).

Chahrour M, Zoghbi HY: The story of Rett syndrome: from clinic to neurobiology. Neuron 56:422-437 (2007).

- Chahrour M, Jung SY, Shaw C, Zhou X, Wong ST: MeCP2, a key contributor to neurological disease, activates and represses transcription. Science 320:1224-1229 (2008)

-Chen RZ, Akbarian S, Tudor M, Jaenisch R: Deficiency of methyl-CpG binding protein- 2 in CNS neurons results in a Rett-like phenotype in mice. Nat Genet 27:327-331 (2001).

Collins AL, Levenson JM, Vilaythong AP, Richman R, Armstrong DL, et al: Mild overexpression of $\mathrm{MeCP} 2$ causes a progressive neurological disorder in mice. Hum Mol Genet 13:2679-2689 (2004)

- Colvin L, Leonard H, de Klerk N, Davis M Weaving L, et al: Refining the phenotype of common mutations in Rett syndrome. J Med Genet 41:25-30 (2004).

D'Esposito M, Quaderi NA, Ciccodicola A, Bruni $\mathrm{P}$, Esposito $\mathrm{T}$, et al: Isolation, physical mapping, and Northern analysis of the Xlinked human gene encoding methyl CpGbinding protein, MECP2. Mamm Genome 7: 533-553 (1996).

- Dietrich MO, Mantese CE, Anjos GD, Souza DO, Farina M: Motor impairment induced by oral exposure to methylmercury in adult mice. Environ Toxicol Pharm 19:169-175 (2005).

Dragich J, Houwink-Manville I, Schanen C: Rett syndrome: A surprising result of mutation in MECP2. Hum Mol Genet 9:2365-2375 (2000).
Dragich JM, Kim YH, Arnold AP, Schanen NC Differential distribution of the MeCP2 splice variants in the postnatal mouse brain. Comp Neurol 501:526-542 (2007).

Georgel PT, Horowitz-Scherer RA, Adkins N, Woodcock CL, Wade PA, et al: Chromatin compaction by human MeCP2. Assembly of novel secondary chromatin structures in the absence of DNA methylation. J Biol Chem 278:32181-32188 (2003).

Guy J, Hendrich B, Holmes M, Martin JE, Bird A: A mouse Mecp2-null mutation causes neurological symptoms that mimic Rett syndrome. Nat Genet 27:322-326 (2001).

Hagberg B, Aicardi J, Dias K, Ramos O: A progressive syndrome of autism, dementia, ataxia, and loss of purposeful hand use in girls: Rett's syndrome: report of 35 cases. Ann Neurol 14:471-479 (1983).

Horton P, Nakai K: Better prediction of protein cellular localization sites with the $\mathrm{k}$ nearest neighbors classifier. Proc Int Conf Intell Syst Mol Biol 5:147-152 (1997).

Huppke P, Held M, Hanefeld F, Engel W, Laccone F: Influence of mutation type and location on phenotype in 123 patients with Rett syndrome. Neuropediatrics 33:63-68 (2002).

Jian L, Archer HL, Ravine D, Kerr A, de Klerk N, et al: p.R270X MECP2 mutation and mortality in Rett syndrome. Eur J Hum Genet 13: 1235-1238 (2005).

Kishi N, Macklis JD: MECP2 is progressively expressed in post-migratory neurons and is involved in neuronal maturation rather than cell fate decisions. Mol Cell Neurosci 27: 306-321 (2004).

Kriaucionis S, Bird A: The major form of MeCP2 has a novel $\mathrm{N}$-terminus generated by alternative splicing. Nucleic Acids Res 32:1818-1823 (2004).

Laccone F, Huppke P, Hanefeld F, Meins M: Mu tation spectrum in patients with Rett syndrome in the German population: Evidence of hot spot regions. Hum Mutat 17:183-190 (2001)
Maezawa I, Swanberg S, Harvey D, LaSalle IM, Jin LW: Rett syndrome astrocytes are abnormal and spread MeCP2 deficiency through gap junctions. J Neurosci 29:5051-5061 (2009).

Meehan RR, Lewis JD, Bird AP: Characterization of MeCP2, a vertebrate DNA binding protein with affinity for methylated DNA. Nucleic Acids Res 20:5085-5092 (1992).

Nan X, Meehan RR, Bird A: Dissection of the methyl-CpG binding domain from the chromosomal protein MeCP2. Nucleic Acids Res 21:4886-4892 (1993).

Ng HH, Bird A: DNA methylation and chromatin modification. Curr Opin Genet Dev 9: 158-163 (1999).

Orford M, Nefedov M, Vadolas J, Zaibak F, Williamson R, et al: Engineering EGFP reporter constructs into a 200 -kb human beta-globin BAC clone using GET recombination. Nucleic Acids Res 28:E84 (2000).

Razin A: CpG methylation, chromatin structure and gene silencing - a three-way connection. EMBO J 17:4905-4908 (1998).

Rett A: On an unusual brain atrophy syndrome in hyperammonemia in childhood. Wien Med Wochenschr 116:723-726 (1966).

Shahbazian MD, Antalffy B, Armstrong DL, Zoghbi HY: Insight into Rett syndrome: $\mathrm{MeCP} 2$ levels display tissue- and cell-specific differences and correlate with neuronal maturation. Hum Mol Genet 11:115-124 (2002)

Trevathan E, Moser HW: Diagnostic criteria for Rett syndrome. Ann Neurol 23:425-428 (1988).

Young JI, Hong EP, Castle JC, Crespo-Barreto $\mathrm{J}$, Bowman $\mathrm{AB}$, et al: Regulation of RNA splicing by the methylation-dependent transcriptional repressor methyl-CpG binding protein 2. Proc Natl Acad Sci USA 102: 17551-17558 (2005). 


\subsection{Mild overexpression of Mecp2 in mice causes a higher susceptibility toward seizures}

In the second part of the thesis, we generated a Mecp2 transgenic model to determine the MECP2 dosage effect on duplication syndrome. To evaluate the MeCP2 dosage effects, we generated $M e c p 2^{W T_{-} E G F P}$ transgenic mouse which was mildly overexpressed $\mathrm{MeCP} 2$ $(\sim 1.5 \mathrm{X})$ (MeCP2 transgenic with endogenous). The Mecp $2^{W T_{-} E G F P}$ transgenic mouse showed increased aggressiveness and higher seizures propensity after pentylenetetrazole (PTZ) (epiliptogenic compound) treatment. Additional studies in $M e c p 2^{W T_{-} E G F P}$ transgenic cultured neurons revealed that after PTZ treatment there was an increase in calcium amplitude as frequency. Further evaluation of ex vivo and in vivo neuronal parameters showed an increase in soma size and reduced tertiary branching sites with increased spine number in $M e c p 2^{W T_{-} E G F P}$ transgenic mouse. From our various results, we conclude that mild $\mathrm{MeCP} 2$ overexpression in mice leads to epileptic seizures as a first symptom.

Chiranjeevi Bodda*, Martesa Tantra*, Rustam Mollajew, Jayamuruga P. Arunachalam, Karolina Can, Albert Rosenberger, Sergej L. Mironov, Hannelore Ehrenreich and Ashraf U. Mannan

*Chiranjeevi Bodda and Martesa Tantra contributed equally to this work.

Status: Accepted in American journal of pathology (In press) (Impact factor: 4.890).

Author contributions to the results:

Chiranjeevi Bodda: Designed and performed the experiments. Western blot analysis, RNA preparation, qRT-PCR analysis, Immunohistochemistry, Immunocytochemistry, Calcium homeostasis, Animal management, Primary neuronal culture, statistical analysis, Golgi Cox staining and analysis. Involved in the manuscript preparation.

Martesa Tantra: Performed the behavioral studies and animal management. Involved in the manuscript preparation.

Rustam Mollajew: Performed in Calcium homeostasis. 
Jayamuruga P. Arunachalam: Generation of the transgenic construct.

Karolina Can: Performed primary neuronal culture work and animal management.

Albert Rosenberger: Performed in statistical analysis.

Sergej L. Mironov: Calcium homeostasis experiments. Involved in the manuscript preparation.

Hannelore Ehrenreich: Behavioral studies experiments and involved in the manuscript preparation.

Ashraf U. Mannan: Designed the experiments. Interpretated the data and prepared the manuscript. 


\section{Mild overexpression of Mecp2 in mice causes a higher susceptibility toward seizures}

Chiranjeevi Bodda ${ }^{1,5,6}$, Martesa Tantra ${ }^{2,5,6}$, Rustam Mollajew ${ }^{3,5}$, Jayamuruga P. Arunachalam ${ }^{1}$, Karolina Can ${ }^{1}$, Albert Rosenberger ${ }^{4}$, Sergej L. Mironov ${ }^{3,5}$, Hannelore Ehrenreich ${ }^{2,5}$ and AshrafU. Mannan ${ }^{1,5,7}$

${ }^{1}$ Institute of Human Genetics, Universitätsmedizin Göttingen, Göttingen, Germany ${ }^{2}$ Division of Clinical Neuroscience, Max Planck Institute of Experimental Medicine, Göttingen, Germany ${ }^{3}$ Department of Neuro- and Sensory Physiology, Universitätsmedizin Göttingen, Göttingen, Germany ${ }^{4}$ Department of Genetic Epidemilogy, Center for Informatics, Statistics and Epidemiology, Universitätsmedizin Göttingen, Göttingen, Germany ${ }^{5}$ Center for Nanoscale Microscopy and Molecular Physiology of the Brain (CNMPB), Göttingen, Germany

An intriguing finding about the gene encoding methy- $\mathrm{CpG}$ binding protein 2 (MeCP2) is that the loss-of-function mutations cause Rett syndrome and duplication (gain-of-function) of MECP2 leads to another neurol ogical disorder temed as MECP2 duplication syndrome. To ensure proper neurodevelopment, a precise regulation of MeCP2 expression is critical and any gain or loss of MeCP2 over a narrow threshold level may lead to postnatal neurological impairment. To evaluate MeCP2 dosage effects, we generated Mecp2 ${ }^{\text {WT_EGFP }}$ transgenic mouse in which MeCP2 (endogenous plus transgenic) is mildly overexpressed ( 1.5X). The transgenic MeCP2 ${ }^{\text {WT_EGFP }}$ fusion protein is functionally active, as cross breeding of these mice with Mecp 2 knockout mi $œ$ led to alleviation of major phenotypes in the null mutant mice induding prema ture lethality. To characterize the Mecp $2^{\text {WT EGFP }}$ mouse model, we performed an extensive battery of behavioral tests, which re vealed that these mice manifest increased aggressiveness and higher pentylenetetrazole-induced seizure propensity. Evaluation of ne uronal pa rameters revealed a reduction in number of tertia ry branching sites and increased spine density in Mecp $2^{\text {WTEEGP }}$ trans genic neurons. Treatment of transgenic neurons with epileptogenic compound-pentylenetetrazole led to a marked increase in a mplitude and frequency of calcium spikes. Based on our ex vivo and in vivo data, we condude that epileptic seizures a re manifested as first symptom when MeCP2 is mildly overexpressed in mice.

\section{Introduction}

The MECP2 gene encodes for methyl-CpG-binding protein 2 (MeCP2). MeCP2 binds to methylated CpG DNA sequences and modulates transcription of gen es in the vicinity of the methylated sequence. ${ }^{1}$ The ability of MeCP2 to bind to the methylated CpGs and its predominant localization to the highly methylated heterochromatin regions of the nucleus, ${ }^{2}$ led researchers to propose that $\mathrm{MeCP} 2$ may act as a global transcriptional repressor. ${ }^{3}$ Subsequently, the majority of studies substantiated the role of MeCP2 in repression of transcription (reviewed in ${ }^{4,5}$ ). Furthermore, MeCP2 was shown to interact with Sin3A and HDAC (Histone deacetylases). ${ }^{6}$ By recruiting HDAC at the methylation loci, MeCP2 further represses transcription at such sites. However, recent studies have also highlighted the role of MeCP2 in transcriptional activation. It was shown that MeCP2 associates with actively transcribed genes. ${ }^{6,7} \mathrm{MeCP} 2$ promotes activation of transcription by associating with the transcriptional activator CREB1 (cAMP responsive element binding protein 1) on an active but not a repressed form of the same gene. ${ }^{6}$

${ }^{6}$ These authors contributed equally to the work ${ }^{7}$ To whom correspondence should be addressed: Dr. Ashraf U. Mannan, Institute of Human Genetics, University of Goettingen HeinrichDueker-Weg 12, D-37073, Goettingen, Germany Phone: +49-551397522, Fax: +49-551-399303 Email: amannan@gwdg.de
A multifaceted role of MeCP2 was further corroborated by the discoveries of its involvement in RNA splicing and chromatin compactions., 9 Mutations in MECP2 gene have been shown to cause a neurodevelopmental disorder known as Rett syndrome (RTT). ${ }^{10}$ Classically, RTT patients develop normally till the age of 6-18 months. After this normal phase of development, RTT patients fall into a stage of developmental stagnation, followed by rapid regression. The patients start showing symptoms such as progressive loss of motor skills, stereotypic hand movements, breathing abnormalities, microcephaly, epileptic seizures, and social interaction impairments reminiscent of autism. ${ }^{11}$ Due to X-chromosome inactivation $(\mathrm{XCl})$, females are mosaics for MECP2 mutations, which can have a mitigating effect, with phenotypes ranging from classic RTT to asymptomatic individuals. ${ }^{12}$ However, male patients carrying MECP2 mutations usually show a very severe phenotype. They typically suffer from neonatal encephalopathy and die in early childhood. ${ }^{13}$ Up to now, over 700 MECP2 mutations have been reported for RTT (HGMD database, Professional version 2012.4 - $14^{\text {th }} \mathrm{Dec}, 2012$; https://portal.biobaseinte rnational .com/hgmd/pro/all.php. All types of mutations have been reported, such as missense, nonsense, splice site, deletion, and insertion. This wide spectrum of MECP2 mutations 
suggests loss-of-function as the likely common pathomechanism for RTT. In addition to these loss-offunction mutations in the MECP2 gene, which cause $\mathrm{RTT}$, till now over 100 cases of copy number gains of the MECP2 gene have been reported. ${ }^{14,15}$ In the majority of cases, duplication of MECP2 locus was observed, however in several instances, triplication was also detected. ${ }^{16,17}$ The gain of MECP2 lead to a neurological disorder termed, MECP2 duplication syndrome, which primarily affects males who display variable phenotypes. Common symptoms include infantile hypotonia, severe mental retardation, autism or autistic features, poor speech development, recurrent infections, progressive spasticity, ataxia, and epilepsy ${ }^{14}, 15,18$. MECP2 duplication is $100 \%$ penetrant in males. ${ }^{14}$ The triplication of the MECP2 locus causes a more severe phenotype. $^{17,} 19$ Most of the reported MECP2 duplication are inherited, however, de novo cases have also been reported. ${ }^{18,20,21}$ Previously, a transgenic mouse (MECP2-Tg1) was generated which overexpresses MeCP2 at twice (2X) the level of endogenous MeCP2. ${ }^{22}$ The phenotypes of these mice are reminiscent of the human MECP2 duplication syndrome. Until the age of 10-12 weeks, these transgenic mice appear normal. Afterwards, they develop progressive neurological symptoms, which include stereotyped and repetitive movements, motor dysfunction, epilepsy, spasticity, ataxia, hypoactivity, kyphosis, and premature death. ${ }^{22}$ Increasing the copy numbers of Mecp2 in the transgenic mice, resulting in higher MeCP2 levels, causes even more severe phenotypes. ${ }^{22}$ Interestingly, in another study, evaluation of a Mecp $2^{\text {flox }}$ allele revealed that due to the modification of the 3'UTR of Mecp2 by insertion of a neomycin cassette, the expression of MeCP2 was reduced by $50 \% .{ }^{23}$ These Mecp $2^{\text {flox } N}$ mice manifest a spectrum of disabilities such as learning and motor deficits, decreased anxiety, and breathing dysfunction. Overall, it is evident that the central nervous system is highly sensitive to the functional level of MeCP2 and any gain or loss of MeCP2 over a narrow threshold level can lead to postnatal neurological impairment. This precise regulation of MeCP2 expression to ensure proper neurodevelopment has important ramifications regarding devising potential therapeutic strategies for correcting the expression level of MeCP2 in RTT patients. To study the pathomechanism underlying the neurological impairment in MECP2 duplication syndrome, a mouse model with only mild overexpression of MeCP2 may help to identify and characterize the earliest pathologies elicited due to gain-of-function properties of MECP2. We therefore generated Mecp $2^{\text {WT_EGFP }}$ transgenic mice, which mildly overexpress MeCP2 ( 1.5X).

\section{Material and methods}

\section{Generation of Mecp $2^{\text {WT_EGFP }}$ transgenic mouse line}

A Bacterial Artificial Chromosome (BAC) clone, pBAC_B22804 containing $\sim 120 \mathrm{~Kb}$ of murine genomic fragment with intact Mecp2 gene and the flanking Opsin 1 and Irak 1 genes was used for generating the transgenic construct. ${ }^{24}$ To generate PBAC_Mecp2 ${ }^{\text {WT_EGFP }}$ construct, the Enhanced green fluorescent protein/Kanamycin-resistant gene (EGFP/Kan) cassette was PCR amplified using pEGFP1 vector as template with primers containing $50 \mathrm{bp}$ flanking sequence from either side of the Mecp2 stop codon. Further more, the endogenous stop codon was replaced by two glycine residues inframe between the MeCP2 protein and the EGFP protein to facilitate the two proteins to fold and function independently. The amplified EGFP/Kan cassette was electroporated into $E$. coli harboring the BAC clone and PGET recombination system ${ }^{25}$, to facilitate the homologous recombination of EGFP/Kan cassette at the site of stop codon of Mecp2. The correct insertion of EGFP/Kan cassette after the recombination event into the BAC clone was confirmed by sequencing. The Mecp2 flanking genes, Opsin 1 and Irak1 were deleted from the modified BAC clone using additional BAC recombineering with Zeocin selection cassette (containing the BAC homology arms and Zeocin antibiotic marker gene driven by EM7 promoter from pSELECT vector) (InvivoGen, Toulouse, France), to avoid any additional phenotype arising from the overexpression of these genes. During the process of Opsin 1 deletion, a Mlu I restriction site was introduced into $\mathrm{BAC}$ clone. The final BAC construct PBAC_Mecp2 ${ }^{\text {WT_EGFP }}$ was linearized with Mlu । restriction enzyme and micro-injected into the male pronuclei of the fertilized mouse oocytes derived from the $\mathrm{FVB} / \mathrm{N}$ strain. Next, the injected oocytes were transplanted into the uteri of the foster mothers. The gen omic DNA isolated from tail biopsies of newborn pups were analyzed for the presence of the transgene by PCR analysis as described previously. $^{24}$

\section{Western Blot Analysis}

For Western blot experiments, total protein extracts were isolated from brain biopsies of fresh male adult mice. In brief, the brain biopsies were collected in ice cold PBS and transferred to cold Iysis buffer $(20 \mathrm{mM}$ Pipes, 2 mM EGTA, $1 \mathrm{mM}$ EDTA, $1 \mathrm{mM}$ DTT, and 0.3 mM PMSF) containing protease inhibitors (Roche, Mannheim, Germany) followed by homogenization using tissue micromotor. The lysates were sonicated on ice and the supernatant was collected after centrifugation at $12,000 \mathrm{~g}$ for $10 \mathrm{~min}$ at $4^{\circ} \mathrm{C}$. An aliquot of $50 \mu \mathrm{g}$ protein lysates were denatured by boiling in a buffer containing sodium dodecyl sulfate 
(SDS) and dithiothreitol, which were resolved by SDSPAGE using a NuPage $4 \%-12 \%$ Bis-Tris precast gel in MES buffer (Invitrogen, Karlsruhe, Germany). The resolved proteins were electro-transferred onto a nitrocellulose membrane (Amersham Biosciences, Braunschweig, Germany). Afterwards, the membrane was blocked in 5\% lyophilized milk powder in TBS-T (100 mM Tris-Cl, pH 7.5; 150 mM NaCl; 0.1\% Tween 20) and then incubated with either anti-MeCP2 antibody (dilution 1: 8,000) raised in rabbit using MeCP2-strep tag fusion protein as antigen (Eurogentec, Cologne, Germany) or anti-GFP antibody (GeneTex, Eching, Germany) (dilution 1: 5,000) at $4^{\circ} \mathrm{C}$ overnight. The following day after washing, the immunoblot was incubated with secondary antibody conjugated with alkaline phosphatase (dilution 1: 10,000) (Sigma-Aldrich, Munich, Germany) for $1 \mathrm{hr}$ at room temperature (RT). Finally, the Western blot was developed by using BCIP/NBT (nitroblue tetrazolium, 5-bromo-4-chloro-3-indolyl phosphate) (Carl-Roth, Karlsruhe, Germany). The intensity of the protein bands in the Western blot were quantified using ImageJ software (http://rsb.info.nih.gov/ij/).

RNA preparation and real-time quantitative reverse transcription PCR (RT-qPCR) analysis

Total RNA was extracted from cerebellum and hippocampus of 6 week old male mice using TRIzol reagent (Invitrogen, Karlsruhe, Germany) according to the manufacturer instructions. The CDNA was synthesized from $2 \mu \mathrm{g}$ of RNA using the SuperScript II (Invitrogen, Karlsruhe, Germany) and oligo-dT primer in a total volume of $20 \mu \mathrm{l}$. For RT-qPCR analysis, the cDNA was further diluted $(1 / 8)$ and was used as a template in Platinum SYBR Green qPCR SuperMixUDG with ROX system (Invitrogen, Karlsruhe, Germany) with Mecp2 gene specific primers (Mecp2_F; 5'-TGGTAGCTGGGATGTTAGGG-3' and Mecp2_R; 5'-CCTTCTTGTCTTTCTTCGCC-3'). The RTqPCR reactions were run in 7900 Sequence Detection System (Applied Biosystems, Darmstadt, Germany). The house-keeping gene, $\beta$-Actin amplicon was used for data normalization. The RT-qPCR experiments were repeated four times with three technical replicate. The data was analyzed by SDS 2.2 software (Applied Biosystems, Darmstadt, Germany) using standard curve method and EXCEL program.

\section{Immunohistochemistry}

The adult male mice were transcardially perfused with $4 \%$ paraformaldehyde in PBS for 3 hrs at $4^{\circ} \mathrm{C}$. The whole brain was dissected and submerged in $15 \%$ sucrose for $1 \mathrm{hr}$ at $4^{\circ} \mathrm{C}$ followed by incubation in 30\% sucrose solution for 3 days and then cryo-sectioned to $40 \mu \mathrm{m}$ thickness. The brain sections were washed 3 times with PBS for $5 \mathrm{~min}$ each and then permeabilized with $0.2 \%$ Triton-X for $30 \mathrm{~min}$ at $4^{\circ} \mathrm{C}$. Thereafter, the slides were again washed 3 times with PBS for $5 \mathrm{~min}$ and incubated in 4\% BSA and $0.1 \%$ Tween-20 (Promega, Mannheim, Germany) for $1 \mathrm{hr}$ at RT. The brain sections were then incubated with antiMeCP2 antibody (1:200; Eurogentec, Cologne, Germany) at RT for $1 \mathrm{hr}$ in $2 \%$ BSA solution. After washing steps, the sections were incubated with secondary antibody conjugated with Cy3 (SigmaAldrich, Munich, Germany) for $1 \mathrm{hr}$ at RT in 2\% BSA solution. After final washing, the slides were air-dried and VectaShield solution (Linaris, Wertheim, Germany) was applied before mounting the slides with coverslips. The sections were observed under a BX60 fluorescence microscope (Olympus, Hamburg, Germany).

\section{Animal management and behavioral analysis}

All experiments have been approved by the local Animal Care and Use Committee. Mice used for the experiments were kept in our behavioral unit under a temperature-controlled environment $\left(21 \pm 2^{\circ} \mathrm{C}\right)$ on a $12 \mathrm{hrs}$ light/dark cycle with food and water ad libitum, unless stated otherwise. A battery of behavioral tests were performed on pre-and postweaning stages of mice. In all experiments, the experimenter was unaware of the genotype ('blinded').

\section{Drug used in animal experiments}

Pentylenetetrazole (PTZ) (Sigma-Aldrich Chemie $\mathrm{GmbH}$, Taufkirchen, Germany), a non-competitive GABA antagonist with epileptogenic properties was dissolved in saline for subcutaneous (s.c.) injection.

\section{Pre-weaning (neonatal) assessments}

Male transgenic mice were bred with FVB/N wild type (WT) female mice to obtain WT and Mecp2 transgenic (TG) animals. A daily inspection for the presence of new litters in the cages was carried out twice a day and the day a litter was first observed was scored as day 0 for that litter. After birth, animals were kept untouched in the home cage with their mothers until postnatal day (P) 3, and at P3 animals were tagged in their feet. Neurodevelopmental evaluation tests were performed daily starting from P4 until P21. The battery of tests provides an assessment of development throughout the neonatal period and the behaviors measured are expressed at different periods throughout the first 21 days of life. These tests have been extensively described elsewhere ${ }^{26,27}$, 28 and consist of observations covering the maturation of physical landmarks as well as developmental milestones (see Supplemental Fig. S1 at http://ajp.amjpathol.org). Weaning was performed at 22 days of age. For the assessment of pre-weaning 
behavior, 14 male WT and 18 male TG litters were used.

\section{Post-weaning (adult) behavior}

Breeding pairs of Mecp2 transgenic male and WT female $\mathrm{FVB} / \mathrm{N}$ mice were used to obtain WT and Mecp2 transgenic mice. Shortly after weaning, mice were transferred to the behavioral unit for testing. Upon arrival and during the whole period of behavioral testing, mice were housed individually in standard plastic cages $(26.5 \times 20 \times 14 \mathrm{~cm})$. Adult behavioral testing was performed starting at the age of 5 weeks. The animal numbers of individual experiments are given in the legend of each corresponding figure.

\section{Experimental design}

\section{Neonatal assessments}

Neonatal assessments comprised three domains: (1) maturation measures targeting physical development, (2) neurodevelopmental measures targeting the development of neurological reflexes, and (3) the development of neuromotor coordination.

\section{Maturation measures (physical development)}

Body weight: The body weight of each pup was registered daily, starting from P4 through P21. Ear opening: The day when an opening in the ear was visualized was registered. Eye opening: The day when the eyes were opened was registered. An eye was considered open when any visible break in the membrane was noticed.

\section{Neurodevelopmental measures}

Surface righting reflex: Animals were restrained on their back on a table and then released. The time needed for each pup to right itself was recorded and the performance was monitored for 3 consecutive days, starting from P4. Score 0 was assigned when pup did not show surface righting reflex and score 1 when surface righting reflex was present. Postural reflex: Starting on P7 onwards, animals were put in a small box and shaken up and down, left and right. Animals were tested until an appropriate response (animals splaying their four feet) was observed and scored as 1 Cliff avoidance: Observed daily from P6 until each test pup, when placed on an edge with forepaws and nose just over the edge, showed retraction within $10 \mathrm{sec}$. Then score 1 was assigned.

Negative geotaxis reflex: Observed daily from P7 onwards, animals were put in a head-down position on a 30 degree inclined surface. The response of each pup was observed for $30 \mathrm{sec}$ and registered as shown in Supplemental Fig. S1 (see at http://ajp.amjpathol.org).

\section{Neuro motor coordination measures}

Wire suspension: The animals were forced to grasp a $3-\mathrm{mm}$ wire and hang from it on their forepaws. Mice were tested starting on P10 onwards until all test pups were able to hold the wire for 30 seconds. Swimming ability: Mice were tested on P8, 12, and 14. On each observation day, one at a time, test pups were placed in a tank of water $\left(30^{\circ} \mathrm{C}\right)$ for a period of 5-15 sec and observed for three aspects of swimming: (1) direction, (2) head position relative to water surface, and (3) use of limbs. Scoring for direction was: sank (0) - floated (1) - swam in circle or arch (2), straight (3); for angle: submerged (0) - nose at the surface (1) - nose and top head at or above the surface but ears still below the surface (2) - similar to (2), except for waterline is now at mid-ear level (3) nose, top head and ears above the surface (4); for limb usage: no paddling (0) - paddling with all four limbs (1) - paddling with hind limbs only, forelimbs held stationary (2).

\section{Adult behavior}

Elevated plus maze: The mouse was placed in the central platform, facing an open arm of the plus-maze inside a room with light intensity set to $130 \mathrm{Ix}$. Behavior was recorded by an overhead video camera and a computer equipped with 'Viewer' software (Biobserve $\mathrm{GmbH}$, St. Augustin, Germany) to calculate the time each animal spends in open or closed arms. The proportion of time spent in open arms was used for estimation of open arm aversion (fear equivalent). Open field: Spontaneous activity in open field was tested in a grey Perspex arena $(120 \mathrm{~cm}$ in diameter, $25 \mathrm{~cm}$ high) placed inside a room with light intensity set to $130 \mathrm{~lx}$. The mouse was positioned in the center and allowed to explore the open field for $7 \mathrm{~min}$. The behavior was recorded by a computer-linked overhead video camera. 'Viewer' software was used to calculate velocity, distance traveled, and time spent in central, intermediate, or peripheral zones of the open field.

Hole board: The hole board test measures exploratory activity. The apparatus consisted of a $21 \times 21 \times 36 \mathrm{~cm}$ transparent Perspex chamber with a non-transparent floor raised $5 \mathrm{~cm}$ above the bottom of the chamber with 16 equally spaced holes, $2 \mathrm{~cm}$ in diameter. Mice were allowed to explore the chamber for $5 \mathrm{~min}$ and the number of explored holes (head dips) was monitored by 2 layers of infra red photo beams connected to a computer with AKS software (TSE Systems GmbH, Bad Homburg, Germany). The light intensity was set to $5 \mathrm{Ix}$ during the test phase. 
Pre-pulse inhibition test: In this test of sensorimotor gating, individual mice were placed in small metal cages $(90 \times 40 \times 40 \mathrm{~mm})$ to restrict major movements and exploratory behavior. The cages were equipped with a movable platform floor attached to a sensor that records vertical movements of the floor. The cages were placed in four sound-attenuating is olation cabinets (TSE Systems $\mathrm{GmbH}$ ). Startle reflexes were evoked by acoustic stimuli delivered from a loudspeaker that was suspended above the cage and connected to an acoustic generator. The startle reaction to an acoustic stimulus, which evokes a movement of the platform and a transient force resulting from this movement of the platform, was recorded with a computer during a recording window of $260 \mathrm{msec}$ (beginning with the onset of pre-pulse) and stored for further evaluation. The recording window was defined from the onset of the acoustic stimulus. An experimental session consisted of a 2 min habituation to $65 \mathrm{~dB}$ background white noise (continuous throughout the session), followed by a baseline recording for $1 \mathrm{~min}$ at background noise. After baseline recording, 6 pulse-alone trials using startle stimuli of $120 \mathrm{~dB}$ intensity and $40 \mathrm{msec}$ duration were applied to decrease influence of within-session habituation. These data were not included in the analysis of the pre-pulse inhibition. For tests of pre-pulse inhibition, the $120 \mathrm{~dB} / 40 \mathrm{msec}$ startle pulse was applied either alone or preceded by a pre-pulse stimulus of $70 \mathrm{~dB}, 75 \mathrm{~dB}$, or $80 \mathrm{~dB}$ sound pressure level and $20 \mathrm{msec}$ duration. An interval of $100 \mathrm{~ms}$ with background white noise was employed between each pre-pulse and pulse stimulus. The trials were presented in a pseudorandom order with an interval ranging from 8 to $22 \mathrm{sec}$. The amplitude of the startle response (expressed in arbitrary units) was defined as the difference between the maximum force detected during a recording window and the force measured immediately before the stimulus onset. Amplitudes were averaged for each individual animal, separately for both types of trials (i.e. stimulus alone or stimulus preceded by a pre-pulse). Pre-pulse inhibition was calculated as the percentage of the startle response using the following formula:

$\%$ pre-pulse inhibition $=100-[($ startle amplitude after pre-pulse and pulse) / (startle amplitude after pulse only) x 100].

Rota-rod: Rota-rod is a test for motor function, balance, and coordination and comprises a rotating drum (Ugo Basile Srl, Comerio, Italy) which is accelerated from 4 to 40 revolutions per minute (rpm) over the course of $5 \mathrm{~min}$. Each mouse was placed individually on a drum and the latency of falling from the drum was recorded using a stopwatch. To assess motor learning, the rota-rod test was repeated $24 \mathrm{hrs}$ later.
Grip strength: A grip strength meter (TSE Systems $\mathrm{GmbH}$ ) was used to assess forelimb grip strength. Mice were lifted and held by their tail so that their forepaws could grasp a wire grid. The mice were then gently pulled backward by the tail with their posture parallel to the surface of the table until they released the grid. The peak force applied by the forelimbs of the mouse was recorded in Pond (P). Each mouse performed the test three times, and the average of the three trials was used for statistical analysis. Assessment of hearing: Individual mice were placed in small metal cages $(90 \times 40 \times 40 \mathrm{~mm})$ to restrict major movements and exploratory behavior. The cages were equipped with a movable platform floor attached to a sensor that records vertical movements of the floor. The cages were placed in four soundattenuating isolation cabinets (TSE Systems $\mathrm{GmbH}$ ). Startle reflexes were evoked by acoustic stimuli delivered from a loudspeaker that was suspended above the cage and connected to an acoustic generator. The startle reaction to an acoustic stimulus (pulse), which evokes a movement of the platform and a transient force resulting from this movement of the platform, was recorded with a computer during a recording window of $100 \mathrm{msec}$ and stored for further evaluation. The recording window was defined from the onset of the acoustic stimulus. An experimental session consisted of a 2 min habituation to $65 \mathrm{~dB}$ background white noise (continuous throughout the session), followed by a baseline recording for $1 \mathrm{~min}$ at background noise. After baseline recording, stimuli of different intensity and fixed $40 \mathrm{msec}$ duration were presented. Stimulus intensity was varied between $65 \mathrm{~dB}$ and $120 \mathrm{~dB}$, such that 19 intensities from this range were used with 3 dB step. Stimuli of the each intensity were presented 10 times in a pseudorandom order with an interval ranging from 8 to $22 \mathrm{sec}$. The amplitude of the startle response (expressed in arbitrary units) was defined as the difference between the maximum force detected during a recording window and the force measured immediately before the stimulus onset. Amplitudes of responses for each stimulus intensity were averaged for individual animals. Mean values for each experimental group were plotted on the graph to provide the stimulus-response curves.

Visual cliff test: This test was used to assess more profound visual deficiencies, e.g. in contrast perception. ${ }^{29}$ The test apparatus consisted of an open-topped box $(70 \times 35 \mathrm{~cm}$ floor, $30 \mathrm{~cm}$ high). The walls of the box were made from white Perspex, and the base was made from clear Perspex. The box was positioned on the edge of a laboratory bench so that half of the base was placed on the bench ("ground" side), and the other half over the edge of the bench, suspended $1 \mathrm{~m}$ above the floor ("air" side). Mice were placed in the middle of the base at the edge of the cliff, and their activity was monitored for $5 \mathrm{~min}$ by a 
computer and the video-tracking system Viewer 2 (Biobserve $\mathrm{GmbH}$ ). The percentage of time each mouse spent on the ground and the air side of the box was calculated. The light intensity inside the room was set to $150 \mathrm{~lx}$.

Olfaction test: In the first three days mice were habituated to the test cages $(29.5 \times 18.5 \times 13 \mathrm{~cm})$; mice were placed for $2 \times 20 \mathrm{~min}$ per day in the cages. On day 3 , mice were deprived of food for $24 \mathrm{hrs}$ before testing, with water ad libitum and a chocolate cookie was placed within the home cage. From day 4 to day 6 , mice were again placed into test cages with a chocolate cookie inside $(2 \times 20 \mathrm{~min})$. After habituation was finished on each day, mice received food for $1 \mathrm{~h} /$ day within their home cages. On day 7 the test took place, individual mice were placed into test cages, in which a piece of a chocolate cookie was hidden under $1.5-\mathrm{cm}$ standard bedding at the end of the cage. The mouse was positioned in the right corner at the opposite end of the cage, and the foodfinding time, i.e. the time from the moment the mouse was placed into the cage to the time it located the cookie and initiated burrowing, was recorded. As soon as the cookie was uncovered, the mouse was not allowed to consume it and was removed from the cage. To control for other sensory, motor, or motivational deficiencies that might influence the food-finding latency, the test was repeated as described above with a piece of chocolate cookie clearly visibly placed on the bedding. A fresh cage and bedding was used for each trial, and all mice were subjected to identical testing procedures. Cut off time was set to $3 \mathrm{~min}$.

Sucrose preference test: The evaluation of anhedonialike behavior was assessed using the sucrose preference test. The sucrose preference test was performed using a two bottles procedure, during which mice have free access to both water and a sucrose solution. Animals were first habituated for 48 hrs to consume water from the two small $(100 \mathrm{ml})$ bottles. After habituation, mice were deprived of water and the sucrose preference was measured during the next 3 days. The first two days served as a habituation to sucrose solution. The results of day 3 were used for the evaluation of sucrose preference. Each day, single-housed mice were presented for 60 min with two bottles -one with tap water and one with $2 \%$ sucrose solution in the home cage. Consumption of water or sucrose solution was measured by weighting the bottles before and after the session. Bottles were counterbalanced across the left and the right sides of the cage, and their position was alternated from test to test. Sucrose preference (percent) was calculated as follows: Preference = [sucrose solution intake ( $\mathrm{ml}$ ) / to tal fluid intake $(\mathrm{ml})$ ] $x$ 100

Resident-Intruder: Intermale aggression was studied in the resident-intruder paradigm. As standard opponent males, we used group-caged males of the same age, also from the same $F V B / N$ strain. A standard opponent was introduced into the home cage of the tested resident male and observation started when a tested resident male sniffed the opponent for the first time. The observation was stopped immediately after the first attack (an attack being defined as a bite) to prevent wounding, but lasted $5 \mathrm{~min}$ if no attack occurred. The latency of attack was recorded by a stop watch. Pentylenetetrazole-induced seizure: The method used here has been previously described by Ferraro and colleagues. ${ }^{30}$ Seizure activity was induced in wakeful mouse using a single subcutaneous injection of 50 $\mathrm{mg} / \mathrm{kg}$ body weight pentylenetetrazole (PTZ). After injection of compound, the mouse was placed in a small, clear homecage and closely observed for 30 min. Latencies to focal (partial clonic), generalized (generalized clonic), and maximal (tonic-clonic) behavioral seizures were recorded. Furthermore, four phases in the continuum of behavioral response to subcutaneous PTZ injection were defined as follows: 1. Hypoactivity (a progressive decrease in motor activity until the animal came to rest in a crouched or prone position with abdomen in full contact with cage 2. Partial clonus (clonus seizure activity affecting face, head, and/or forelimb or forelimbs) 3. Generalized clonus (sudden loss of upright posture, whole body clonus involving all four limbs and tail, rearing and autonomic signs) 4. Tonic-clonic (maximal) seizure (generalized seizure characterized by tonic hindlimb extension - also associated with death) Finally, latencies to partial clonus (PC), gen eralized clonus (GC), and tonic-clonic (TC) seizures were summed to assign each mouse a seizure score that was used as a quantitative trait measure for mapping according to the following equation:Seizure score $=[(0.2)(1 / P C$ latency $)+(0.3)(1 / G C$ latency $)+$ (0.5) (1/TC latency)] x $1000 \quad$ The weighting factors $(0.2,0.3$, and 0.5$)$ in the equation were included as means of incorporating a measure of the progressive nature of the PTZ-induced seizure phenotype into the severity rating because generalized clonus is regarded as a more significant event than partial clonus, and tonic hind limb extension is regarded as the most severe component of the phenotype. Therefore, the seizure score reflects the degree of progression of the seizure phenotype in each mouse. ${ }^{30}$

\section{Hindlimb clasping test}

To quantify hind-limb clasping, ${ }^{31}$ P40 stage mice were picked up from the cage by tail and suspended $10 \mathrm{~cm}$ above the cage for $30 \mathrm{sec}$ to allow the clasping of hindlimbs. During this time mice were videotaped. 
The video was analyzed, and the duration of hindlimb clasping was calculated for each mouse.

\section{Primary neuronal culture and immunocytochemical analysis}

For neuronal cell preparation, brains from three P7 stage male mice were collected and put into dissection solution ( $0.72 \mathrm{~g}$ bovine albumin, $0.347 \mathrm{~g}$ $\mathrm{MgSO}_{4}$ in $240 \mathrm{ml}$ Hanks medium) on ice. The hippocampus was dissected from the whole brain, the meninges were removed and the tissue samples were cut into small pieces and incubated in Hanks solution for 5-10 min on ice. The tissue samples were then digested at $37^{\circ} \mathrm{C}$ for $10 \mathrm{~min}$ with $6 \mathrm{mg}$ of trypsin and $60 \mu \mathrm{g}$ of DNAase ( $2 \mathrm{KUnits} / \mu \mathrm{l}$ ) in $2 \mathrm{ml}$ of digestion solution $(0.8 \mathrm{~g} \mathrm{NaCl}, 35 \mathrm{mg} \mathrm{NaHCO}, 37 \mathrm{mg} \mathrm{KCl}, 99$ $\mathrm{mg} \mathrm{Na}_{2} \mathrm{HPO}_{4}$ in $100 \mathrm{ml}$ of $\left.\mathrm{H}_{2} \mathrm{O}, \mathrm{pH} \sim 7.3-7.4\right)$. The reaction was stopped by addition of $2.4 \mathrm{mg}$ of trypsin inhibitor (Sigma-Aldrich, Munich, Germany) in $4 \mathrm{ml}$ of dissection solution and incubated at RT for $10 \mathrm{~min}$. The samples were then incubated in a solution of 0.5 $\mathrm{ml}$ of horse serum and $2.5 \mathrm{ml}$ of dissection solution for $10 \mathrm{~min}$ at RT. The digested hippocampal cells were triturated with three different sizes of pipettes coated with Sigmacote (Sigma-Aldrich, Munich, Germany). The homogenate was centrifuged at $100 \times \mathrm{xg}$ at $4^{\circ} \mathrm{C}$ for $10 \mathrm{~min}$. The cells obtained were resuspended in $1 \mathrm{ml}$ of culture medium A [0.5 $\mathrm{g} \mathrm{D}$ Glucose, $0.2 \mathrm{ml}(12.5 \mathrm{mg} / \mathrm{ml})$ insulin (Sigma-Aldrich, Munich, Germany), $1 \mathrm{ml}$ (200 mM) glutamax , $50 \mu \mathrm{l}$ $(10 \mathrm{mg} / \mathrm{ml})$, gentamicin , $10 \mathrm{mg}$ transferring and 10 $\mathrm{ml}$ horse serum upto $100 \mathrm{ml}$ with MEM Eagle (SigmaAldrich, Munich, Germany). The cell suspension was seeded (4000-8000 cells per well) in pre-incubated culture plates with coverslips coated with poly-DLysine and laminin (BD Bioscience, Heidelberg, Germany) in culture medium $A$ and incubated at $37^{\circ} \mathrm{C}$ in $5 \% \mathrm{CO}_{2}$. The medium was replaced after overnight incubation. After 4 days, culture media was changed to medium B $[50 \mu l$ gentamicin (Sigma-Aldrich, Munich, Germany), $125 \mu \mathrm{l}$ bFGF (Invitrogen, Karlsruhe, Germany), $250 \mu \mathrm{l} \mathrm{L-Glutamine,} 2 \mathrm{ml} \mathrm{B27}$ Supplement (Gibco, Darmstadt, Germany), $125 \mu \mathrm{l}$ Cytosine Arabinoside (4 mM) upto $100 \mathrm{ml}$ with Neurobasal medium (Gibco, Darmstadt, Germany)]. The medium was changed every 2 days until the day of neuronal cell analysis, when cells were fixed and immunostained with anti-MAP2 antibody (Cell Signaling, Frankfurt, Germany) (dilution 1: 500) (Abcam, Cambridge, UK) and visualized by BX60 fluorescence microscope (Olympus, Hamburg, Germany). The evaluation of neuronal parameters such as cell soma area and number of primary, secondary, and tertiary branch sites was performed by Image J software ${ }^{32}$ and the total neurite lengths were measured by Neuron J software ${ }^{33}$ (www.imagescience.org/meijering/software/neuronj/
). The analysis was performed with the experimenter being unaware of the genotype ('blinded'). The average data was derived from wild type and transgenic mice, 9-10 each.

\section{Sholl analysis}

To evaluate the complexity of a neuron such as dendrite distribution and arborization, we performed Sholl analysis ${ }^{34}$ on captured images of primary neurons. In brief, concentric circles (Scholl lines) were drawn at $5 \mu \mathrm{m}$ increments up to a radius of $250 \mu \mathrm{m}$ from the centroid of the neuron soma till the tip of the longest neurite. The numbers of crossings made by neurites originating from soma through each Scholl lines were calculated by Image J software. The Crossings of neurites at each Scholl line were summed and the mean and standard deviation were calculated.

\section{Measurements of calcium influx in prim ary neurons}

Primary culture of hippocampal neurons was prepared as described above. The coverslips with neurons were placed on the microscope stage (at RT) in a chamber continuously superfused at $34^{\circ} \mathrm{C}$ at 1 $\mathrm{ml} / \mathrm{min}$ with HEPES-buffered salt solution (136 mM $\mathrm{NaCl}, 5 \mathrm{mM} \mathrm{KCl}, 1.25 \mathrm{mM} \mathrm{CaCl}_{2}, 0.8 \mathrm{mM} \mathrm{MgCl}_{2}, 6 \mathrm{mM}$ glucose, 10 HEPES, $\mathrm{pH}$ 7.4). The experimental solutions were produced by adding aliquots of corresponding stock solutions directly to the chamber solution. The neurons were treated with $1 \mu \mathrm{M}$ fura-2AM (calcium indicator dye, Invitrogen, Karlsruhe, Germany) for $20 \mathrm{~min}$. The cells were viewed through a $40 x$ objective in an upright Axioscope2 microscope (Zeiss, Goettingen, Germany). Excitation (380 nm) was generated by LED and the fluorescence $(520 \pm 19$ $\mathrm{nm}$ ) was recorded with a cooled CCD camera. Images were captured at intervals of $0.5 \mathrm{sec}$, and analyzed using MetaMorph software (Roper Scientific, Planegg/Martinsried, Germany). Free calcium values (C) were obtained according to ${ }^{35}$ as:

$$
\begin{array}{r}
1-f \\
f-R
\end{array}
$$

where the dissociation constant for calcium binding to fura-2 is $K=0.22 \mu \mathrm{M}^{36}, f=F / F_{\max }$. The maximal fluorescence $F_{\max }$ was measured after application of 1 $\mu \mathrm{M}$ ionomycin in calcium free solution and $F_{\min }$ was obtained after introduction of $5 \mathrm{mM}$ calcium into the chamber. The calibration gave $R=F_{\min } / F_{\max }=0.21 \pm$ 0.02 .

To examine slow calcium buffering in neurons, we induced calcium loads by depolarization-activated calcium influx with $50 \mathrm{mM} \mathrm{KCl}$ and followed calcium 
recovery to the basal levels. The time-constants of calcium recovery, together with depolarizationinduced calcium increases and resting calcium levels allow to assess the contribution of mechanisms involved in calcium regulation. ${ }^{37}$ The mean values of time-constants, resting and elevation of calcium were determined in the wild-type and transgenic cells. PTZ tests were applied to examine responses of neurons to epileptogenic stimuli. Calcium changes were recorded for 12 to 16 neurons in the image field. We determined the amplitude and frequency of calcium spikes, counted the number of active neurons, and averaged the data for six biological replicates of wild type and Mecp $2^{\text {WT_EGFP }}$ transgenic neuron.

\section{Golgi-Cox st aining}

The whole mouse brains were dissected from 3 weeks old mice and Golgi staining was performed using the FD Rapid GolgiStain Kit (FD Neurotechnologies, Columbia, MD). The dissected brains was rinsed with double distilled water and then immersed in a Solution $A / B$ mixture (impregnation) for 6-7 days at RT. Afterward, the brains were incubated in Solution C (cryoprotection) for 2 days and thereafter frozen in anisopentane/dry ice bath. The brains were immediately sectioned into 100-150 $\mu \mathrm{m}$ slices using a CM 1900 cryostat (Leica, Wetzlar, Germany) and the slices were mounted on slide pre-coated with $0.4 \%$ gelatin (Sigma-Aldrich, Munich, Germany). After the samples were dried, they were dehydrated by immersing them in solution with incremental proportion of ethanol. The staining procedure for development of the black precipitate was performed using kit reagents according to the manufacturer instruction. Afterward, cover slips were mounted using Eukitt quick hardening mounting medium (Fluka, Neu Ulm, Germany) and the slides were visualized using BX60 microscope (Olympus, Hamburg, Germany). The morphology of pyramidal neurons was traced from the captured images through a graph pad by using Neuron J software and neuronal parameters were evaluated as described above. The spine density was calculated as average number of spines sprouting from a block unit of 10 $\mu \mathrm{m}$ of neurite. The average data was derived from wild type and transgenic mice, 5-6 each.

\section{Statistical analysis}

For neuronal parameters evaluation, the differences between wild type and Mecp $2^{\text {WT_EGFP }}$ transgenic neurons were calculated by applying Wilcoxon's Rang sum statistics or, if appropriate, by Student's $t$-test. We set the overall level of significance to $5 \%$. For the number of branching sites as the mainly focused phenotypes were corrected for multiple testing according Bonferroni assuming four independent tests (area, length, number of spines per $10 \mu \mathrm{m}$, and branching points). Data are represented as mean \pm s.d. in figures and text. In the pre-weaning behavior assessment, regression analyses were used to compare the performance between TG and WT littermate control mice: variables scored 0 or 1 were analyzed by logistic regression. Additionally, Fischer's exact test for categorical data on each observation day and two-way repeated measurement ANOVA including Bonferroni post-hoc test were used where applicable. Statistical significance for adult behavioral phenotyping was evaluated using Mann Whitney Utest and two-way repeated measurement ANOVA including Bonferroni post-hoc test where applicable. A critical value for significance of $p<0.05$ was used throughout the study. Data are represented as meants.e.m. in figures and text. For RT-qPCR data, the statistical significance between wild type and Mecp $2^{\text {WT_EGFP }}$ transgenic mice were calculated by Student's $t$-test. All statistical analyses were performed with either GraphPad Prism 4.0 (La Jolla, CA) or SAS Version 9.2, SAS Institute Inc. (Cary, NC) or SPSS for Windows version 17.0 (Chicago, IL).

\section{RESULTS}

Reduced expression of MeCP2 from Mecp2 ${ }^{\text {WT_EGFP }}$ allele

The Mecp $2^{\text {WT_EGFP }}$ transgenic mouse was generated by microinjection of linearized pBAC_Mecp2 ${ }^{\text {WT_EGFP }}$ construct (Fig. 1A) into fertilized oocytes of FVB/N mice. For the generation of the pBAC_Mecp2 ${ }^{\text {WT_EGFP }}$ construct, we used a BAC clone (B22804). This BAC contains $\sim 120 \mathrm{~kb}$ of a mouse genomic fragment, which consists of the complete Mecp2 gene including all fours exons, as well as flanking/regulatory sequences. $^{24}$ The BAC clone also contain the complete transcriptional unit of $O p \sin 1$ gene, which is 5' upstream of Mecp2 and part of the Irak1 gene, which is located downstream 3' end of the Mecp2 gene. The sequences of Opsin 1 and Irak1 genes were deleted from the BAC clone by GET recombination, ${ }^{24}$ using the zeocin selection cassette to exclude any toxic effect in the transgenic animals due to duplication of these genes (Fig. 1A). The pups obtained after microinjection were tested for the integration of the transgene into the genomic sequence by PCR genotyping using a primer pair specific for the transgene. ${ }^{24}$ Through PCR genotyping several founders were identified, however subsequent breeding and transmission analysis of Mecp $2^{\text {WTEGFP }}$ allele among the founders led to the establishment of one successful transgenic line. From the breeding of this transgenic line with FVB/N mice, we obtained equal numbers of male and female mice suggesting that the transgene was integrated into an autosomal chromosome. 
A

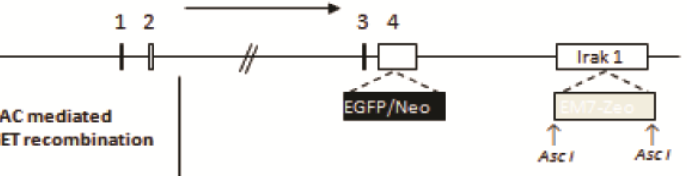

$12 \quad 34$
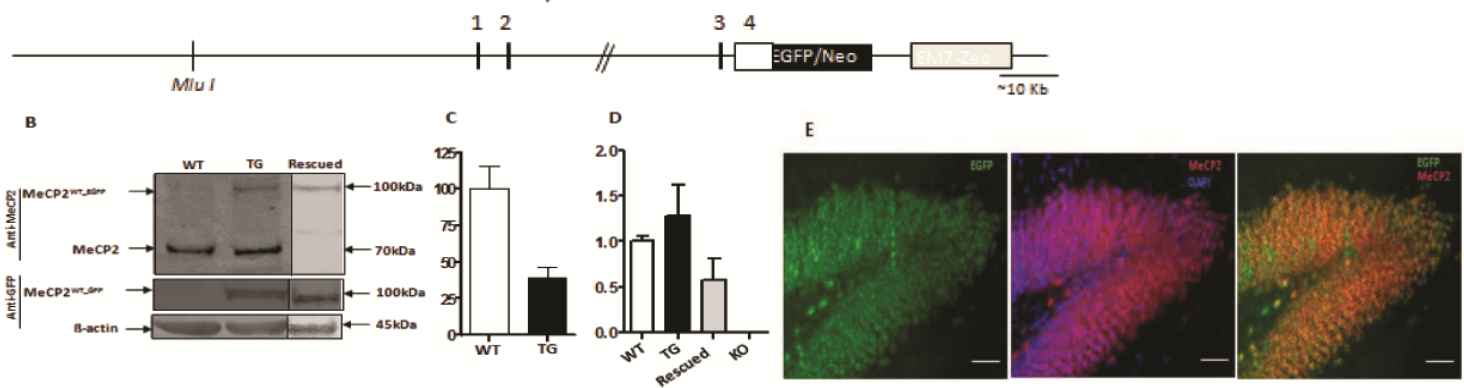

$\mathrm{E}$

Figure 1: Expression analysis of MeCP2 from the BAC transgene. (A) Schematic diagram illustrating the generation of the pBAC_Mecp 2 ${ }^{\text {WT EGFP }}$ construct using GET recombination in the BAC clone. An EGFP/Kan cassette was inserted in -frame at stop codon of Mecp 2 in exon 4 and was replaced with 2 gycine residues in the BAC clone. The sequences of Opsin 1 and Irak1genes were deleted from the BAC clone by GET recombination using the zeocin selection cassette. (B) Western blot analysis using MeCP2 antibody on the total protein extract isolated from brain samples revealed in addition to the endogenous MeCP2 (70 kDa) an additional MeCP2 protein corresponding to MeCP2 ${ }^{\text {WTEGFP }}$ of size $\sim 100 \mathrm{kDa}$ in the transgenic mice. Additionally, immunoblots with anti-GFP antibody confirmed that the $\sim 100 \mathrm{kDa}$ size protein was indeed MeCP2 ${ }^{\mathrm{WT} \_ \text {EGP }}$. Furthermore, Western analysis with brain extract of rescued mice $\left(T^{\mathrm{WT}} /-:-/ \mathrm{y}\right)$, generated by breeding Mecp $2^{\text {WTEGFP }}$ transgenic mice with Mecp 2 knockout mice revealed only expression of MeCP2 ${ }^{\text {WIEGFP }}$ of size $\sim 100$ $\mathrm{kDa}$. (C) Quantification of the protein bands intensities from at least five immunoblots revealed that relative expression of MeCP2 ${ }^{\text {WI EGFP }}$ was about $40 \pm 4.1 \%$ to that of endogenous MeCP2. (D) Quantitative Real Time-PCRanalysis sugges ts that reduced expression of transgenic $\mathrm{MeCP2}{ }^{\text {WTEGFP }}$ is due to the diminished level of mRNA. (E) Immunohistochemical analysis of hippocampus showed a similar expression pattern for the transgenic MeCP2 ${ }^{\text {WT_EGFP }}$ protein as compared to endogenous MeCP2. WT; wild type, KO; knock out, TG; transgenic adult

The Mecp $2^{\text {WTEGFP }}$ transgenic mouse line was maintained in heterozygote state $\left(\mathrm{T}^{\mathrm{WT} / \mathrm{f}}\right)$ by backcrossing with FVB/N mice. From such breeding, we obtained $50 \%$ transgenic mice $\left(\mathrm{T}^{\mathrm{WT} / \mathrm{T}}\right.$ ) and $50 \%$ wild-type littermates. To determine whether the MeCP2 $2^{\text {WT_EGFP }}$ is expressed in the transgenic mice, we performed Western blot analysis with total protein extracted from the brain biopsies from the adult Mecp $2^{\text {WT_EGFP }}$ transgenic male mice. The immunoblot with antibody against MeCP2 revealed expression of two MeCP2 proteins. In addition to the endogenous MeCP2 ( 70 kDa) band, a transgenic MeCP2 WT_EGFP band of size $\sim 100 \mathrm{kDa}$ was detected in the brain of transgenic mice. In contrast, only endogenous MeCP2 was detectable in wild-type mice (Fig. 1B). Moreover, immunoblot analysis with GFP antibody detected the $\sim 100$ kDa MeCP2 ${ }^{\text {WT_EGFP }}$ protein, only in transgenic mice (Fig. 1B). From Western blot, it is obvious that the intensity of MeCP2 ${ }^{\text {WT_EGFP }}$ transgenic protein is remarkably lower as compared to endogenous MeCP2 band. This observation prompted us to quantify the relative intensity of the transgenic protein to endogenous protein by Image J software. Densitometrical quantification of the protein bands intensities from five independent immunoblots revealed that relative expression of $\mathrm{MeCP} 22^{\text {WT_EGFP }}$ was about $40 \pm 4.1 \%$ to that of endogenous MeCP2 (Fig. 1C). To determine whether the reduced expression MeCP2 ${ }^{\text {WT_EGFP }}$ protein from the transgene was due to lower amount of mRNA, we performed quantitative Real Time-PCR analysis.
Indeed, we also detected a reduced level of transgenic mRNA (Fig. 1D). To determine the cellular expression pattern of the MeCP2 ${ }^{\text {WT_EGFP }}$ protein, we performed immunohistochemical analysis of brain sections. MeCP2 ${ }^{\text {WT_EGFP }}$ protein was visualized by GFP fluorescence and MeCP2 antibody staining, which also detected endogenous MeCP2 protein. The expression pattern of MeCP2 ${ }^{\text {WT_EGFP }}$ protein was similar to that of endogenous MeCP2 (Fig. $1 \mathrm{E}$ and also see Supplemental Fig. S2 at http://ajp.amjpathol.org).

Prolonged lifespan of Mecp2 null mutant mice upon expression of Mecp2 ${ }^{\text {WTEGFP }}$ allele

We bred Mecp $2^{\text {WTEGFP }}$ transgenic mice with Mecp2 knockout mice ${ }^{31}$ to express the transgenic allele in Mecp2 null background $\left(\mathrm{T}^{\mathrm{WT} /-} ;-/ \mathrm{y}\right)$. Western blot analysis with MeCP2 antibody using total protein extracted from brain revealed expression of MeCP2 ${ }^{\text {WT_EGFP }}$ protein only ( 100 kDa) (Fig. 1B). Remarkably, the premature lethality at the age of $\sim 10$ weeks, reported for null mutants, was rescued by the expression of the transgenic allele. These mice have a prolonged life span, as our observation over a period of $\sim 9$ months did not detect any early deaths. Hindlimb clasping, a typical feature of Mecp2 null mutant mice, was also absent in these mice (see Supplemental Fig. S3 at http://ajp.amjpathol.org).

Mecp $2^{\text {WTEGFP }}$ transgenic mice exhibit increased aggressiveness and seizure propensity 
The transgenic mice appeared normal upon cursory observation. To characterize the behavioral phenotype of Mecp $2^{\text {WT_EGFP }}$ transgenic mice, we performed a series of behavioral tests at both pre- (03 weeks) and post (after 5 weeks onward) -weaning stages.

\section{Pre-weaning behavior analysis}

The number of animals used in the analysis of maturation markers and neurodevelopmental measures was: Mecp2 transgenic male (TG) $n=18$, WT littermate male $n=14$.

\section{Maturation measures}

\section{Body weight}

Body weight of animals was taken daily from P4 through to P21 and the data was analyzed with twoway repeated measurement ANOVA. We did not find any significant differences between genotypes in the body weight measured (see Supplemental Table S1 at http://ajp.amjpathol.org). As expected, all mice progressively increased their body weight as we observed from P4 through to P21 (data not shown), indicating a comparable growth rate between TG and WT littermates.

\section{Ear and eye opening}

The day when at least one eye was open and the day an aperture was seen in the ear was registered daily starting from P4. No differences existed between genotypes regarding the day of the ear and the eye opening (see Supplemental Table S1at http://ajp.amjpathol.org). All test mice have their ears and eyes fully opened on P14 (data not shown).

\section{Neurodevelopmental measures (neurological reflexes and neuromotor coordination)}

There were no significant differences observed between groups in terms of the neurological reflexes tested in surface righting, postural, cliff avoidance, and negative geotaxis reflex (see Supplemental Table S1 at http://ajp.amjpathol.org). Also, we observed a comparable performance between groups during the acquisition of neuromotor coordination assessed from wire suspension and neonatal swimming activity (see Supplemental Table S1 at http://ajp.amjpathol.org).

\section{Post-weaning (adult) behavior analysis}

Adult behavioral phenotyping of male transgenic mice with mild Mecp2 overexpression as well as their WT littermates was performed beginning at the age of 5 weeks old (Table 1). Behavioral analysis was performed with less stressful tests at the beginning and more stressful tests toward the end in the following order: elevated plus maze, open field, hole board, prepulse inhibition, rota-rod, hearing, visual cliff, sucrose preference, grip strength, olfaction, resident-intruder and finally, Pentylenetetrazoleseizure induction. The number of animals used in the adult behavioral analys is is given in the corresponding figure legends of each read out. For behavioral analyses, we used 10-27 wild type and 6-22 transgenic mice (dependent on the complexity of the test, lower or higher numbers of mice are needed).

\section{Mild overexpression of Mecp2 selectively influences behavioral alterations}

While basic behavior, sensory and motor functions, as well as sensorimotor gating remain unchanged by mild overexpression of Mecp2, our results revealed that social behavior and seizure propensity of transgenic animals overexpressing Mecp2 were altered (Table 1, Fig. 2 and see Supplemental Fig. S4 at http://ajp.amjpathol.org). During daily handling of the animals, we observed that mice displayed a higher tendency to bite when handled. We performed the resident-intruder paradigm to investigate whether mild Mecp2 overexpression was associated with an increased aggressive behavior. Indeed, tested at the age of 8 weeks, we found that transgenic mice were more aggressive compared to the WT littermates (Fig. 2A). The latency of the first attack of TG mice towards the intruder was significantly reduced, compared to their WT littermates $(p=0.048)$.
A

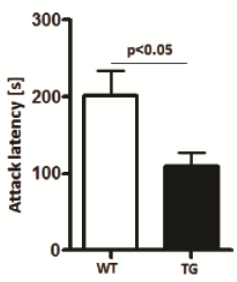

B

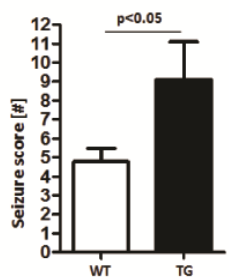

Figure 2: Phenotypic characterization of Mecp2 $2^{\text {WTEGFP }}$ transgenic mice. (A) To test aggressiveness, we performed the resident-intruder paradigm. The latency of the first attack of transgenic mice (8 weeks old) towards the intruder was significantly reduced, compared to their wild type littermates. (B) The transgenic mice ( 30 weeks old) also manifested increased sensitivity to pentylenetetrazole induced seizures. Mice (WT= 10-27; $T G=6-22)$. Data are presented as meants.e.m.

Also, we repeatedly observed spontaneous seizures in the transgenic mice. Thus, to assess seizure susceptibility, we induced seizures by administering pentylenetetrazole (PTZ, $50 \mathrm{mg} / \mathrm{kg}$ of body weight) subcutaneously. ${ }^{30}$ We detected increased PTZinduced seizure activity in 30 week-old transgenic mice $(p=0.042)$ compared to wild type littermates (Fig. 2B). 
Mild Mecp2 overexpression causes increased som a size and fewer branching sites in cultured neurons

The ex vivo cultured hippocampal neurons are considered as well-characterized model for the evaluation of neuronal development. ${ }^{38}$ We cultured hippocampal neurons from postnatal day 7 (P7) Mecp $2^{\text {WT_EGFP }}$ transgenic and wild type male mice to determine the effect of mild overexpression of Mecp2 during the process of neuronal development and differentiation. The primary neurons were cultured for 14 days, then immunostained with antiMAP2 (microtubule-associated protein 2) antibody (Fig. 3A-B). MAP2 is a neuron-specific cytoskeletal protein that is enriched in dendrites. ${ }^{39}$ The stained neurons were traced and analyzed by Image J software for calculating the soma size. The neuronal parameters such as total length of neurites, number of neurites and number of primary, secondary, and tertiary branch sites were evaluated by Neuron J software. The mean soma size of 91 transgenic neurons was slightly larger compared to those of 83 wild type neurons ( $p=0.0008$ ) (Fig. $3 C$ ). However, no significant difference could be seen for the total length of neurites projecting from transgenic neurons $(p=0.1536)$ (Fig. 3D). Analysis of branching sites of neurites revealed in average lower number of branching sites in transgenic neurons, although clearly significant only for tertiary sites (primary sites: $p=0.6000$, secondary sites: $p=0.0496$ and tertiary sites: $p<0.0001$ ) (Fig. $3 E-G$ ). To further evaluate the complexity of neurons, we performed Sholl analysis on the traced images. ${ }^{34}$ Sholl analysis is used to evaluate the morphological complexity of imaged neurons by counting the number of neurite intersections for concentric circles of increasing radius arising from the cell soma (see Supplemental Fig. S5 at http://ajp.amjpathol.org). This quantitative analysis revealed diminished apical neurite branching in transgenic neurons.

\section{Pyramidal neurons of Mecp2 ${ }^{\text {WTEGFP }}$ transgenic mice show higher spine density}

To evaluate the effect of mild Mecp2 overexpression on neurons in vivo, we visualized the hippocampal neurons by Golgi-Cox staining of tissue sections. The Golgi-Cox staining allows high resolution visualization of dendrites and spines in histological section, thus enabling us to calculate the qualitative and quantitative parameters of neurons. ${ }^{40,41,42}$ The stained pyramidal neurons (Fig. 4A) were reconstructed by semi-automatic tracing using Neuron-J software (Fig. 4B) and analyzed similarly as described above for cultured neurons. We did not observe significant difference in soma size between transgenic and wild type neurons (Fig. 4C), although the total length of transgenic neurites was increased (Fig. 4D). To determine the spine density of neurites, we used higher magnification images of basal dendrites from CA1 region (Fig. 4E). Spine density for neurite unit length of $10 \mu \mathrm{m}$ revealed in average a slightly higher density of spines in transgenic neurites (mean: $14.4 \mu \mathrm{m}$ ) than WT neurites (mean: $13.6 \mu \mathrm{m}$ ) $(p=0.0324)$ (Fig. 4F).

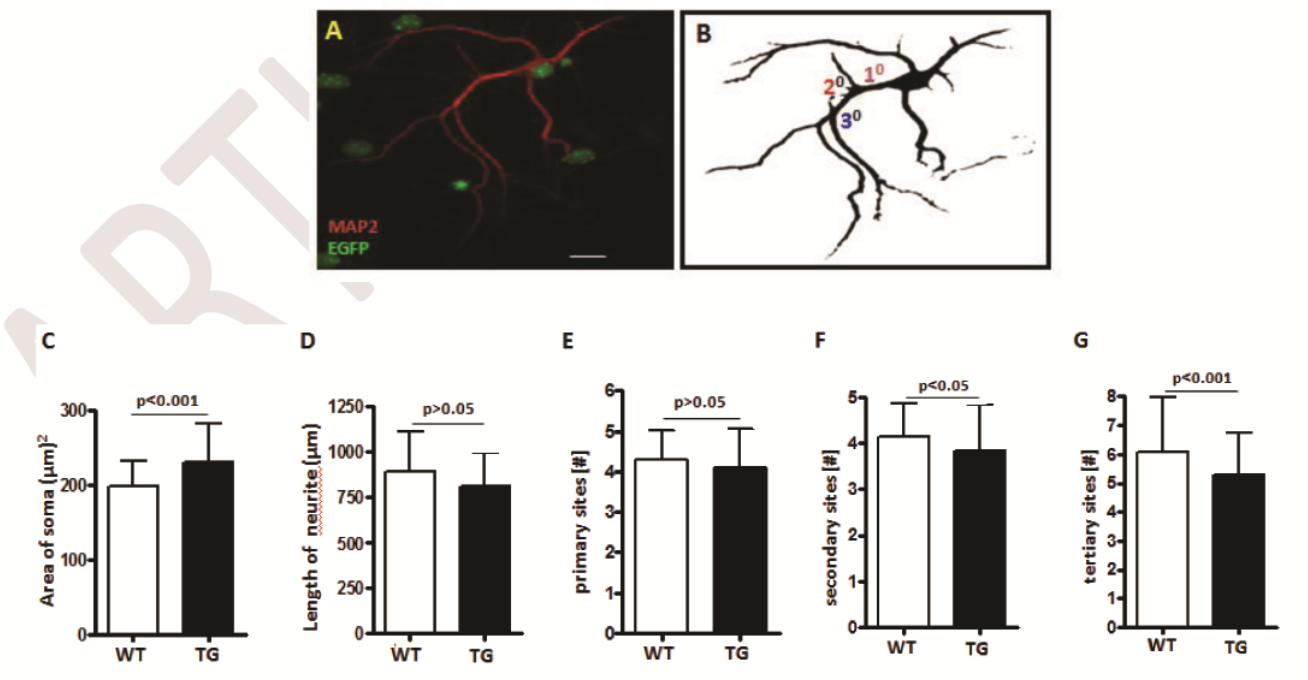

Figure 3: Evaluation of neuronal parameters of cultured (14 days) neurons from hippocampus of postnatal day 7 old mice. (A) Immunostaining of the transgenic Mecp2 ${ }^{\text {WTEEFP }}$ primary neuronal cells with MAP2 (red), the MeCP2 ${ }^{\text {WTEGFP }}$ expression was visualized by green fluorescence. (B) The stained neuron images were traced by Image J and Neuron J softwares and neuronal parameters were analyzed. (C) The soma size of transgenic (TG) neurons was slightly larger compa red to wild type (WT) neurons. (D) The totallength of TG neurons was slightly smaller. (E-G) The numbers of branch sites were reduced in TG neurons, especially a significant reduction in tertiary branch sites was observed in TG neurons. Number of neurons (WT=83; TG=91); ns-not significant; $1^{0}$-primary, $2^{0}$-secondary, $3^{0}$-tertiary branch sites; \#-number; scale bar $50 \mu \mathrm{m}$ (A-B). 


\author{
Calcium homeostasis in Mecp $2^{\text {WTEGFP }}$ transgenic \\ neurons
}

Calcium responses of cultured primary hippocampal neurons were evaluated by applying depolarizationinduced calcium influx (50 $\mathrm{mM} \mathrm{KCl}$ ) and $\mathrm{IP}_{3}$-mediated calcium release from endoplasmic reticulum (ER) after activation of $\mathrm{P}_{2 \gamma}$ receptors with $1 \mathrm{mM}$ ATP. ${ }^{43}$ Our measurements revealed that transgenic neurons in comparison to wild type neurons, had higher levels of resting calcium $(0.075 \pm 0.05 \mu \mathrm{M}$ vs. $0.052 \pm 0.03$ $\mu \mathrm{M})$, calcium elevations due to depolarization were also higher $(0.34 \pm 0.08 \mu \mathrm{M}$ vs. $0.25 \pm 0.06 \mu \mathrm{M})$ and the amplitudes of ATP-driven calcium release were smaller $(0.21 \pm 0.04 \mu \mathrm{M}$ vs. $0.31 \pm 0.05 \mu \mathrm{M})$ (Fig. $5 \mathrm{C}$ $D)$. The time-course of calcium recovery in transgenic neurons was distinctly slower, both after depolarization and calcium release (Fig. 5). The mean time constant of calcium recovery in wild type was $6.1 \pm 0.4 \mathrm{sec}$ (Fig. 5A) and in transgenic cells, it was about three times longer, $18.6 \pm 1.2 \mathrm{sec}$ (Fig. 5B). We further observed that transgenic neurons were more prone to spontaneous calcium oscillations that may indicate intrinsic differences in the vulnerability towards external stimuli. Spontaneous calcium spiking was seldom observed in wild type neurons (6/97 cells, or $6 \%)$, whereas in transgenic neurons, spontaneous activity was encountered more frequently (12/98 cells or $12 \%)$. Since in the behavioral test, the transgenic mice manifested a higher propensity towards PTZ-induced seizure activity (Fig. 2C). We evaluated the response of cultured hippocampal neurons to PTZ.
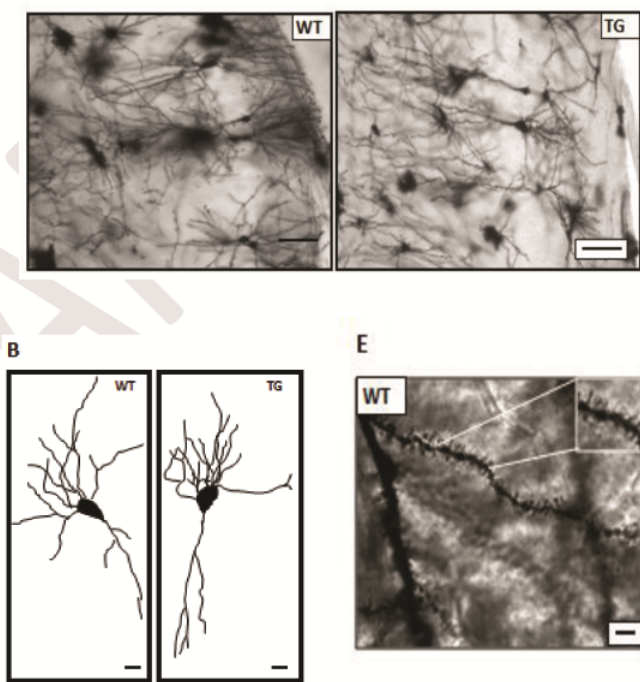
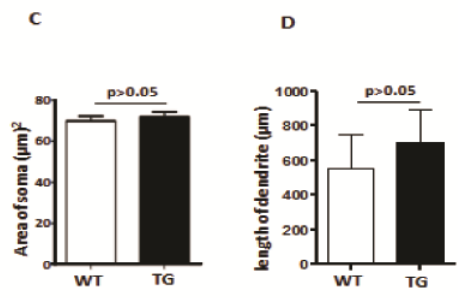

Spontaneous and elicited calcium spikes (indicators of spontaneous discharges of the neurons) are usually considered as a correlate of epileptic seizures. ${ }^{44,45}$ The wild type neurons rarely showed spontaneous calcium transients and $10 \mathrm{mM} \mathrm{PTZ}$ induced only weak effect (Fig. 5E). The transgenic neurons frequently demonstrated spontaneous calcium spikes whose amplitude and frequency were markedly increased after PTZ tr eatment (Fig. 5F).

\section{DISCUSSION}

Evaluation of the quantitative effect of MeCP2 expression level on phenotypes is highly relevant, as duplication of MECP2 causes severe neurological impairment $^{14,18,22}$ and on the contrary, loss of function mutations causes RT. ${ }^{10}$ It is evident that precise regulation of $\mathrm{MeCP} 2$ expression is essential for proper neurodevelopment. To determine the consequence of $\mathrm{MeCP} 2$ dosage, we generated a transgenic Mecp $2^{\text {WTEGFP }}$ mouse model mildly overexpressing MeCP2. The BAC construct used for the generation of Mecp $2^{\text {WT_EGFP }}$ transgenic mice consist of complete promoter and regulatory elements necessary for the spatio-temporal expression pattern of MeCP2. ${ }^{22,24}$ Also, to exclude the possibility of interference in the phenotype of Mecp $2^{\text {WTEEFP }}$ mice due to overexpression of Opsin 1 and Irak1, we deleted both genes in the BAC construct. When expression pattern of MeCP2 ${ }^{\text {WT_EGFP }}$ from the transgene was compared with endogenous MeCP2, we observed a similar expression pattern thus confirming that the BAC transgene mimics the endogenous MeCP2 expression.

D

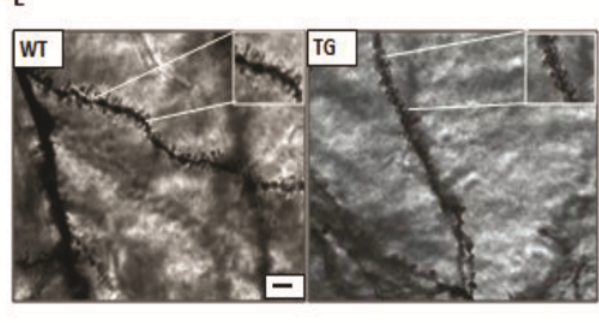

$\mathbf{F}$

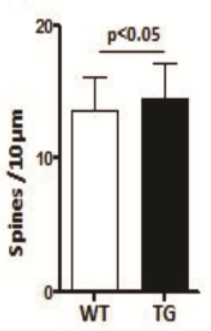

Figure 4: Characterization of pyramidal neurons in hippocampal sections by histological staining. (A) The pyramidal neurons in the hippocampal sections of 3 weeks old mice were visualized by Golgi-Cox staining. (B) The neurons morphology reconstructed by semiautomatic tracing using Neuron-J softwa re and neuronal parameters. (C-D) The cell soma size were comparable between transgenic (TG) and wild type (WT) neurons, total length of TG neurites was slightly longer. (E) The spine density was calculated from higher magnification images. (F) The spine density for neurite unit length of $10 \mu \mathrm{m}$ was higher in TG neurons. The spine density was plottedas mean value per unit length of $10 \mu \mathrm{m}$ for neurite length of $\sim 2500 \mu \mathrm{m}$. Number of neurons (WT=50; TG=50); ns-not significant; Scale bar $100 \mu \mathrm{m}$ ( $A-B$ ), 10 
Also in a previous study, we showed that expression pattern of a transgenic MeCP2 $2^{270 \_E G P}$ (generated from the same BAC clone) was comparable to the endogenous protein. ${ }^{24}$ In the pBAC_Mecp2 ${ }^{270 \_E G F P}$ construct, the EGFP/Kan cassette was inserted after 270 amino acids into exon 4 of Mecp2. Overall, the MeCP2 $2^{270 \_E G P}$ transgenic protein is equivalent to human p.R270X mutation. ${ }^{24}$ Interestingly, in the Western blot, the intensity of transgenic MeCP2 ${ }^{\text {WT_EGFP }}$ protein band was much weaker than endogenous MeCP2. Quantification of protein bands intensity revealed that the expression level of transgenic protein was nearly half $(40 \pm 4.1 \%)$ as compared to the endogenous MeCP2 protein. To determine whether the reduced expression from the transgene was due to lower level of mRNA or posttranscriptional regulation, we performed RT-qPCR analysis. Our data indicates that the diminished level of mRNA may be the underlying reason for lower level of transgenic MeCP2 ${ }^{\text {WT_EGFP }}$ protein. A previous study has shown that modification of 3' UTR of Mecp2 by insertion of a neomycin cassette and polyadenylation sequence in Mecp $2^{\text {flox }}$ allele causes $50 \%$ reduction of expression as compared to the endogenous level in these mice. ${ }^{23}$ During the generation of Mecp $2^{\text {WT_EGFP }}$ transgenic mice, we also modified the 3' UTR of Mecp2 by insertion of an EGFP/Kan cassette, which could be the underlying cause for reduced expression. However, a regulatory inhibition (at least partially) at the site of transgenic integration cannot be completely excluded. To determine whether MeCP2 ${ }^{\text {WT_EGFP }}$ protein expressed from the transgenic locus is functionally active, we crossed Mecp $2^{\text {WTEGFP }}$ transgenic mice with Mecp2 knockout mice.
An expression level of $\sim 50 \%$ of $\mathrm{MeCP} 2^{\text {WT_EGFP }}$ in the null-background was able to rescue the premature lethality reported in these mice. We did not detect any indication of early death in these mice over a period of 9 months. Also, the hind-limb clasping phenotype of null mice was alleviated by transgene expression. Overall, these findings clearly indicate that MeCP2 ${ }^{\text {WT_EGFP }}$ protein is functional and C-termini fusion of EGFP protein does not interfere with biological function of MeCP2 in the transgene. Nevertheless, we wish to stress that $\sim 50 \%$ of MeCP2 ${ }^{\text {WT_EGFP }}$ expression might not necessarily rescue all the progressive phenotypes of null mutant mice and further investigation will be necessary to exclude any late stage symptoms. Mecp $2^{\text {WT_EGFP }}$ transgenic mice appear phenotypically normal and were negative for hind-limb clasping (observation over 9 months). To identify any relevant behavioral symptoms in these mice, we performed a battery of tests involving basic and social behavior, motor performance, sensory functions, and sensorimotor gating Our investigation revealed that in most behavioral parameters the performance of transgenic mice were comparable to that of wild type siblings and with the progression of age there was no deterioration in the symptoms. However, the animals showed increased aggression and propensity towards PTZ-induced seizures. ${ }^{30}$ The phenotype of Mecp2 ${ }^{\text {WT_EGFP }}$ transgenic mice $(\sim 1.5 \mathrm{X})$ was in stark contrast to the previously reported MECP2-Tg1 mice (2X), which manifest severe neurological phenotypes. ${ }^{22}$ MECP2-Tg1 mice display stereotyped and repetitive movements, motor dysfunction, epilepsy, spasticity, ataxia, hypoactivity, kyphosis, and premature death. $^{22}$

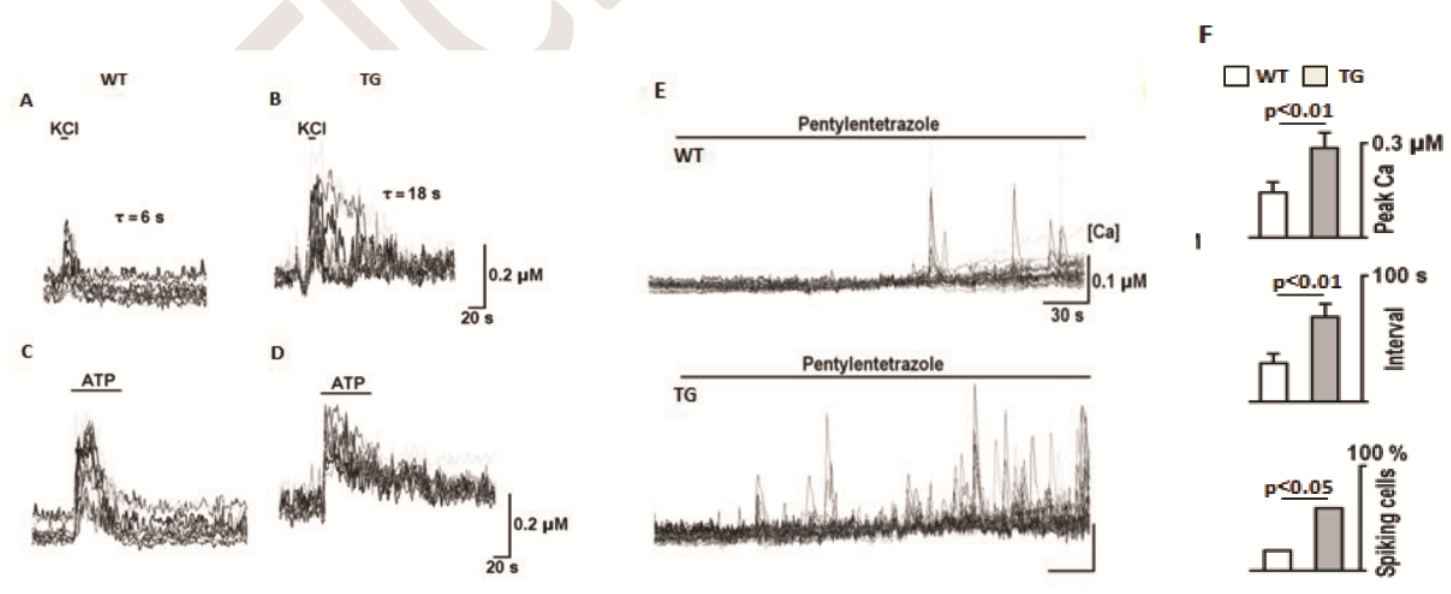

Figure 5: Impaired calcium response in hippocampal neurons, cultured for 14 days. (A-B) Each panel shows calcium responses to membrane depolarization in 12 to 16 neurons. The depolarization with $50 \mathrm{mM} \mathrm{KCl}$ was followed by calcium recovery to basal levels. The mean time constant of calcium recovery was about three times longer in transgenic (TG) neurons than wild type (WT). (C-D) Calcium release afteractivation of $P_{2 y}$ receptors with $1 \mathrm{mM}$ ATP led toa smaller amount of calcium release in the TG neurons. (E) Epileptogenic stimulation with $10 \mathrm{mM} \mathrm{PTZ} \mathrm{(pentylenetetrazole)} \mathrm{enhanced} \mathrm{sponta} \mathrm{neous} \mathrm{calcium} \mathrm{spikes} \mathrm{substantially}$ in the. transgenic neurons. (F) The amplitudes and frequencies of spontaneous calcium spikes and the number of active cells after PTZ exposure. The values were distinctly higher in TG neurons. 
In MECP2-Tg1 mice, the phenotypes appear at an early stage (10-12 weeks) and deteriorate progressively. Overall, by means of our generated mouse model expressing $1.5 \mathrm{X}$ level of MeCP2, we could reinforce the notion that the effect of $\mathrm{MeCP} 2$ on neurodevelopment is quantitative. Furthermore, unlike doubling of MeCP2 dosage which causes severe neurological impairment, only $\sim 1.5 \mathrm{X}$ level of overexpression of MeCP2 elicits milder phenotype. The expression level of MeCP2 is critical for early neuronal development and $\mathrm{MeCP} 2$ function is vital even at a single-neuron level. ${ }^{46}$ To assess the effect of mild overexpression ( 1.5X) of MeCP2 on neurons, we evaluated neuronal parameters of cultured neurons. We observed a slight but statistically significant increase in soma size. The reduced number of tertiary branching sites in Mecp $2^{\text {WT_EGFP }}$ transgenic as compared to wild type neurons was also statistically significant. When we analyzed the neuronal parameters of Golgi-Cox stained, we observed no difference in soma size. This discrepancy could be due to sensitivity of two different experimental systems used for neuronal parameters The morphological features of neurons are explicitly visible in primary culture therefore even subtle changes can be calculated. However exogenous conditions in the primary culture can also create distortion, which might not be representative to in vivo form. Remarkably, in Golgi-Cox stained neurons, we detected a slight increase (statistically significant, in spine density in the transgenic neurons. Previous studies have shown that loss of MeCP2 leads to substantial reduction in spine density, ${ }^{47,48,49}$ thus it is reasonable to expect enhanced spine density during MeCP2 overexpression. Overall, it seems that mild overexpression of MeCP2 subtly deters the maturation of neurons. Furthermore, we observed an impaired calcium homeostasis with a slower timecourse of calcium decay in Mecp $2^{\text {WTEGFP }}$ transgenic neurons. It was manifested by increase in basal calcium levels, prolongation of calcium recovery to basal levels after brief depolarization, and smaller amount of calcium released from intracellular stores in transgenic neurons. The calcium imbalance could be the underlying cause for the observed exaggerated response of the transgenic neurons to epileptogenic compound-PTZ. ${ }^{30,45}$ Improper calcium handling can make these neurons more vulnerable to external stimuli encountered during early development. A similar disturbance in calcium homeostasis was also observed in Mecp2 null mutant neurons, ${ }^{50}$ which suggest that both lack and overexpression of MeCP2 may lead to deleterious effect. It is interesting to note that epileptic seizures are a major phenotype reported both in RTT and MECP2 duplication syndrome. Remarkably, MECP2 disruptions also lead to neuropsychiatric disorder such as Angelman-like syndrome and in many instances these patients also manifest epileptic seizures. ${ }^{51,52}$ In this context, it is noteworthy that the primary phenotype observed in the Mecp $2^{\text {WTEGFP }}$ transgenic mice was an increased propensity to epileptic seizures, as observed in our behavioral tests as well as at the resolution of single neurons (ex vivo). In both, in vivo and ex vivo settings, the seizure activity was induced by epiletogenic compound-PTZ and in the transgenic condition the induction was remarkably stronger. In conclusion, it is evident from our study that epileptic seizure propensity is highly sensitive to functional level of $\mathrm{MeCP} 2$ and appears as a primary phenotype in mouse due to mild overexpression of MeCP2. In future genetherapeutical approaches to correct the MeCP2 expression either in RTT or MECP2 duplication syndrome, the optimum dosage of the treatment may have to be determined so that epilepsy does not occur as a consequence.

\section{Acknow ledgements}

The authors thank Heike Hühn for technical assistance, Stephan Wolf and Anja Ronnenberg for doing an excellent job in breeding, maintenance, and testing of mice. We also thank Mayur Vadhvani for her help with neuronal parameters analysis.

\section{Supplemental Data}

Supplemental data for this article can be found at http://aip.amipathol.org.

\section{References}

1. Lewis JD, Meehan RR, Henzel WJ, Maurer-Fogy I, Jeppesen $P$, Klein F, Bird A: Purification, sequence, and cellular localization of a novel chromosomal prot ein that binds to methylated DNA, C ell 1992, 69:905-914

2. Shahbazian MD, Antalffy B, Armstrong DL, Zoghbi HY: Insight into Rett syndrome: MeCP2 levels display tissue- and cellspecific differences and correlate with neuronal maturation, Human molecular genetics 2002, 11:115-124

3 Nan, X., Campoy, F.J. and Bird, A: MeCP2 is a transcriptional repressor with abundant binding sites in genomic chromatin. Cell 1997, 88:471-481

4. Chahrour M, Zoghbi HY: The story of Rett syndrome: from clinic to neurobiology, Neuron 2007, 56:422-437

5. Guy J, Cheval H, Selfrid ge J, Bird A: The role of MeCP2 in the brain, Annu Rev Cell D ev Biol 2011, 27:631-652

6. Chahrour M, Jung SY, Shaw C, Zhou X, Wong ST, Qin J, Zoghbi HY: MeCP2, a key contributor to neurological disease, activates and represses transcription, Science 2008, 320:1224-1229

7. Yasui DH, Peddada S, Bied a MC, Vallero RO, Hogart A, $\mathrm{N}$ agaraja RP, Th atcher KN, Farnham PJ, Lasalle JM : Integrated epigeno mic analyses of neuronal MeCP2 reveal a role for long-range 
interaction with active gen es, Proc Natl Acad Sci U S A 2007, 104:19416-19421

8. Georgel PT, Horo witz-Scherer RA, Adkins N, Woodcock CL, Wad PA, Hansen JC: Chromatin compaction by human MeCP2. Assembly of novel secondary chromatin structures in the absence of DNA methylation, J Biol Chem 2003, 278:32181 32188

9. Young Jl, Hong EP, Castle JC, Crespo-Bar reto J, Bowman AB, Rose MF, Kang D, Richman R, Johnson JM, Berget S, Zoghbi HY: Regulation of RNA splicing by the methylation-dependent transcriptional repressor methyl-CpG binding protein 2, Proc Natl Acad Sci U S A 2005, 102:17551-17558

10. Amir RE, Van den Veyver IB, Wan M, Tran CQ, Franc ke U, Zoghb HY: Rett syndrome is caused by mutations in X-linked MECP2, encoding methyl-CpG-binding protein 2, Nat Genet 1999, 23:185-188

11. Neul JL, Kaufmann WE, Glaze DG, Christodoulou J, Clarke AJ Bahi-Buisson N, Leonard $\mathrm{H}$, Bailey ME, Schanen NC, Zappella M, Renieri A, Huppke P, Percy AK: Rett syndrome: revised diagnostic criteria and nomenclature, Ann Neurol 2010, 68:944 950

12. Wan $\mathrm{M}$, Lee SS, Zhang $\mathrm{X}$, Houwink-Man ville I, Song HR, Amir RE, Budden S, Naidu S, Pereira JL, Lo IF, Zoghbi HY, Schan en NC, Francke $U$ : Rett syndrome and beyond: recurrent spontaneous and fami lial M ECP2 mutations at CpG hotspots, Am J Hum Gen et 1999, 65:1520-1529

13. Kriaucionis S, Bird A: DNA methylation and Rett syndrome, Hum Mol Genet 2003, 12 Spec No 2 :R221-227

14. Ramocki MB, Tavyev YJ, Peters SU: The MECP2 duplication syndrome, Am J Med G enet A 2010, 152A:1079-1088

15. Van Esch H: M ECP2 Duplication Syndrome, Mol Syndromol 2012, 2:128-136

16. Carvalho CM, Ramocki MB, Pehlivan D, Franco LM, GonzagaJauregui $C$, Fan g $P$, McCall A, Pivnick EK, Hines-Dowell $S$, Seave LH, Friehling L, Lee $S$, Smith R, Del Gaudio D, Withers $M$, Liu $P$, Cheung SW, Belmont JW, Zoghbi HY, Hastings PJ, Lupski JR: Inverted genomic segments and complex triplication rearran gements are mediated by inverted repeats in the human genome, $\mathrm{N}$ at $\mathrm{G}$ enet 2011, 43:1074-1081

17. Carvalho CM, Zhang F, Liu P, Patel A, Sahoo T, Bacino CA, Shaw C, Peacock S, Pursley A, Tavyev YJ, Ramocki MB, Nawara M, Obersztyn E, Vianna-Morgante AM, Stankiewicz P, Zoghbi HY, Cheung SW, Lupski JR: Co mplex rear rangements in patients with duplications of MECP2 can occur by fork stalling and template switching, Hu m Mol Gen et 2009, 18:2188-2203

18. Ramocki MB, Peters SU, Tavyev $Y$ J, Zh ang F, Carvalho $\mathrm{CM}$, Sch aaf $C P$, Richman R, Fang P, Glaze DG, Lupski JR, Zoghbi HY: Autism and other neuropsychiatric symptoms are prevalent in individuals with MeCP2 duplication syndro me, Ann Neurol 2009, 66:771-782

19. del Gaudio D, Fang P, Scaglia F, Ward PA, Craigen WJ, Glaze DG, Neul JL, Pat el A, Lee JA, Irons M, Berry SA, Pursley AA, Grebe TA, Freedenberg $D, M$ artin RA, Hsich GE, Khera JR, Friedman NR, Zoghbi HY, Eng CM, Lupski JR, Beaud et AL, Cheung SW, Roa BB Increased MECP2 gen e copy number as the result of genomic duplication in n eurod evelopmentally delayed males, Gen et $\mathrm{M}$ ed 2006, 8:784-792

20. Clayton-Smith J, Walters S, Hobson E, Burkitt-Wright E, Smith R, Toutain A, Amiel J, Lyonnet S, Mansour S, Fitzpat rick D, Ciccone R, Ricca I, Zuffardi O, Donnai D: Xq28 duplication present ing with intestinal and bladder dysfunction and a distinctive facial appea rance, Eur J Hum G enet 2009, 17:434-443

21. Smyk M, Obersztyn E, Nowako wska B, Nawara M, Cheung SW, Mazurczak T, Stankiewicz $P$, Bocian E: Different-sized duplications of $\mathrm{Xq28}$, including MECP2, in three males with mental retardation, absent or delayed speech, and recurrent infections, Am J Med Gen et B Neuropsychiatr Genet 2008, 147B:799-806

22. Collins AL, Levenson JM, Vilaythong AP, Richman R, Armstrong DL, Noebels JL, David Sweatt J, Zoghbi HY: Mild overexpression of MeCP2 causes a progressive neurological disorder in mice, Hum Mol Gen et 2004, 13:2679-2689

23. Samaco RC, Fryer JD, Ren J, Fyffe S, Chao HT, Sun Y, G reer JJ, Zoghbi HY, Neul JL: A partial loss of function allele of methylCpG-binding protein 2 predicts a human neurodevelop mental syndrome, Hu m Mol Gen et 2008, 17:1718-1727

24. Kifayathullah LA, Arunachalam JP, Bodda C, Agbemen yah HY, Laccone FA, Mann an AU: MeCP2 mutant protein is expressed in astrocytes as well as in neurons and localizes in the nucleus, Cytogen et G enome Res 2010, 129:290-297

25. Orford M, Nefedov M, Vadolas J, Zaibak F, Williamson R, loannou PA: Engin eering EGFP reporter constructs into a $200 \mathrm{~kb}$ human b eta-globin BAC clone using GET Reco mbination, Nucl eic Acids Res 2000, 28:E84

26. Schapiro S, Salas M, Vukovich K: Hormonal effects on ontogen of swimming ability in the rat: assessment of central nervous system develop ment, Science 1970, 168:147-150

27. Vorhees CV Butcher RE, Brunner RL, Sobotka TJ:-A developmen tal test battery for neurob ehavio ral toxicity in rats: a preliminary analysis using monosodium glutamate calcium carrageenan, and hydroxyurea, Toxicol Appl Pharmacol 1979, 50:267-282

28. Santos M, Silva-Fernandes A, Oliveira $P$, Sousa $N$, Maciel $P$ : Evidence for abnormal early development in a mouse model of Rett syndrome, Gen es Brain Behav 2007, 6:277-286

29. Crawley IN: Behavioral phenotyping of transgenic and knockout mice: experimental design and evaluation of general health, sensory functions, motor abilities, and specific behavioral tests, Brain Res 1999, 835:18-26

30. Ferraro TN, Golden GT, Smith GG, St Jean P, Schork NJ, Mulholland N, Ballas C, Schill J, Buono RJ, Berrettini WH: Mapping loci for pentylenetetrazol-induced seizure susceptibility in mice, J Neu rosci 1999, 19:6733-673931.

31. Guy J, Hendrich B, Holmes M, Martin JE, Bird A: A mouse Mecp2 null mutation causes neurological symptoms that mimic Rett syndrome, $\mathrm{N}$ at $\mathrm{G}$ enet 2001, 27:322-326

32. Meijering $E$, Jacob $M$, Sarria JC, Stein er $P$, Hirling $H$, Unser $M$ Design and valid ation of a tool for neurite tracing and an alysis in fluorescence microscopy images, Cytometry A 2004, 58:167-176

33. Abràmoff MD, Magalhães PJ, Ram SJ: Image Processing with Image , Biophotonics Internation al 2004, 11:36-42

34. Sholl DA: Dendritic organization in the neurons of the visual and motor cortic es of the c at, J Anat 1953, 87:387-406

35. Grynkiewicz G, Poenie M, Tsien RY: A new generation of Ca2 indicators with greatly improved fluorescence properties, J Bio Chem 1985, 260:3440-3450

36. Grynkiewicz G, Poenie M, Tsien RY: A new gen eration of $\mathrm{Ca} 2$ Grynkiewicz G, Poenie M, Tsien RY: A new gen eration of Ca2 +
indicators with greatly imp roved fluorescence properties, The Journal of biologic al chemistry 1985, 260:3440-3450

Mironov SL: Plas malemmal and intracellular $\mathrm{Ca}+$ pumps as main determinants of slow $\mathrm{Ca} 2+$ buffering in rat hippocampal neurones, Neuropharmacology 1995, 34:1123-1132 Dotti CG, Sullivan CA, Ban ker GA: The establishment of polarity by hippocampal neurons in culture, J Neurosci 1988, 8:14541468

39. Kosik KS, Finch EA: MAP2 and tau segregate into dendritic and axonal do mains after the elaboration of morphologically distinct neurites: an immunocytochemical study of cultured rat cereb rum, J Neurosci 1987, 7:3142-3153

40. Graveland GA, Williams RS, Difiglia M: Evidence for degenerative and regenerative changes in neostriatal spiny neurons in Huntington's diseas e, Science 1985, 227:770-773

41. Mendizabal-Zubiaga JL, Reblet C, Bueno-Lopez JL: The underside of the cerebral cortex: layer VNI spiny invert ed neurons, J Anat 2007, 211:223-236

42. Pilati N, Barker $M$, Panteleimonitis S, Donga $R$, Hamann $M$ : A rapid method combining Golgi and Nissl staining to study neuronal morphology and cytoarchitecture, J Histochem Cytochem 2008, 56:539-550

43. Mironov SL: Metabotropic ATP receptor in hippocampal and thalamic neurones: pharmacology and modulation of $\mathrm{Ca} 2+$ mobilizing mechan is ms, Neuroph armacology 1994, 33:1-13

44. Delorenzo RJ, Sun DA, Blair RE, Sombati S: An in vitro model of stroke-induced epilepsy: elucidation of the roles of glutamate and calciu $m$ in the induction and maintenance of stroke-induced epilep togen esis, Int Rev Neurobiol 2007, 81:59-84

45. Trevelyan AJ, Sussillo D, Watson BO, Yuste R: Modular propagation of epileptiform activity: evidence for an inhibitory veto in neocortex, J N eurosci 2006, 26:12447-12455

46. Chao HT, Zoghbi HY, Rosenmund C: MeCP2 controls excitatory synaptic stren gth by regulatin g glutamatergic synapse number, Neuron 2007, 56:58-65

47. Belichenko NP, Belichenko PV, Mobley WC: Evidence for both neuronal cell autonomous and nonautonomous effects of methyl-CpG-binding protein 2 in the cerebral cortex of female mice with M ecp2 mutation, $\mathrm{N}$ eurobiol Dis 2009, 34:71-77

48. Stuss DP, Boyd JD, Levin DB, Delaney KR: MeCP2 mutation results in compartment-specific reductions in dendritic branching and spine density in layer 5 motor cortic al neurons of YFP-H mice, PLoS On e 2012, 7:e31896

49. Landi S, Putign ano E, Boggio EM, Giustetto M, Pizzorusso T, Ratto GM: The short-time structu ral plasticity of dendritic spines is altered in a model of Rett syndrome, Sci Rep 2011, 1:4548. Mironov SL, Skorova E, Hartelt N, Mironova LA, Hasan MT, Kugler S: Remodelling of the respiratory network in a mouse 
model of Rett syndrome depends on b rain-derived n eurotrophic factor regulated slow calcium buffering, J Physiol 2009, 587:2473-2485

51. Milani D, Pantaleoni C, D'Arrigo S, Selico rni A, Riva D: Another patient with MECP2 mutation without classic Rett syndrome phenotype, Pediatr N eurol 2005, 32:355-357

52. Watson $P, B$ Back $G$, Ramsden $S$, Barrow $M$, Super $M$, Kerr B,

Clayton-Smith J: Angelman syndrome phenotype associated with mutations in MECP2, a gene encoding a methyl CpG binding protein, J Med Gen et 2001, 38:224-228 


\section{Discussion}

The Rett syndrome (RTT) is a postnatal neurodevelopmental disorder, primarily affecting girls. Mutations in X-linked MECP2 gene encoding for the methyl-CpG- binding protein $(\mathrm{MeCP} 2)$ is the primary cause for RTT. However, a wide range of studies suggests a multifaceted role of MeCP2 protein. Various studies showed that MeCP2 is actively involved in transcriptional modulation, chromatin compaction, RNA splicing and chromatin looping (Nan et al., 1997; Nan et al., 1998; George et al., 2003; Young et al., 2003; Cusack et al., 2004; Horike et al., 2005; Young et al., 2005; Yasui et al., 2007; Nikitina et al., 2007a; Nikitina et al., 2007b; Chahrour et al., 2008; Skene et al., 2010; Mellen et al., 2012). In the current study, we elucidated the function of MeCP2 using different mouse model systems. Firstly, we generated a mouse model with human equivalent mutation R270X to evaluate the role of this mutation at cellular (neuronal and non-neuronal) and behavioral levels. In addition, we identified several $\mathrm{MeCP} 2$ target proteins in the astrocytes by using proteomics approach. Furthermore, we characterized a transgenic mouse mildly overexpressing MeCP2 to determine the gene dosage effect.

\subsection{Functional characterization of Mecp2 mutant mouse models}

\subsubsection{Various Mecp2 model systems}

To investigate the pathomechanism of RTT, numerous mouse models that alter the expression or function of MeCP2 have been generated in different laboratories (Guy et al., 2001; Shahbazian et al., 2002a; Collins et al., 2004; Guy et al., 2007; Lawson-Yuen et al., 2007; Samaco et al., 2011; Goffin et al., 2012).

\subsubsection{Mecp2 $2^{\text {tm1.1Bird }}$ knockout mouse model}

The first Mecp2 mouse model was generated by Guy et al, (2001). This Mecp2 
conditional knockout mice lacked both exon 3 and exon 4 of Mecp2 and no expression of MeCP2 mRNA and protein were detectable. The Mecp $2^{\text {tm1.1Bird }}$ knockout mouse displayed stiffness, uncoordinated gait and reduced spontaneous movements at the age of 3-8 weeks. In addition, this mouse undergoes severe weight loss, reduced brain size, shivering, abnormal breathing, hindlimb clasping and die at the age of $~ 8-10$ weeks (Guy et al., 2001).

\subsubsection{Reversal of neurological defects in $M e c p 2^{\text {lox-stop }} / y$ mouse model}

Interestingly, another mouse model $M e c p 2^{\text {lox-stop } / y}$ was generated by Guy et al. (2007), in order to demonstrate that the robust neurological phenotype of Mecp $2^{\text {lox-stop }} / y$ mice can be reversed. To understand the reversal of Mecp 2 mechanism, the authors generated a mouse model wherein the Mecp2 gene was silenced by insertion of a lox-stop cassette with in exon 3 and exon 4 (Guy et al., 2007). The $M e c p 2^{\text {lox-stop }} / y$ mice showed symptoms at the age of 6 weeks, such as irregular breathing, hyperventilation, long apnea, abnormal gait and hindlimb clasping. The symptoms of $M e c p 2^{\text {lox-stop }} / y$ mice were similar to those in phenotypes of $M e c p 2^{\text {tm1.1Bird }}$ knockout mice (Guy et al., 2007). Remarkably, when the Mecp2 expression was activated under its own promoter through cre mediated release of lox-stop cassette either in neonatal or adult $M e c p 2^{\text {lox-stop }} / y$ mice, led to rescue of the RTT phenotype.

\subsubsection{Mecp $2^{\mathrm{R} 308 \mathrm{X}}$ mutant mouse expressing a truncated MeCP2 protein}

In RTT patients the $M e c p 2^{\mathrm{R} 308 \mathrm{X}}$ mutation causes neonatal encephalopathy, ataxia, severe mental retardation with seizures and premature death (Shahbazian et al., 2001; Zoghbi et al., 2001). To elucidate the molecular role of R308X mutation, Shahbazian et al, (2002a) generated a Mecp $2^{308 / y}$ mutant mouse. They inserted a stop codon after R308 (R308X, arginin residue was replaced by stop codon) amino acid residue in the carboxy terminal position of murine Mecp2. The mutant mice developed normally until 6 weeks, however, later they developed most of the neurological deficits similar to Mecp $2^{\text {tm1.1Bird }}$ knockout mice. The major symptoms of $M e c p 2^{308} / y$ mice are hypoactivity, hindlimb clasping, tremors, seizures, 
ataxia, motor dysfunction and social impairments (Shahbazian et al., 2002a; Moretti et al., 2005; Chao et al., 2010).

\subsubsection{Mecp2 $2^{\mathrm{T} 158 \mathrm{~A}}$ mutant mouse model}

The substitution of threonine to alanine at 158 position (T158A) in MeCP2 is one of the most common missense mutations which occurs in RTT patients (Colvin et al., 2004). To elucidate the pathomechanism associated with T158A mutation, Goffin et al, (2012) generated a knockin mouse model wherein they mutated threonine 158 to alanine that is equivalent to the human T158A mutation. The Mecp $2^{\mathrm{T} 158 \mathrm{~A}} / \mathrm{y}$ mouse recapitulated almost all the phenotypic features of $M e c p 2^{\text {tm1.1Bird }}$ knockout mouse, including progressive motor impairments, hindlimb clasping and premature lethality.

\subsubsection{5 $M e c p 2^{\mathrm{R} 168 \mathrm{X}}$ nonsense mutation mouse model}

Furthermore, Lawson and colleagues generated a knockin mouse by replacing arginine 168 with a stop codon (Lawson-Yuen et al., 2007). The R168X is one of the most frequent mutations detected in RTT patients (Colvin et al., 2004). The Mecp $2^{\mathrm{R} 168 \mathrm{X}} / \mathrm{y}$ mutant mouse recapitulated most of the phenotypic features of the $M e c p 2^{\text {tm1.1Bird }}$ knockout mouse, including irregular breathing, weight loss and scoliosis (Lawson-Yuen et al., 2007). The phenotypic features of different mouse models of RTT are summarized in table 4.1 and figure 4.1. 
Table 4.1. Summary of different mouse models of RTT with molecular defects and behavioral characteristics. MBD: Methyl Binding Domain, TRD: Transcriptional Repression Domain.

\begin{tabular}{|c|c|c|}
\hline Mouse model & Protein Expression & Behavioral features \\
\hline \multirow[t]{2}{*}{$\begin{array}{l}\text { Mecp }^{\text {tm1.1Bird }} \\
\text { Exons } 3 \text { and } 4 \text { were } \\
\text { deleted } \\
\text { (Guy et al., 2001) }\end{array}$} & \multirow[t]{2}{*}{$\begin{array}{l}\text { No protein expression } \\
\text { was detected }\end{array}$} & $\begin{array}{l}\text { 1) Respiratory } \\
\text { abnormalities, increased } \\
\text { anxiety and reduced social } \\
\text { approach (Calfa et al., } \\
\text { 2011) }\end{array}$ \\
\hline & & $\begin{array}{l}\text { 2) Showed decreased } \\
\text { motility (Panayotis et al., } \\
\text { 2011) }\end{array}$ \\
\hline \multirow[t]{2}{*}{$\begin{array}{l}\text { Mecp } 2^{\text {lox-Stop } / y} \\
\text { Mecp2 gene was silenced } \\
\text { by lox-Stop cassette } \\
\text { (Guy et al., 2007) }\end{array}$} & \multirow[t]{2}{*}{$\begin{array}{l}\text { No protein expression } \\
\text { was detected }\end{array}$} & $\begin{array}{l}\text { 1) Symptoms were delayed } \\
\text { and developed at the age } \\
\text { of } \sim 6 \text { weeks (Guy et al., } \\
2007 \text { ) }\end{array}$ \\
\hline & & $\begin{array}{l}\text { 2) Behaves like a } \\
\text { Mecp } 2^{\text {tm1.1Bird }} \text { null mice } \\
\text { (Guy et al., 2007) }\end{array}$ \\
\hline \multirow{3}{*}{$\begin{array}{l}\text { Mecp } \mathbf{2}^{308} / \mathrm{y} \\
\text { Premature stop codon at } \\
308 \text { amino acids } \\
\text { embedded in MBD domain } \\
\text { and a part of TRD domain } \\
\text { (Shahbazian et al., 2002a) }\end{array}$} & \multirow{3}{*}{ Truncated protein } & $\begin{array}{l}\text { 1) Enhanced anxiety like } \\
\text { behavior (Chao et al., 2010) }\end{array}$ \\
\hline & & \begin{tabular}{|l|} 
2) Reduced motility (De \\
Fililpis et al., 2010)
\end{tabular} \\
\hline & & $\begin{array}{l}\text { 3) Problems in social } \\
\text { approach and interactions } \\
\text { (Shahbazian et al., 2002a; } \\
\text { Moretti et al., 2005) }\end{array}$ \\
\hline \multirow{2}{*}{$\begin{array}{l}\text { Mecp } 2^{\text {R168X }} / \mathrm{y} \\
\text { Nonsense mutation at } 168 \\
\text { amino acids position } \\
\text { replacing Arginine with } \\
\text { stop codon in the MBD } \\
\text { domain (Lawson-Yuen et } \\
\text { al., 2007) }\end{array}$} & \multirow{2}{*}{ Truncated protein } & $\begin{array}{l}\text { 1) Reduced anxiety like } \\
\text { behavior }\end{array}$ \\
\hline & & $\begin{array}{l}\text { 2) Reduced motility } \\
\text { (Lawson-Yuen et al., 2007; } \\
\text { Chao et al., 2012) }\end{array}$ \\
\hline \multirow{3}{*}{ 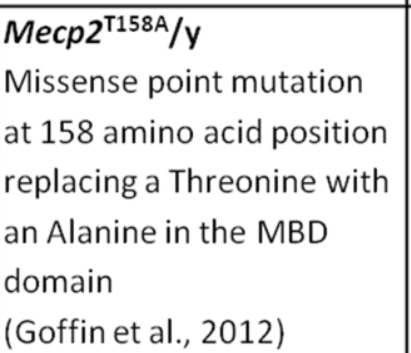 } & \multirow{3}{*}{ Truncated protein } & $\begin{array}{l}\text { 1) Reduced anxiety (Goffin } \\
\text { et al., 2012) }\end{array}$ \\
\hline & & $\begin{array}{l}\text { 2) Reduced motility (Goffin } \\
\text { et al., 2012) }\end{array}$ \\
\hline & & $\begin{array}{l}\text { 3) Problems in learning } \\
\text { and hindlimb clasping } \\
\text { (Goffin et al., 2012) }\end{array}$ \\
\hline
\end{tabular}




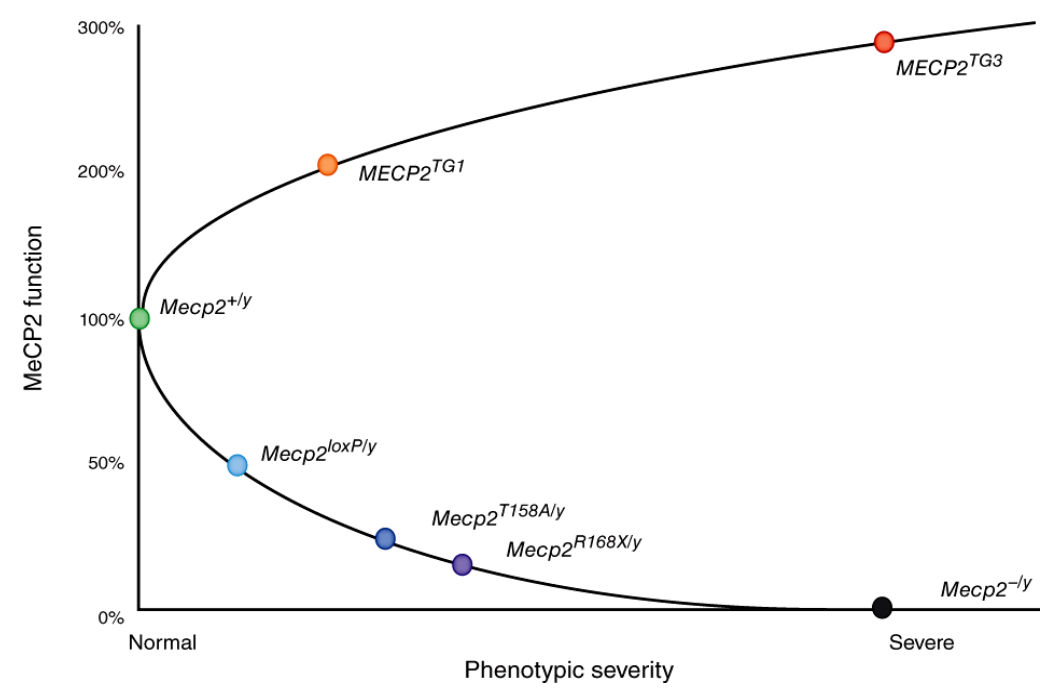

Figure 4.1. Spectrum of phenotypes of various mouse models with different types of Mecp2 mutations.

In case of loss of function (Rett syndrome), phenotypic severity is associated with decreased expression activity of MeCP2 as shown by comparison of wild type $\left(\mathrm{Mecp}^{+/ y}\right), M e c p 2^{\text {loxP/y }}, M e c p 2^{\text {TI58A/y }}, M e c p 2^{R 168 X / y}$ and Mecp2 knockout mice $\left(\mathrm{Mecp}^{-/ y}\right)$. In contrast, in case of gain of function of MeCP2, which is associated with duplication syndrome, the phenotypic severity is higher with increased expression of MeCP2 as shown by comparison of $M e c p 2^{+/ y}, M E C P 2^{\mathrm{Tg} 1}$ (2 fold overexpression) and $M E C P 2^{\mathrm{Tg} 3}$ (4 fold overexpression). (Adapted from Chao et al., 2012).

\subsubsection{Functional characterization of $M e c p 2^{R 270 X_{-} E G F P}$ mutant mouse model}

A wide spectrum of MECP2 mutations have been reported in RTT patients. However 8 recurrent missense and nonsense mutations (R106W; R133C; T158M; R168X; R255X; R270X; R294X; and R306C) account for up to two thirds of the total mutations reported in RTT patients (Dragich et al., 2000; Chahrour et al., 2007). Among the 700 different mutations, the R270X is one of the most frequent mutations reported in RTT cohorts (Dragich et al., 2000; Bebbington et al., 2008). The R270X nonsense mutation is located within the TRD-NLS region of $\mathrm{MeCP} 2$ protein and exhibits more severe phenotype and higher mortality rate as compared to other mutations (Colvin et al., 2004; Jain et al., 2005). In contrast, the R294X and R306C mutations that are situated after the TRD-NLS domain in MeCP2 manifest milder phenotypes (Colvin et al., 2004). 


\subsubsection{Generation of $M e c p 2^{R 270 X_{-} E G F P}$ mutant mouse model}

To evaluate the pathomechanism associated with R270X mutation, we generated a $M e c p 2^{R 270-E G F P}$ transgenic mouse that is equivalent to the human mutation. We used Bacterial Artificial Chromosome (BAC) construct for generating the Mecp2 $2^{R 270 E E G F P}$ transgenic mouse, which consists of endogenous promoter and regulatory elements of Mecp2. In addition, the Enhanced Green Fluorescent Protein/Kanamycin (EGFP/Kan) cassette was inserted after 270 amino acids of the murine Mecp2 gene. We bred the Mecp $2^{R 270 X_{-} E G F P}$ transgenic male mouse with Mecp2 knockout female to obtain $M e c p 2^{R 270 X}$ knockin (KI) mouse (Figure 4.2.A). To determine the Mecp $2^{R 270 \_E G F P}$ protein expression, we performed Western blot analysis with total protein from brain samples. The Western blot confirmed an additional MeCP2 protein band of $65 \mathrm{kDa}$ size, corresponding to transgenic protein in Mecp $2^{R 270-E G F P}$ and KI mice (Figure 4.2.B).

A)

B)
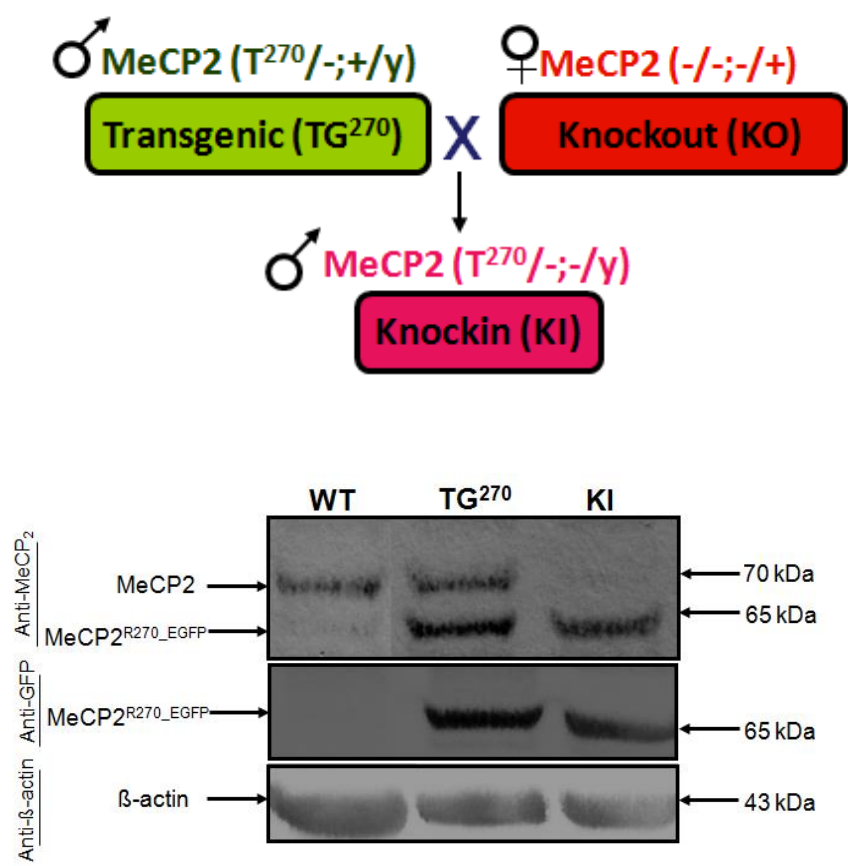

Figure 4.2. Schematic diagram of mouse breeding and validation of MeCP2 protein expression

A) Schematic breeding strategy between $M e c p 2^{R 270 \_E G F P}$ heterozygous transgenic male andMecp 2 knockout 
(KO) heterozygote female to obtain Mecp2 knockin (KI). B) Western blot analysis using MeCP2 antibody on the total brain protein revealed the endogenous MeCP2 protein at $70 \mathrm{kDa}$ size and an additional transgenic MeCP2 protein corresponding to $65 \mathrm{kDa}$ in Mecp $2^{R 270 \_E G F P}\left(\mathrm{TG}^{270}\right)$ transgenic mice. In Mecp2 knockin (KI) brain no endogenous MeCP2 protein was detectable $(70 \mathrm{kDa})$ and only expression of transgenic Mecp2 $2^{R 270 \_E G F P}$ (65 kDa) was observed. In addition, immunoblots with anti-GFP antibody confirmed the protein band at $65 \mathrm{kDa}$ was indeed transgenic MeCP2 $2^{\text {R270_EGFP }}$ protein.

Initial assessment showed no neurological impairments in Mecp $2^{R 270 \_E G F P}$ transgenic mice, but KI mice were positive for hindlimb clasping (Figure 4.3). The Mecp $2^{R 270 E E G F P}$ mice were phenotypically normal up to age of 1 year. However, to characterize the phenotypes of the Mecp $2^{270 \_E G F P}$ transgenic and KI mice, an extensive battery of behavioral tests including motor, sensory, social and cognitive functions will be necessary.

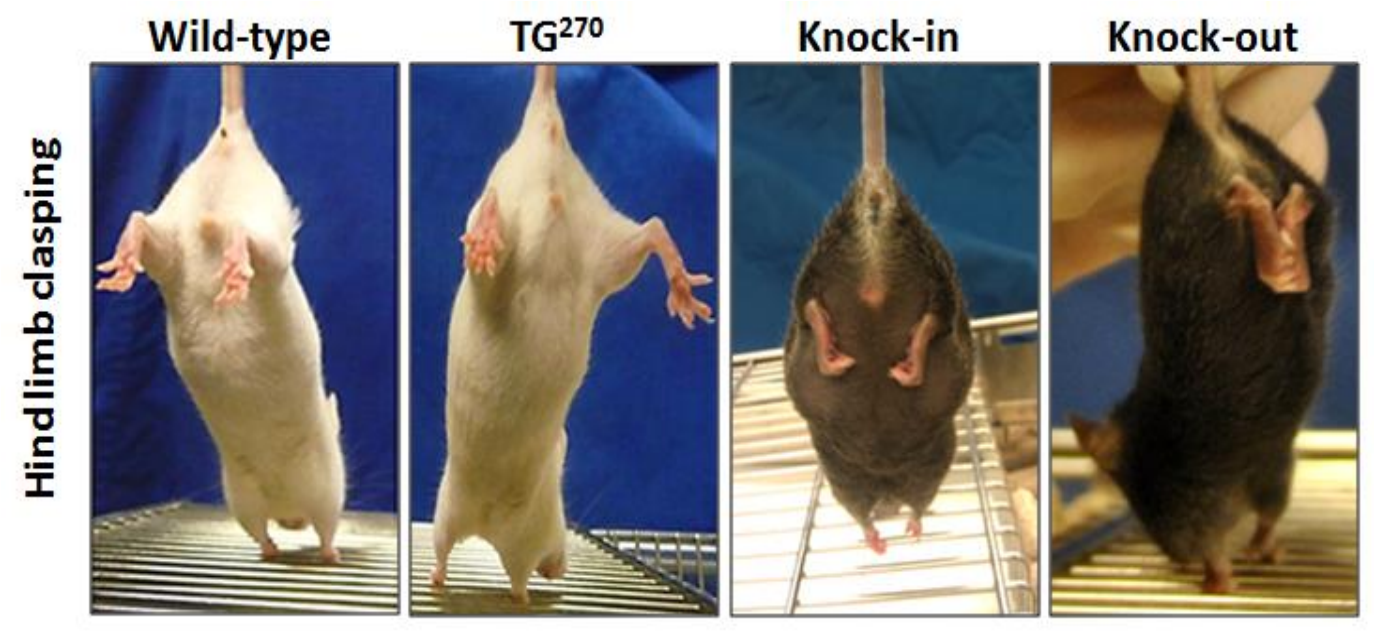

Figure 4.3. Hindlimb clasping test. The Mecp $2^{R 270 E G G F}$ transgenic mice $\left(\mathrm{TG}^{270}\right)$ were negative for hindlimb clasping test as were the wild-type mice. Interestingly we observed delayed onset of hindlimb clasping in knockin mouse at the age of 4 months. The Mecp2-knockout mice was postitive for hindlimb clasping at the age of 40 days.

\subsubsection{Evaluation of neuronal parameters of Mecp $2^{\text {R270_EGFP }}$ mutant mice}

To characterize the phenotype at the cellular level, we evaluated the neuronal parameters of primary hippocampal neurons prior to the manifestation of the symptoms. In order to determine the defects in the neuronal differentiation and development, we prepared hippocampal primary neuronal cultures from P7 stage of $M e c p 2^{R 270-E G F P}\left(\mathrm{TG}^{270}\right), \mathrm{KI}$ and $\mathrm{KO}$ male mice. After 14 days of the culture, we evaluated the neuronal parameters such as soma 
size, total length of the neurites and the complexity of the branching sites, such as primary, secondary and tertiary branching sites. These parameters were measured by blind genotyping. We did not observe any differences in the neurite length and soma size between WT and $M e c p 2^{R 270-E G F P}\left(\mathrm{TG}^{270}\right)$ neurons, but we detected reduced neurite length and soma size in KI as compared to WT (Figure 4.4.A and 4.4.B). Notably, the complexity of branching sites, particularly the secondary and tertiary branching sites of Mecp $2^{R 270 \_E G F P}\left(\mathrm{TG}^{270}\right)$ and $\mathrm{KI}$ neurons were decreased compared to WT neurons (Figure 4.4.C-D).

A)

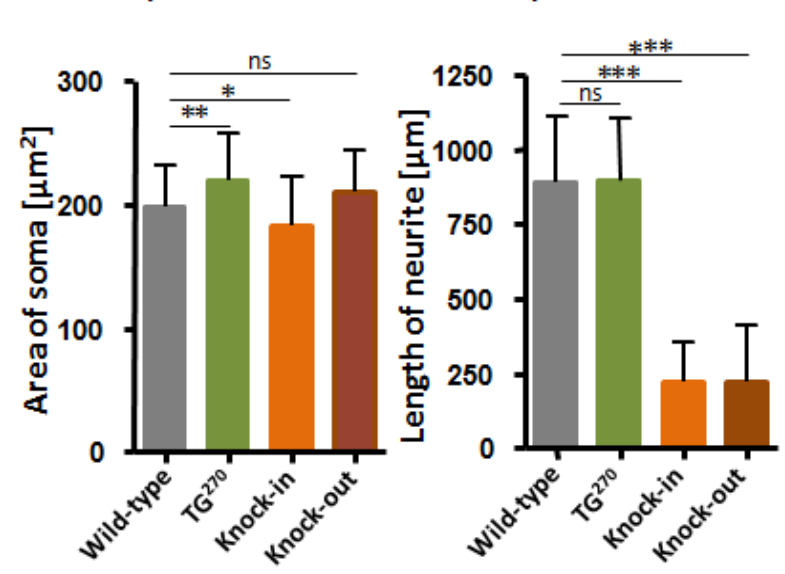

C)

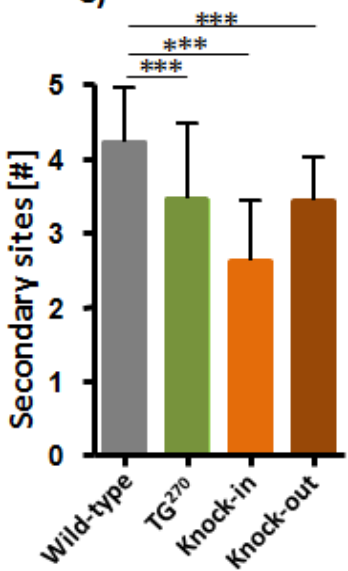

D)

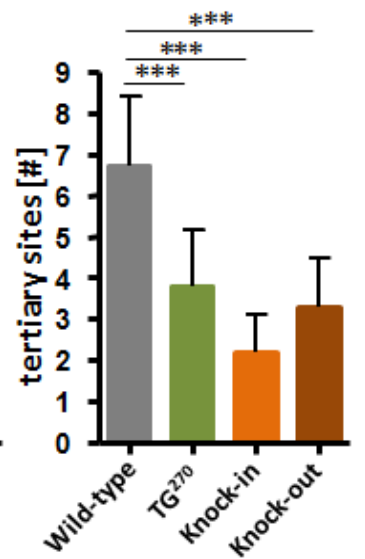

Figure 4.4. Evaluation of hippocampus neuronal parameters. The hippocampal neurons were immunostained with MAP2 antibody and neuronal parameters were analyzed for the stained neurons by Image $\mathbf{J}$ and Neuron $\mathbf{J}$ softwares. A) The area of soma size in $M e c p 2^{R 270 \_E G F P}\left(\mathrm{TG}^{270}\right)$ neuron was larger than wildtype soma. In contrast the soma size of knockin (KI) neuron was smaller as compared to wild type neurons. B) The total lengths of knockin (KI) and knockout (KO) neurites were significantly smaller as compared to wildtype and $M e c p 2^{\text {R270_EGFP }}\left(\mathrm{TG}^{270}\right)$ neurons. C-D) The number of secondary and tertiary branching sites were significantly reduced in $M e c p 2^{R 270 \_E G F P}\left(\mathrm{TG}^{270}\right)$, knockin $(\mathrm{KI})$ and knockout $(\mathrm{KO})$ neurons compared to wildtype neurons. ${ }^{*} \mathrm{p}<0.05, * * \mathrm{p}<0.001, * * * \mathrm{p}<0.0001$, ns- not significant.

The Golgi-Cox staining is a widely used technique to characterize the neuronal phenotype in in vivo in the whole brain (Corsi et al 1987; Ramon-Moliner et al., 1970; Robinson et al., 1997). The whole brains of 6 weeks old mice were dissected and Golgi staining was performed. The dissected brains were immersed in impregnation solution (mixture of $\mathrm{A} / \mathrm{B}$ ) for 7 days followed by cryoprotection solution $\mathrm{C}$ treatment for 2 days. Subsequently, the brains were sectioned into $150 \mu \mathrm{m}$ thick slices and dehydrated. Later, images of pyramidal neurons 
were captured from Golgi-Cox stained neurons and the spine density were calculated by using Image $\mathbf{J}$ software. There was no significant difference in spine density between $M e c p 2^{R 270 \_E G F P}$ and WT, but we observed reduced spine density in $\mathrm{KI}$ and $\mathrm{KO}$ as compared to WT neurons (Figure 4.5).

A)

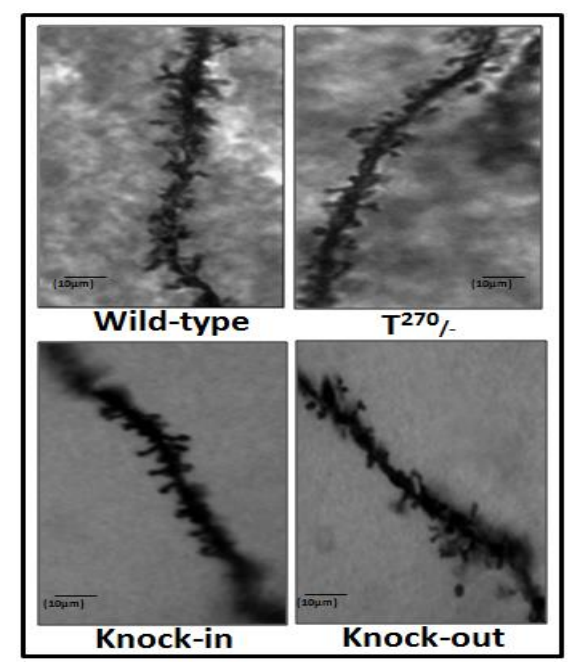

B)

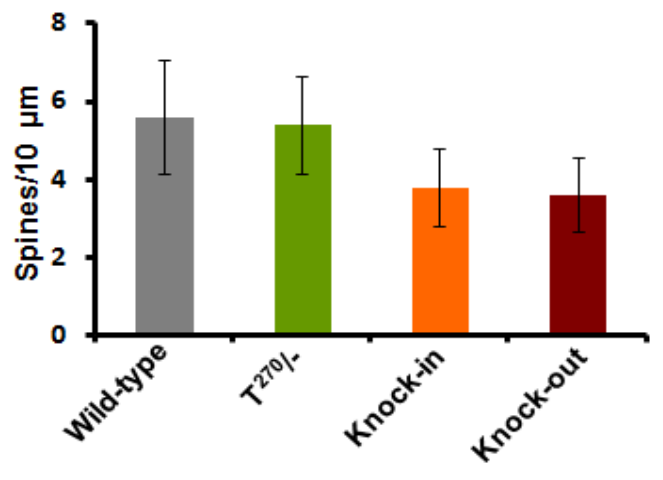

Figure 4.5. Evaluation of spine density in Mecp2 mouse models. A) Decreased spines in the basal dendrites of CA1 pyramidal neurons observed in knockin (KI) and knockout (KO) mice but no changes were found in $\operatorname{Mecp} 2^{\text {R270_EGFP }}\left(\mathrm{TG}^{270}\right)$ mice compared to WT mice. B) The spine density of Wildtype, Mecp $2^{270 E E G F P}$, knockin (KI) and knockout (KO) was plotted as mean value of $10 \mu \mathrm{m}$ per unit length for neurite length.

Collectively from these results, we speculate that the MeCP2 $2^{\mathrm{R} 270 \_\mathrm{EGFP}}$ protein has a deleterious effect on neuronal morphology and alters the spine density.

Further studies such as neuro-physiological and molecular studies with Mecp2 $2^{R 270-E G F P}$ transgenic and KI mice will shed light on the effect of R270X mutation on synaptic plasticity, connectivity, transmission and synaptic functional changes in the brain. 


\subsection{Phenotypical consequences of mild Mecp2 overexpression and estimation of gene-doses effects in a mouse model}

A loss-of-function mutation in $M E C P 2$ causes RTT syndrome and gain of $M E C P 2$ leads to duplication syndrome. In both cases it leads to neurological impairments (Amir et al., 1999; Collins et al., 2004; Ramocki et al., 2009; Ramocki et al., 2010; Carvalho et al., 2011) (Figure 4.6).

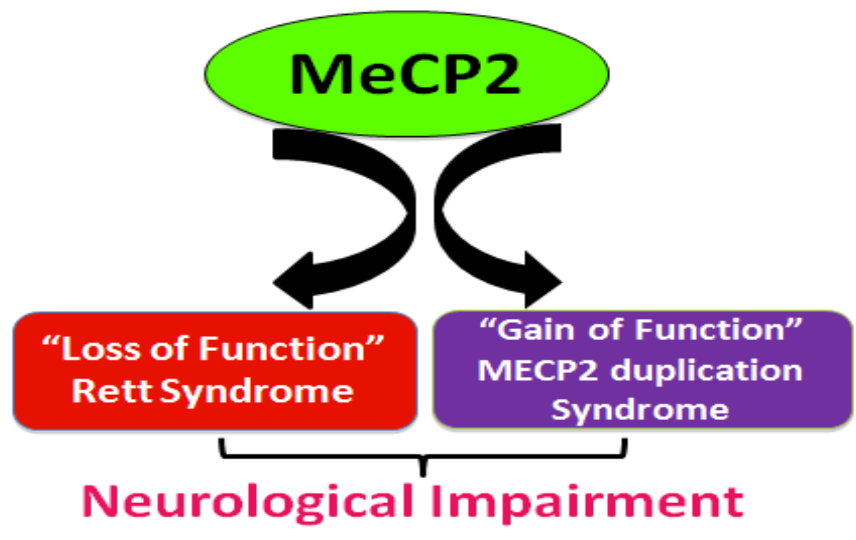

Figure 4.6. Schematic diagram showing consequence of loss and gain of MeCP2 function. Loss of function mutation causes Rett syndrome, in contrast, gain of function of MeCP2 lead to duplication syndrome. In both incidences, neurological impairments are manifested in patients.

The MECP2 duplication syndrome primarily affects $1-4$ boys in 50,000 male births (http://mecp2.wordpress.com/2012/02/06/how-many-children-and-adults-have-mecp2-

duplication-syndrome/\#more-868). The symptoms of MECP2 duplication syndrome includes severe mental retardation, hypotonia, epileptic seizures, anxiety, aggression and severe respiratory infections (Ramocki et al., 2010; Van Esch et al., 2012). The patients with triplication of MECP2 manifest even more severe phenotype than duplication syndrome patients (Gaudio et al., 2006; Carvalho et al., 2009). To determine the consequence of MECP2 dosage, different mouse models were generated (Collins et al., 2004; Samaco et al., 2011; Na et al., 2012). The MECP2 transgenic mouse model expressing MeCP2 at double the amount as compared to endogenous level, displayed motor defects, stereotypies, seizures, 
aggressiveness, spasticity and ataxia (Table 4.2) (Collins et al., 2004; Samaco et al., 2011). In addition, the MeCP2-2X mice showed heightened anxiety, decreased activity and premature death between 20 weeks to 1 year of age (Collins et al., 2004). Interestingly, the transgenic mice expressing in excess of threefold MeCP2 protein (MeCP2-4X) exhibited very severe phenotypes as compared to MeCP2-2X transgenic mice and die within 3 weeks of age (Table 4.2) (Collins et al., 2004; Samaco et al., 2011; Na et al., 2012).

Table 4.2. Mouse models of $M E C P 2$ duplication syndrome with their behavioral studies.

\begin{tabular}{|c|c|c|}
\hline Mouse model & Protein Expression & Behavioral studies \\
\hline \multirow{3}{*}{$\begin{array}{l}\text { Mecp } 2^{\mathrm{Tg}} 2 \mathrm{X} \\
\text { Introduction of whole } \\
\text { human MECP2 gene under } \\
\text { its own regulatory system } \\
\text { by using P1-derived artificial } \\
\text { chromosome (PAC) } \\
\text { (Collins et al., 2004) }\end{array}$} & \multirow[t]{3}{*}{$\sim 2$ folds of MeCP2 protein } & $\begin{array}{l}\text { 1) } 20 \text { weeks old mice showed } \\
\text { increased performance in } \\
\text { rotarod and contextual learning } \\
\text { (Collins et al., 2004) }\end{array}$ \\
\hline & & $\begin{array}{l}\text { 2) Impaired fear conditioning } \\
\text { (Collins et al., 2004) }\end{array}$ \\
\hline & & $\begin{array}{l}\text { 3) Progressive neurological } \\
\text { impairment, seizures, } \\
\text { aggressiveness and died } \\
\text { between } 20 \text { weeks to } 1 \text { year of } \\
\text { age (Collins et al., 2004) }\end{array}$ \\
\hline \multirow{3}{*}{$\begin{array}{l}\text { Mecp2 } 2^{\mathrm{Tg} 4 \mathrm{X}} \\
\text { Several copies of MECP2 } \\
\text { gene contains large } \\
\text { genomic clone with its own } \\
\text { regulatory system by using } \\
\text { PAC system } \\
\text { (Collins et al., 2004; Na et } \\
\text { al., 2011) }\end{array}$} & \multirow[t]{3}{*}{$\sim 4$ folds of MeCP2 protein } & $\begin{array}{l}\text { 1) More severe phenotypes } \\
\text { than Mecp } 2^{\mathrm{Tg}} 2 \mathrm{X} \text { model ( } \mathrm{Na} \text { et } \\
\text { al., 2011) }\end{array}$ \\
\hline & & $\begin{array}{l}\text { 2) Progressive neurological } \\
\text { abnormalities, seizures, } \\
\text { aggressiveness ( } \mathrm{Na} \text { et al., 2011) }\end{array}$ \\
\hline & & $\begin{array}{l}\text { 3) Showed freezing like } \\
\text { behavior and died within } 3 \\
\text { weeks of age ( } \mathrm{Na} \text { et al., 2011) }\end{array}$ \\
\hline
\end{tabular}

To determine the effect of MeCP2 dosage, we generated a Mecp $2^{\text {WT_EGFP }}$ transgenic mouse that mildly $(\sim 1.5 \mathrm{X})$ overexpresses MeCP2 (endogenous plus transgenic). A detailed behavioral analysis of Mecp $2^{W T_{-} E G F P}$ mice revealed an increase in aggressiveness and seizures propensity like behavior. Evaluation of neuronal parameters both at ex vivo and in vivo levels showed impaired secondary and tertiary branching sites and increased spine density in $M e c p 2^{W T_{-} E G F P}$ transgenic neurons. Treatment of $M e c p 2^{W T_{-} E G F P}$ transgenic neurons with 
pentylenetetrazole (PTZ) causes an increased calcium spikes amplitude with a higher frequency.

Overall, from these studies we can conclude that precise regulation of MeCP2 expression is necessary for appropriate neurodevelopment. These finding has an important ramification regarding devising potential therapeutic strategies for correcting the expression level of MeCP2 in RTT and MECP2 duplication syndrome patients. Any step towards increasing the levels of MeCP2 either through gene/protein therapy in the RTT patients or reducing $\mathrm{MeCP} 2$ expression through siRNA mediated down-regulation in the $M E C P 2$ duplication syndrome must be considered carefully to avoid further neurological impairments.

\subsubsection{Mild overexpression of Mecp2 has negligible effect on differential regulation of target genes}

To estimate the gene dosage effects and predict the level at which potential nontolerable side effects might occur, mouse models with mild overexpression have been instrumental. Evaluation of the quantitative effect of MeCP2 expression level on phenotypes is highly relevant, as duplication of $M E C P 2$ causes severe neurological impairment and have substantial effects on target gene expression (Collins et al., 2004; Ramocki et al., 2009; Ramocki et al., 2010). To determine how MECP2 target genes expression is regulated in $M e c p 2^{W T_{-} E G F P}$ mouse, we performed qRT-PCR analysis on a selected set of MeCP2 target genes (Gdf11, Lrplb, Pygm, Robo1, Bdnf and Ddc) (Ben-Shachar et al., 2009; Urdinguio et al., 2008), which showed substantial differential regulation in $M e c p 2^{T g} 2 \mathrm{X}$ and $M e c p 2$ knockout mice.

The qRT-PCR was performed with total RNA isolated from cerebellum and hippocampus of P40 stage Mecp $2^{W T_{-} E G F P}$ transgenic and Mecp2 knockout mice. Overall, the expression pattern of target genes in cerebellum of null mice was similar to that previously reported (Chahrour et 
al., 2008; Ben-Shachar et al., 2009), thus validating our qRT-PCR assay (Figure. 4.7). In transgenic cerebellum, the expression pattern of target genes showed minor changes as compared to wild type cerebellum (Figure. 4.7). When, we compared the expression pattern of MeCP2 target genes between cerebellum and hippocampus, we observed region specific regulations for $B d n f, G d f 11$ and $L r p 1 b$ genes (Figure. 4.7).Interestingly, we observed a mild overexpression of Robol in transgenic cerebellum (Figure. 4.7), which is contrasting to expression pattern reported for Robol in $M E C P 2-\mathrm{Tg}$ cerebellum, where it shows significant down-regulation (Ben-Shachar et al., 2009). The effect of MeCP2 dosage on Robol regulation is highly relevant, as we observed a mild up-regulation of Robol in Mecp $2^{W T_{-} E G F P}$; however $2 \mathrm{X}$ expression of $\mathrm{MeCP} 2$ causes a considerable down-regulation of this target gene in the cerebellum (Ben-Shachar et al., 2009). Thus, a reduced dosage of MeCP2 by half fold elicits an opposite effect on the expression pattern of Robol.
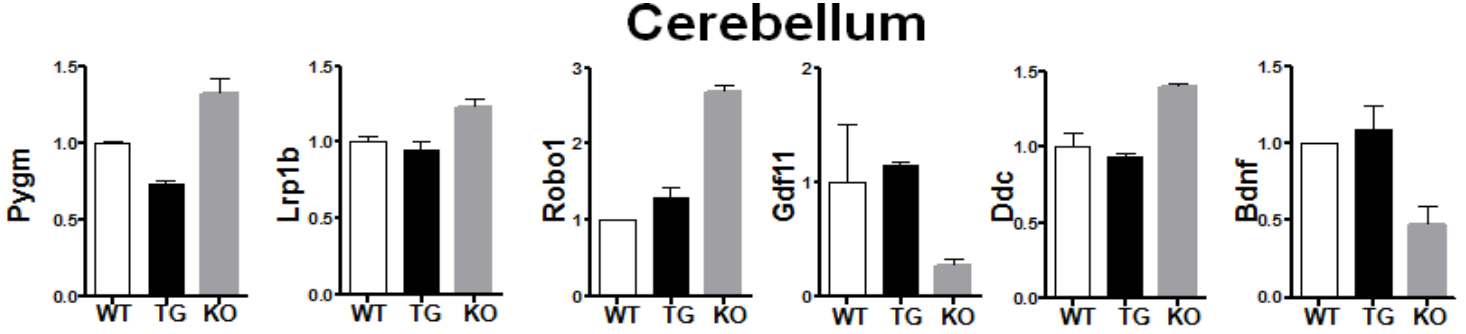

Hippocampus
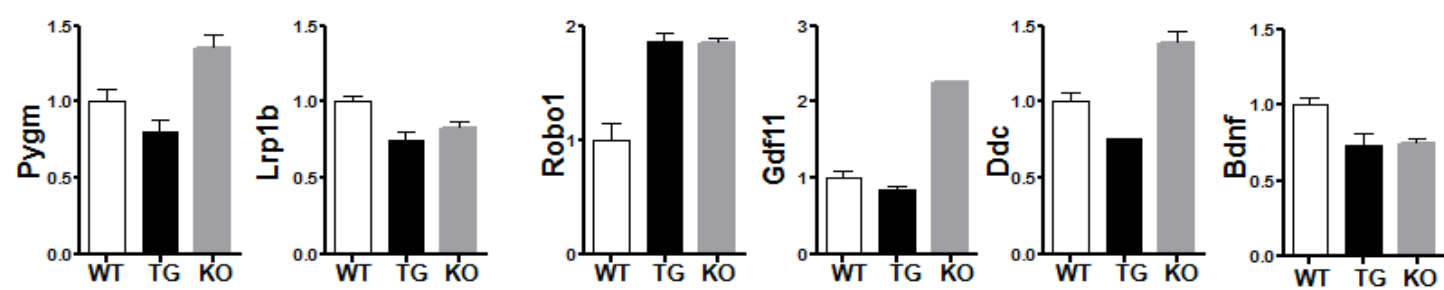

Figure 4.7. To determine the effect of mild Mecp2 overexpression $(\sim 1.5 \mathrm{X})$ on target genes regulation. We selected several of the known genes, whose expression is significantly regulated by $\mathrm{MeCP} 2$, namely $D d c$, Bdnf Gdf11, Lrplb, Pygm and Robol, for quantitative (q)RT-PCR) analysis. The expression pattern of target genes showed minor changes in transgenic cerebellum as compared to wild type. Furthermore, we observed region specific regulations of Bdnf, Gdfl1, Robol and Lrplb genes between cerebellum and hippocampus. KO, knockout; TG, transgenic; WT, wild type. 
Overall, through the characterization of our generated mouse model overexpressing $\sim 1.5 \mathrm{X}$ level of $\mathrm{MeCP} 2$, we could reinforce the notion that the effect of $\mathrm{MeCP} 2$ on neurodevelopment is quantitative. Furthermore, unlike doubling of $\mathrm{MeCP} 2$ dosage causing the severe neurological impairment, a $\sim 1.5 \mathrm{X}$ level of $\mathrm{MeCP} 2$ only elicit milder phenotype with epileptic seizures propensity. Importantly, the complementation of Mecp2 null mice with a half dosage of transgenic Mecp $2^{W T_{-} E G F P}$ was sufficient to alleviate the major symptoms and led to prolongation of the life span. We conclude, that RT-PCR assay of Mecp2 target genes may be a suitable approach to evaluate the success of MeCP2 supplementary therapy in the future. This assay will particularly assist in determining the optimal dosage of MeCP2, which will not elicit deleterious side-effects yet will be sufficient to rescue the major symptoms.

\subsection{Role of Mecp2 in astrocytes}

Previous studies suggested that Mecp2 is exclusively expressed in neurons (Shahbazian et al., 2002; Kishi et al., 2004; Zoghbi et al., 2009). However recently several studies including our own report have shown that MeCP2 is also expressed in non-neuronal cells like glia, astrocytes, microglia and oligodendrocytes (Ballas et al., 2009; Maezawa et al., 2009; Zoghbi et al., 2009; Kifayathullah et al., 2010). These studies concluded that the differences with previous studies are due to the use of different antibodies and various immunohistochemical methods (Tochiki et al., 2012; Zoghbi et al., 2009). Recent studies have shown that the role of $\mathrm{MeCP} 2$ in non-neuronal cell types such as glia, astrocytes, oligodendrocytes and microglias is to promote neuronal maturation and differentiation (Davalos et al., 2005; Markiewicz et al., 2006; Barres et al., 2008; Ballas et al., 2009; Maezawa et al., 2009; Zoghbi et al., 2009). In fact, these non-neuronal cells expressing $\mathrm{MeCP} 2$ are in close contact with neighboring neurons for supporting growth and preventing them from the neuronal excitotoxity (Ballas et al., 2009). 
Astrocytes are the major component of the glial cell population in the central nervous system (CNS) (Molfsky et al., 2012). Astrocytes play key roles in guidance of neuronal cell migration, synaptic transmission, plasticity, excitability, energy metabolism, detoxification, free radical scavenging and preventing neuronal excitotoxicity (Davalos et al., 2005; Markiewicz et al., 2006; Barres et al., 2008).

Recently, Ballas and colleagues demonstrated, that the wild type as well as Mecp2deficient neurons displayed shorter and lesser number of dendrites, when co-cultured with Mecp2-null astrocytes (Ballas et al., 2009; Zoghbi et al., 2009). These findings suggests that some unknown factors from Mecp2-deficient astrocytes cause toxic effect to the neighboring neurons and inhibit the maturation of neurons (Ballas et al., 2008; Maezawa et al., 2009; Zoghbi et al., 2009). Furthermore, conditioned media from the Mecp2-knockout astrocytes phenocopied the astrocytic effect, suggesting that the unknown factor(s) secreted by the mutant astrocytes contribute to the neuronal damage thereby to developmental defects in a non-cell-autonomous manner (Ballas et al., 2009). These findings prompted us to determine the non-cell-autonomous role of Mecp2 in astrocytes contributing to RTT pathogenesis.

\subsubsection{Establishment of astrocyte culture}

To characterize the role of Mecp2 deficient astrocytes in the neuronal defects in a noncell-autonomous manner, we prepared astrocytes from hippocampus and cortex from P0-P2 stage of wildtype, knockin and knockout male mice. After 16 days of pure astrocyte culture, we immunostained the cells with astrocyte markers such as GFAP (Glial fibrillary acidic protein) and EAAT1 (Excitatory amino acid transporter 1) antibodies (Figure 4.8.A). Later, the images of stained astrocytes were analyzed with Image $\mathbf{J}$ software to quantify the purity of the astrocytes (Figure 4.8.B). The Image $\mathrm{J}$ analysis revealed the astrocyte purity was over 90\% (Figure 4.8.B). 
A)
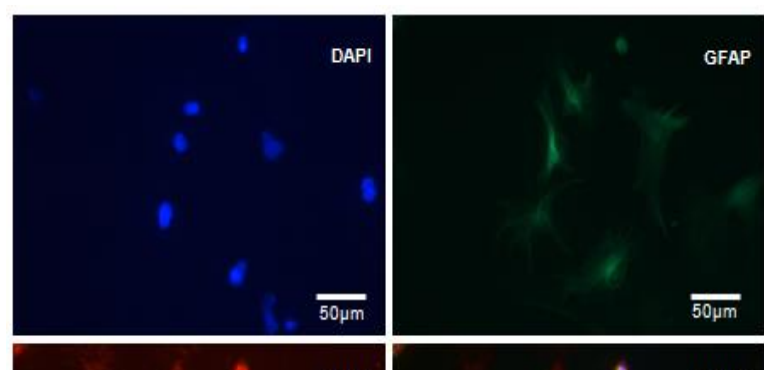

EAAT1
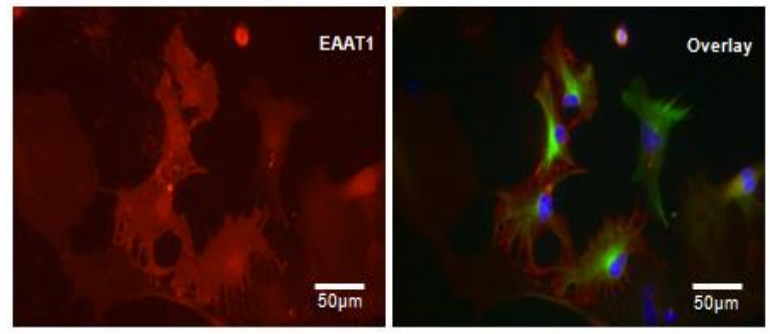

B)

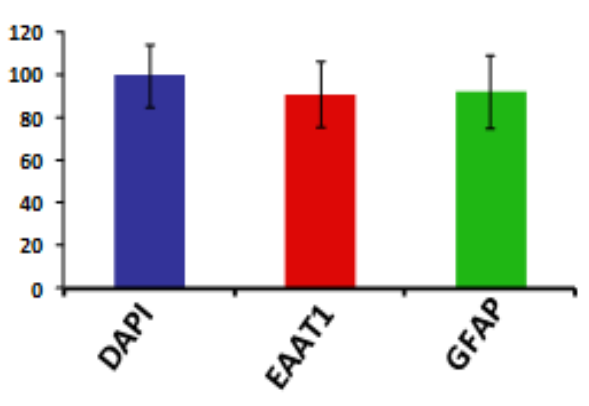

Figure 4.8. Immunostaining of astrocyte cell culture. A) After 16 day of culturing astrocytes were stained with GFAP and EAAT1 antibodies. Immunostaining with GFAP and EAAT1 revealed majority of cultured cells were astrocytes. B) Image $\mathbf{J}$ software quantification of immunostained cells revealed that the astrocytes purity was over $90 \%$ in cultured cells. Scale bar $50 \mu \mathrm{m}$.

\subsubsection{Proteomics approach to identify the MeCP2 target proteins in astrocytes}

The 16 days old cultured astrocytes from wild type, knockout and knockin mice were washed in PBS and lysed with RIPA buffer. After lysis, the extracted astrocyte protein was denatured and resolved on the SDS-PAGE (4\%-12\% mini gel) and stained with Colloidal Coomassie. Subsequently, small sections of gel of various band sizes were extracted from the gel and digested overnight with trypsin. After digestion, peptides were extracted and run on the Liquid Chromatography-Mass Spectrometry/Mass or Liquid Chromatography- tandem Mass Spectrometry (LC-MS/MS) and proteomics analysis in combination with Label free quantification algorithms (LFQ) was performed (Quintana et al., 2009; Luber et al., 2010). The proteomic experiments were performed in three independent technical repeats and data were combined to obtained average values by using MaxQuant (version 1.0.13.13) analyser (Cox et al., 2008). Before analyzing the results from LC-MS/MS, we removed the major contaminating peptides by filtering . Later, we standardized the average peptides number and 
the intensity peak values were normalized. The abundance of the proteins and their peptides that showed significant differential expression were obtained from volcano plot ( $\log _{2}$ ratio vs $\log _{10}(\mathrm{p})$ ) (Luber et al., 2010) between knockin, knockout as compared to wildtype by statistical simulations. In our proteomic evaluation, we reliably and reproducibly identified 5000 differentially expressed proteins from each subset of wildtype, knockin and knockout samples. The identified proteins and their gene IDs were obtained from International Protein Index (http://www.ebi.ac.uk/IPI/IPIhelp.html, http://www.genenames.org/ and http://www.uniprot.org/). Furthermore, we used harvester portal (http://harvester.kit.edu/HarvesterPortal) to identify the molecular function of differentially expressed proteins according to their Gene Ontology (GO) using a False discovery rate (FDR) corrected value as $\mathrm{p}<0.05$. To summarize, we identified 69 proteins which were up-regulated and 29 proteins which were down-regulated in knockin (KI) astrocytes compared to wildtype. Furthermore, 50 proteins were up-regulated and 32 proteins were down-regulated in knockout (KO) over wildtype. Gene ontology analysis of the Mecp2 target proteins disclosed the functional groups, such as desmosomal proteins, mitochondrial, transporter proteins, signaling transduction, oxidative stress, ribosomal and RNA processing in knockin (KI) and knockout (KO) compared to wildtype (WT) astrocytes as summarized in the pie charts (Figure 4.9). 


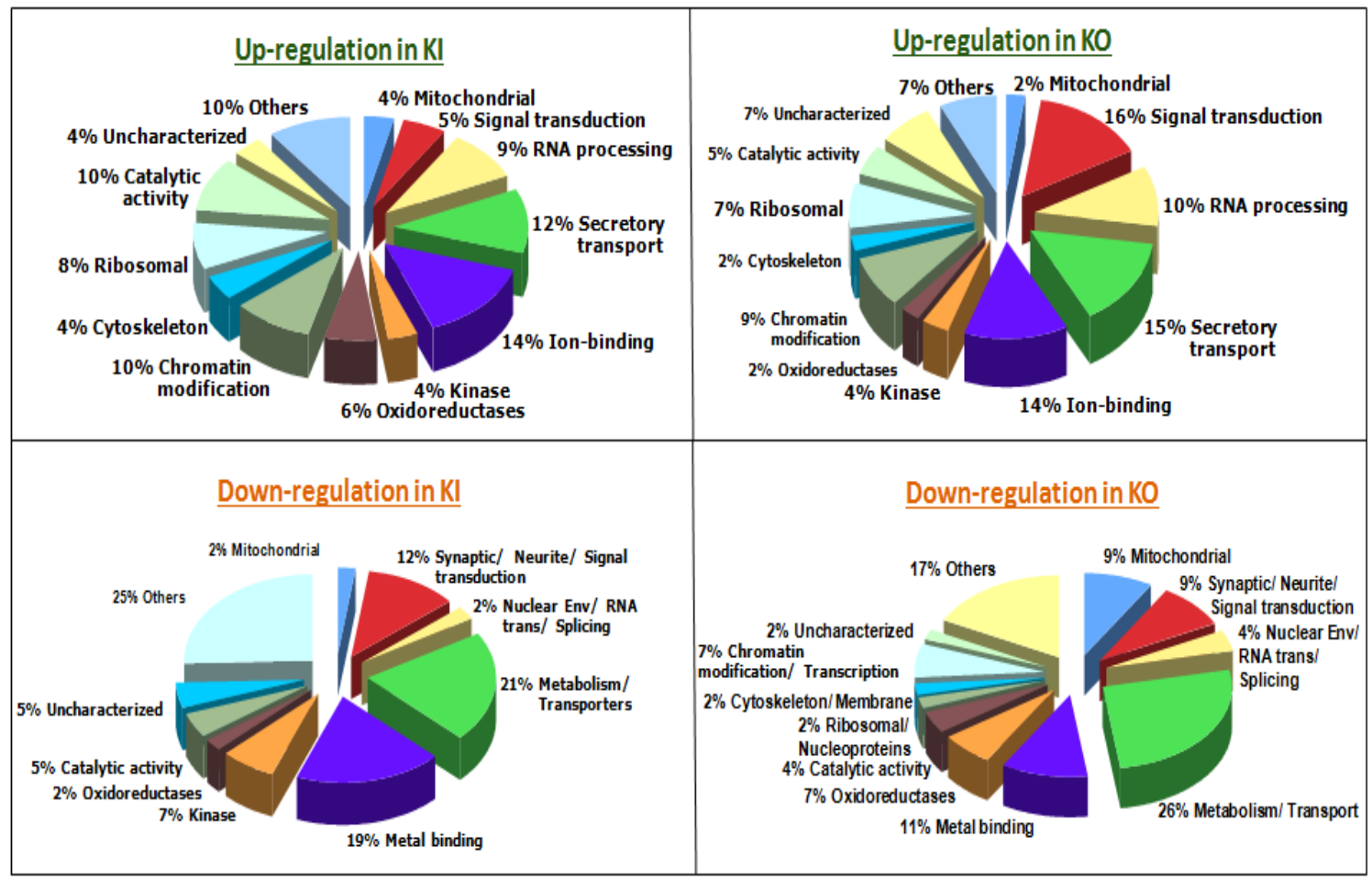

Figure 4.9. Summary of functional groups of differentially expressed Mecp2 target proteins in astrocytes. By using Gene Ontology (GO), we identified 69 proteins which were up-regulated and 29 proteins were down-regulated in knockin over wildtype astrocytes. Additionally, 50 proteins were up-regulated and 32 proteins were down-regulated in knockout compared to wildtype astrocytes. GO category for each target protein was determined using the Harvester portal resources (http://harvester.kit.edu/HarvesterPortal). The percentage of differentially expressed genes in each GO categorized set, such as mitochondrial, transporter, demosomal, signal transduction and oxidative stress in knockin (KI) and knockout (KO) as compared to wildtype (WT) astrocyte protein samples are represented in the form of pie chart.

\subsubsection{Validation of differential expression of selected MeCP2 target proteins by}

\section{Western blot}

In order to validate the Label Free Quantification (LFQ) proteomics results we selected a set of MeCP2 target proteins that were significantly altered in knockin, knockout and wildtype astrocytes. The selected MeCP2 target proteins those are involving in cell to cell interaction and desmosome formation (Dsp, Pkp1), glutamate transportation (Slc25a18) and oxidative stress (Txn2). The differential expression in knockin and knockout as compared to 
wildtype astrocytes was confirmed by Western blot analysis. A brief description of selected $\mathrm{MeCP} 2$ target proteins are provided below.

\section{Dsp (Desmoplakin)}

Desmoplakin also known as desmosomes, is located in intercellular junctions, where it assist in tightly anchoring the adjacent cells (Bomslaeger et al., 1996; Kathleen et al., 1996). The Label Free Quantification (LFQ) proteomic analysis revealed down regulation of Dsp in knockin and knockout as compared to wildtype (Figure 4.10). Interestingly, Western blot analysis confirmed that the relative expression of Dsp protein was 2 fold lower in knockout as compared to wildtype (Figure 4.11). However, due to lack of knockin mice we validated of knockout mice through Western blot analysis.

\section{Pkp1 (Plakophilin 1)}

Plakophilin 1 belongs to plakophilin family, is localized to cell desmosomes and is involved in the linking of the cytoskeleton (McMillan et al., 2003). The LFQ intensity analysis indicated that PKP1 showed lower expression in knockin and knockout as compared to wildtype (Figure 4.10). In Western blot analysis, the expression of Pkp1 showed minor downregulation (75\%) in knockout compared to wildtype (Figure 4.11).

\section{Slc25a18 (Solute carrier family 25 member 18)}

Slc25a18 gene encodes for a protein that function as mitochondrial glutamate carrier. The main function of this transporter protein is the transport of glutamate from across the inner mitochondrial membrane (Pardo et al., 2001; Giuseppe et al., 2002). The LFQ analysis showed that Slc25a18 protein showed down regulation in knockin and knockout as compared to wildtype (Figure 4.10). Currently, we are in the process of standardization of conditions for Western blot analysis. 


\section{Txn2 (Thioredoxin 2)}

Txn2 gene belongs to thioredoxin family. This mitochondrial membrane protein protects against oxidant induced apoptosis and plays an essential role in cell apoptosis (Damdimopoulos et al., 2002; Chen et al., 2002; Zhou et al., 2007). Mutations in Txn2 causes damage of mitochondria that leads to overproduction of reactive oxygen species (ROS) that can lead to neurodegeneration (Martin et al., 2006). The LFQ analysis revealed that protein Txn2 was up-regulated in knockin and knockout as compared to wildtype (Figure 4.10). The standardization of conditions for Western blot analysis is in progress.
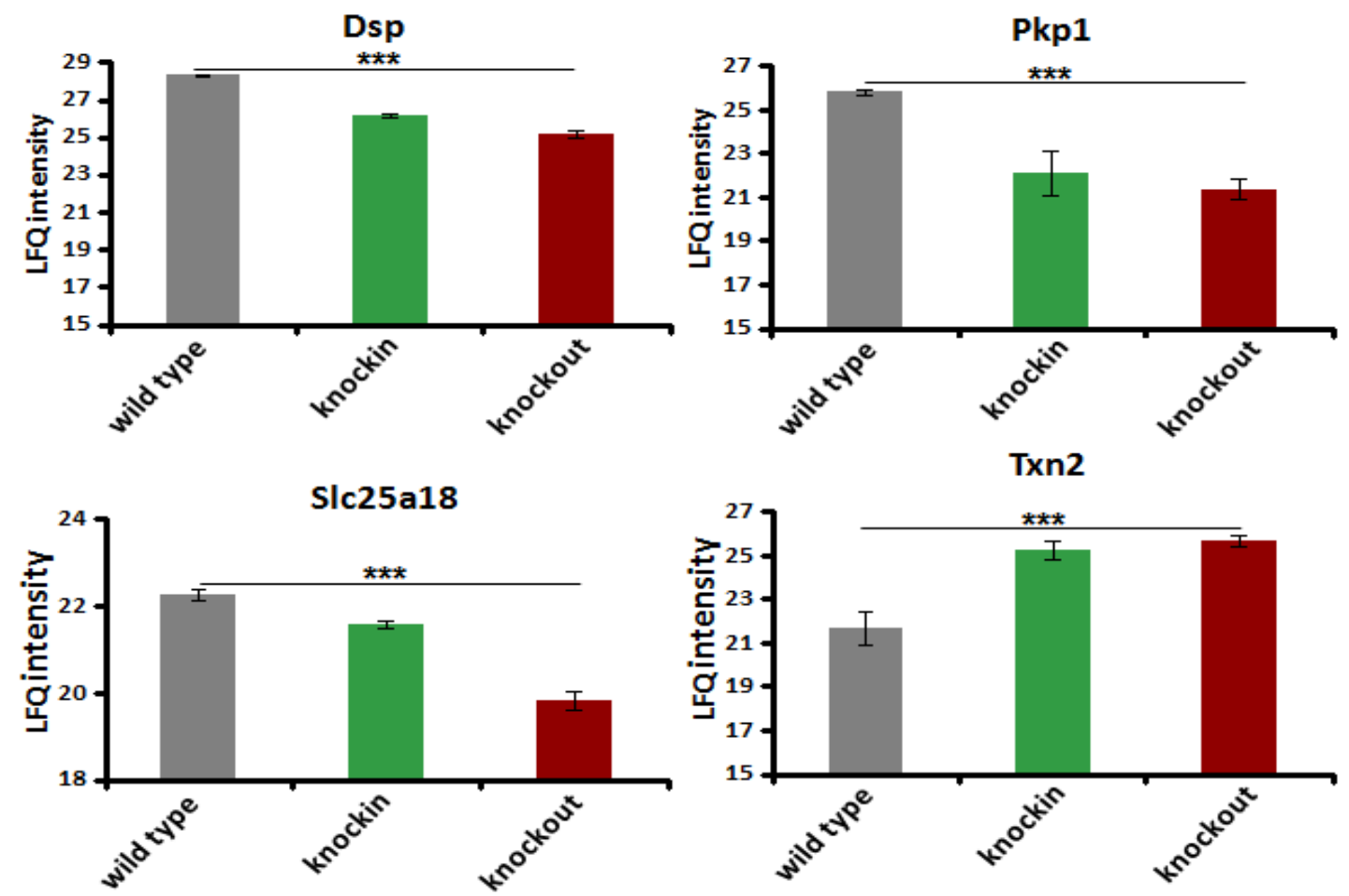

Figure 4.10. A histogram representation of selected proteins which showed significant changes in proteomic analysis. From the different peptide intensities of Label Free Quantification (LFQ), we identified several proteins, which belongs to cell adhesion and desmosomal proteins (Dsp and Pkp1), oxidative reductase (Txn2) and mitochondrial glutamate carrier proteins (Slc25a18). LFQ intensity, Label Free Quantification intensity. $* * * \mathrm{p}<0.0001$ 
Our preliminary analysis suggests that $\mathrm{MeCP} 2$ target proteins in astrocytes play a key role in cell adhesions through desmosomal proteins. MeCP2 also regulates ROS through Txn2 and glutamate homeostasis via Slc25a18.

A)

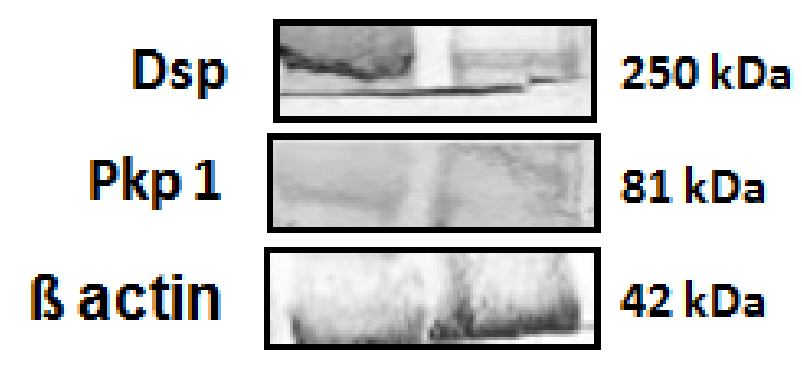

B)

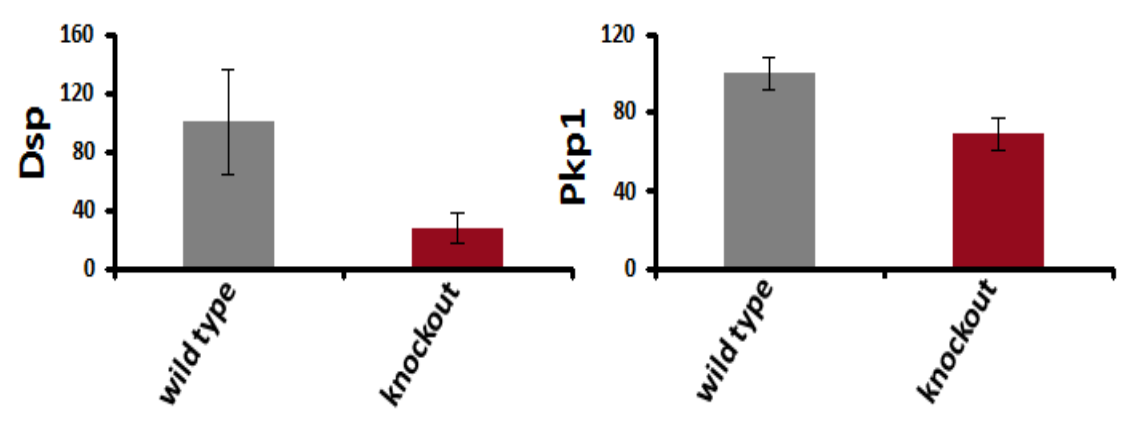

Figure 4.11. Validation of MeCP2 target protein expression by Western blot . A) Western blot using Dsp and Pkp1 antibodies with the total protein of knockout and wildtype astrocytes. In immunoblots protein size of $250 \mathrm{kDa}$ corresponding to Dsp and $81 \mathrm{kDa}$ to Pkp1 was detected. Additionally, immunoblot with anti- $\beta$ actin (42 $\mathrm{kDa}$ ) antibody was performed as a loading control. B) Quantification of the protein intensities by using image $\mathbf{J}$ software revealed that the protein expression of Dsp was $40 \%$ lower, whereas the expression of Pkp1 was reduced by $75 \%$ in knockout compared to wildtype astrocytes.

\subsubsection{Exploring therapeutic intervention by down/up-regulation of astrocyte factors in an ex vivo system- Future perspectives}

Further experimental studies such as an ex vivo assay can be established to test the effect of non-cell autonomous astrocytes factors, identified through proteomics approach. In this co-culture assay, the identified proteins from the proteomics can be modulated either by lentiviral mediated shRNA knockdown or overexpress and then evaluate its effect on neuronal 
growth. Through this assay system, we will be able to dissect out those proteins (factors) which are most effective in rescuing the phenotype. In future, appropriate mouse models can be generated for such astrocyte factors to evaluate their therapeutical efficiency.

Establishing the role of glial dysfunction in RTT pathogenesis could provide a new avenue for understanding RTT and will assist us in developing novel therapy for this disease Furthermore, such studies will provide us with mechanistic insight into the cross-talk between astrocytes and neurons thus enabling us to identify the non-cell autonomous factors from the astrocytes, which are responsible for mediating such cross-talk. 


\section{References}

Adams VH, McBryant SJ, Wade PA, Woodcock CL, Hansen JC: Intrinsic disorder and autonomous domain function in the multifunctional nuclear protein, mecp2. J Biol Chem 282:15057-15064 (2007).

Amir RE, Van den Veyver IB, Schultz R, Malicki DM, Tran CQ, Dahle EJ, Philippi A, Timar L, Percy AK, Motil KJ, Lichtarge O, Smith EO, Glaze DG, Zoghbi HY: Influence of mutation type and x chromosome inactivation on rett syndrome phenotypes. Ann Neurol 47:670-679 (2000).

Amir RE, Van den Veyver IB, Wan M, Tran CQ, Francke U, Zoghbi HY: Rett syndrome is caused by mutations in x-linked mecp2, encoding methyl-cpg-binding protein 2. Nat Genet 23:185-188 (1999).

Amir RE, Zoghbi HY: Rett syndrome: Methyl-cpg-binding protein 2 mutations and phenotypegenotype correlations. Am J Med Genet 97:147-152 (2000).

Armstrong D, Dunn JK, Antalffy B, Trivedi R: Selective dendritic alterations in the cortex of rett syndrome. J Neuropathol Exp Neurol 54:195-201 (1995).

Armstrong DD: Neuropathology of rett syndrome. J Child Neurol 20:747-753 (2005).

Armstrong DD, Dunn K, Antalffy B: Decreased dendritic branching in frontal, motor and limbic cortex in rett syndrome compared with trisomy 21. J Neuropathol Exp Neurol 57:1013-1017 (1998).

Asaka Y, Jugloff DG, Zhang L, Eubanks JH, Fitzsimonds RM: Hippocampal synaptic plasticity is impaired in the mecp2-null mouse model of rett syndrome. Neurobiol Dis 21:217-227 (2006).

Ballas N, Lioy DT, Grunseich C, Mandel G: Non-cell autonomous influence of mecp2-deficient glia on neuronal dendritic morphology. Nat Neurosci 12:311-317 (2009).

Banerjee A, Castro J, Sur M: Rett syndrome: Genes, synapses, circuits, and therapeutics. Front Psychiatry 3:34 (2012).

Barres BA: The mystery and magic of glia: A perspective on their roles in health and disease. Neuron $60: 430-440$ (2008).

Belichenko PV, Hagberg B, Dahlstrom A: Morphological study of neocortical areas in rett syndrome. Acta Neuropathol 93:50-61 (1997).

Belichenko PV, Oldfors A, Hagberg B, Dahlstrom A: Rett syndrome: 3-d confocal microscopy of cortical pyramidal dendrites and afferents. Neuroreport 5:1509-1513 (1994).

Belichenko PV, Wright EE, Belichenko NP, Masliah E, Li HH, Mobley WC, Francke U: Widespread changes in dendritic and axonal morphology in mecp2-mutant mouse models of rett syndrome: Evidence for disruption of neuronal networks. J Comp Neurol 514:240-258 (2009).

Ben-Shachar S, Chahrour M, Thaller C, Shaw CA, Zoghbi HY: Mouse models of mecp2 disorders 
share gene expression changes in the cerebellum and hypothalamus. Hum Mol Genet 18:2431-2442 (2009).

Bienvenu T, Chelly J: Molecular genetics of rett syndrome: When DNA methylation goes unrecognized. Nat Rev Genet 7:415-426 (2006).

Bornslaeger EA, Corcoran CM, Stappenbeck TS, Green KJ: Breaking the connection: Displacement of the desmosomal plaque protein desmoplakin from cell-cell interfaces disrupts anchorage of intermediate filament bundles and alters intercellular junction assembly. J Cell Biol 134:985-1001 (1996).

Calfa G, Percy AK, Pozzo-Miller L: Experimental models of rett syndrome based on mecp2 dysfunction. Exp Biol Med (Maywood) 236:3-19 (2011).

Carvalho CM, Ramocki MB, Pehlivan D, Franco LM, Gonzaga-Jauregui C, Fang P, McCall A, Pivnick EK, Hines-Dowell S, Seaver LH, Friehling L, Lee S, Smith R, Del Gaudio D, Withers M, Liu P, Cheung SW, Belmont JW, Zoghbi HY, Hastings PJ, Lupski JR: Inverted genomic segments and complex triplication rearrangements are mediated by inverted repeats in the human genome. Nat Genet 43:1074-1081 (2011).

Carvalho CM, Zhang F, Liu P, Patel A, Sahoo T, Bacino CA, Shaw C, Peacock S, Pursley A, Tavyev YJ, Ramocki MB, Nawara M, Obersztyn E, Vianna-Morgante AM, Stankiewicz P, Zoghbi HY, Cheung SW, Lupski JR: Complex rearrangements in patients with duplications of mecp2 can occur by fork stalling and template switching. Hum Mol Genet 18:2188-2203 (2009).

Chahrour M, Jung SY, Shaw C, Zhou X, Wong ST, Qin J, Zoghbi HY: Mecp2, a key contributor to neurological disease, activates and represses transcription. Science 320:1224-1229 (2008).

Chahrour M, Zoghbi HY: The story of rett syndrome: From clinic to neurobiology. Neuron 56:422-437 (2007).

Chao HT, Chen H, Samaco RC, Xue M, Chahrour M, Yoo J, Neul JL, Gong S, Lu HC, Heintz N, Ekker M, Rubenstein JL, Noebels JL, Rosenmund C, Zoghbi HY: Dysfunction in gaba signalling mediates autism-like stereotypies and rett syndrome phenotypes. Nature 468:263-269 (2010).

Chao HT, Zoghbi HY: Mecp2: Only 100\% will do. Nat Neurosci 15:176-177 (2012).

Chao HT, Zoghbi HY, Rosenmund C: Mecp2 controls excitatory synaptic strength by regulating glutamatergic synapse number. Neuron 56:58-65 (2007).

Chen Y, Cai J, Murphy TJ, Jones DP: Overexpressed human mitochondrial thioredoxin confers resistance to oxidant-induced apoptosis in human osteosarcoma cells. J Biol Chem 277:33242-33248 (2002).

Collins AL, Levenson JM, Vilaythong AP, Richman R, Armstrong DL, Noebels JL, David Sweatt J, Zoghbi HY: Mild overexpression of mecp2 causes a progressive neurological disorder in mice. Hum Mol Genet 13:2679-2689 (2004).

Colvin L, Leonard H, de Klerk N, Davis M, Weaving L, Williamson S, Christodoulou J: Refining the phenotype of common mutations in rett syndrome. J Med Genet 41:25-30 (2004). 
D'Esposito M, Quaderi NA, Ciccodicola A, Bruni P, Esposito T, D'Urso M, Brown SD: Isolation, physical mapping, and northern analysis of the x-linked human gene encoding methyl cpg-binding protein, mecp2. Mamm Genome 7:533-535 (1996).

Damdimopoulos AE, Miranda-Vizuete A, Pelto-Huikko M, Gustafsson JA, Spyrou G: Human mitochondrial thioredoxin. Involvement in mitochondrial membrane potential and cell death. J Biol Chem 277:33249-33257 (2002).

Dani VS, Chang Q, Maffei A, Turrigiano GG, Jaenisch R, Nelson SB: Reduced cortical activity due to a shift in the balance between excitation and inhibition in a mouse model of rett syndrome. Proc Natl Acad Sci U S A 102:12560-12565 (2005).

Davalos D, Grutzendler J, Yang G, Kim JV, Zuo Y, Jung S, Littman DR, Dustin ML, Gan WB: Atp mediates rapid microglial response to local brain injury in vivo. Nat Neurosci 8:752-758 (2005).

De Filippis B, Ricceri L, Laviola G: Early postnatal behavioral changes in the mecp2-308 truncation mouse model of rett syndrome. Genes Brain Behav 9:213-223 (2010).

del Gaudio D, Fang P, Scaglia F, Ward PA, Craigen WJ, Glaze DG, Neul JL, Patel A, Lee JA, Irons M, Berry SA, Pursley AA, Grebe TA, Freedenberg D, Martin RA, Hsich GE, Khera JR, Friedman NR, Zoghbi HY, Eng CM, Lupski JR, Beaudet AL, Cheung SW, Roa BB: Increased mecp2 gene copy number as the result of genomic duplication in neurodevelopmentally delayed males. Genet Med 8:784-792 (2006).

del Gaudio D, Fang P, Scaglia F, Ward PA, Craigen WJ, Glaze DG, Neul JL, Patel A, Lee JA, Irons M, Berry SA, Pursley AA, Grebe TA, Freedenberg D, Martin RA, Hsich GE, Khera JR, Friedman NR, Zoghbi HY, Eng CM, Lupski JR, Beaudet AL, Cheung SW, Roa BB: Increased mecp2 gene copy number as the result of genomic duplication in neurodevelopmentally delayed males. Genet Med 8:784-792 (2006).

Dragich J, Houwink-Manville I, Schanen C: Rett syndrome: A surprising result of mutation in mecp2. Hum Mol Genet 9:2365-2375 (2000).

Dragich JM, Kim YH, Arnold AP, Schanen NC: Differential distribution of the mecp2 splice variants in the postnatal mouse brain. J Comp Neurol 501:526-542 (2007).

Fiermonte G, Palmieri L, Todisco S, Agrimi G, Palmieri F, Walker JE: Identification of the mitochondrial glutamate transporter. Bacterial expression, reconstitution, functional characterization, and tissue distribution of two human isoforms. J Biol Chem 277:19289-19294 (2002).

Francke U: Mechanisms of disease: Neurogenetics of mecp2 deficiency. Nat Clin Pract Neurol 2:212221 (2006).

Fukuda T, Itoh M, Ichikawa T, Washiyama K, Goto Y: Delayed maturation of neuronal architecture and synaptogenesis in cerebral cortex of mecp2-deficient mice. J Neuropathol Exp Neurol 64:537-544 (2005). 
Georgel PT, Horowitz-Scherer RA, Adkins N, Woodcock CL, Wade PA, Hansen JC: Chromatin compaction by human mecp2. Assembly of novel secondary chromatin structures in the absence of DNA methylation. J Biol Chem 278:32181-32188 (2003).

Glaze DG: Rett syndrome: Of girls and mice--lessons for regression in autism. Ment Retard Dev Disabil Res Rev 10:154-158 (2004).

Goffin D, Allen M, Zhang L, Amorim M, Wang IT, Reyes AR, Mercado-Berton A, Ong C, Cohen S, Hu L, Blendy JA, Carlson GC, Siegel SJ, Greenberg ME, Zhou Z: Rett syndrome mutation mecp2 t158a disrupts DNA binding, protein stability and erp responses. Nat Neurosci 15:274-283 (2012).

Green KJ, Jones JC: Desmosomes and hemidesmosomes: Structure and function of molecular components. Faseb J 10:871-881 (1996).

Guerrini R, Parrini E: Epilepsy in rett syndrome, and cdkl5- and foxg1-gene-related encephalopathies. Epilepsia 53:2067-2078 (2012).

Guy J, Gan J, Selfridge J, Cobb S, Bird A: Reversal of neurological defects in a mouse model of rett syndrome. Science 315:1143-1147 (2007).

Guy J, Hendrich B, Holmes M, Martin JE, Bird A: A mouse mecp2-null mutation causes neurological symptoms that mimic rett syndrome. Nat Genet 27:322-326 (2001).

Hagberg B: Rett's syndrome: Prevalence and impact on progressive severe mental retardation in girls. Acta Paediatr Scand 74:405-408 (1985).

Hendrich B, Bird A: Identification and characterization of a family of mammalian methyl-cpg binding proteins. Mol Cell Biol 18:6538-6547 (1998).

Horike S, Cai S, Miyano M, Cheng JF, Kohwi-Shigematsu T: Loss of silent-chromatin looping and impaired imprinting of dlx5 in rett syndrome. Nat Genet 37:31-40 (2005).

Huppke P, Held M, Hanefeld F, Engel W, Laccone F: Influence of mutation type and location on phenotype in 123 patients with rett syndrome. Neuropediatrics 33:63-68 (2002).

Jian L, Archer HL, Ravine D, Kerr A, de Klerk N, Christodoulou J, Bailey ME, Laurvick C, Leonard H: P.R270x mecp2 mutation and mortality in rett syndrome. Eur J Hum Genet 13:1235-1238 (2005).

Jones PL, Veenstra GJ, Wade PA, Vermaak D, Kass SU, Landsberger N, Strouboulis J, Wolffe AP: Methylated DNA and mecp2 recruit histone deacetylase to repress transcription. Nat Genet 19:187-191 (1998).

Kaufmann WE, Worley PF, Taylor CV, Bremer M, Isakson PC: Cyclooxygenase-2 expression during rat neocortical development and in rett syndrome. Brain Dev 19:25-34 (1997).

Kerr B, Alvarez-Saavedra M, Saez MA, Saona A, Young JI: Defective body-weight regulation, motor control and abnormal social interactions in mecp2 hypomorphic mice. Hum Mol Genet 17:1707-1717 (2008). 
Kishi N, Macklis JD: Mecp2 is progressively expressed in post-migratory neurons and is involved in neuronal maturation rather than cell fate decisions. Mol Cell Neurosci 27:306-321 (2004).

Kishi N, Macklis JD: Mecp2 is progressively expressed in post-migratory neurons and is involved in neuronal maturation rather than cell fate decisions. Mol Cell Neurosci 27:306-321 (2004).

Kline DD, Ogier M, Kunze DL, Katz DM: Exogenous brain-derived neurotrophic factor rescues synaptic dysfunction in mecp2-null mice. J Neurosci 30:5303-5310 (2010).

Kriaucionis S, Bird A: DNA methylation and rett syndrome. Hum Mol Genet 12 Spec No 2:R221-227 (2003).

Kriaucionis S, Bird A: The major form of mecp2 has a novel n-terminus generated by alternative splicing. Nucleic Acids Res 32:1818-1823 (2004).

Laurvick CL, Msall ME, Silburn S, Bower C, de Klerk N, Leonard H: Physical and mental health of mothers caring for a child with rett syndrome. Pediatrics 118:e1152-1164 (2006).

Lawson-Yuen A, Liu D, Han L, Jiang ZI, Tsai GE, Basu AC, Picker J, Feng J, Coyle JT: Ube3a mrna and protein expression are not decreased in mecp2r168x mutant mice. Brain Res 1180:1-6 (2007).

Lewis JD, Meehan RR, Henzel WJ, Maurer-Fogy I, Jeppesen P, Klein F, Bird A: Purification, sequence, and cellular localization of a novel chromosomal protein that binds to methylated DNA. Cell 69:905914 (1992).

Maezawa I, Jin LW: Rett syndrome microglia damage dendrites and synapses by the elevated release of glutamate. J Neurosci 30:5346-5356 (2010).

Maezawa I, Swanberg S, Harvey D, LaSalle JM, Jin LW: Rett syndrome astrocytes are abnormal and spread mecp2 deficiency through gap junctions. J Neurosci 29:5051-5061 (2009).

Markiewicz I, Lukomska B: The role of astrocytes in the physiology and pathology of the central nervous system. Acta Neurobiol Exp (Wars) 66:343-358 (2006).

McMillan JR, Haftek M, Akiyama M, South AP, Perrot H, McGrath JA, Eady RA, Shimizu H: Alterations in desmosome size and number coincide with the loss of keratinocyte cohesion in skin with homozygous and heterozygous defects in the desmosomal protein plakophilin 1. J Invest Dermatol 121:96-103 (2003).

Meehan RR, Lewis JD, Bird AP: Characterization of mecp2, a vertebrate DNA binding protein with affinity for methylated DNA. Nucleic Acids Res 20:5085-5092 (1992).

Mellen M, Ayata P, Dewell S, Kriaucionis S, Heintz N: Mecp2 binds to 5hmc enriched within active genes and accessible chromatin in the nervous system. Cell 151:1417-1430 (2012). 
Mnatzakanian GN, Lohi H, Munteanu I, Alfred SE, Yamada T, MacLeod PJ, Jones JR, Scherer SW, Schanen NC, Friez MJ, Vincent JB, Minassian BA: A previously unidentified mecp2 open reading frame defines a new protein isoform relevant to rett syndrome. Nat Genet 36:339-341 (2004).

Molofsky AV, Krencik R, Ullian EM, Tsai HH, Deneen B, Richardson WD, Barres BA, Rowitch DH: Astrocytes and disease: A neurodevelopmental perspective. Genes Dev 26:891-907 (2012).

Moretti P, Bouwknecht JA, Teague R, Paylor R, Zoghbi HY: Abnormalities of social interactions and home-cage behavior in a mouse model of rett syndrome. Hum Mol Genet 14:205-220 (2005).

Moretti P, Levenson JM, Battaglia F, Atkinson R, Teague R, Antalffy B, Armstrong D, Arancio O, Sweatt JD, Zoghbi HY: Learning and memory and synaptic plasticity are impaired in a mouse model of rett syndrome. J Neurosci 26:319-327 (2006).

Na ES, Nelson ED, Kavalali ET, Monteggia LM: The impact of mecp2 loss- or gain-of-function on synaptic plasticity. Neuropsychopharmacology 38:212-219 (2013).

Nan X, Campoy FJ, Bird A: Mecp2 is a transcriptional repressor with abundant binding sites in genomic chromatin. Cell 88:471-481 (1997).

Nan X, Campoy FJ, Bird A: Mecp2 is a transcriptional repressor with abundant binding sites in genomic chromatin. Cell 88:471-481 (1997).

Nan X, Meehan RR, Bird A: Dissection of the methyl-cpg binding domain from the chromosomal protein mecp2. Nucleic Acids Res 21:4886-4892 (1993).

Nan X, Ng HH, Johnson CA, Laherty CD, Turner BM, Eisenman RN, Bird A: Transcriptional repression by the methyl-cpg-binding protein mecp2 involves a histone deacetylase complex. Nature 393:386389 (1998).

Nan X, Ng HH, Johnson CA, Laherty CD, Turner BM, Eisenman RN, Bird A: Transcriptional repression by the methyl-cpg-binding protein mecp2 involves a histone deacetylase complex. Nature 393:386389 (1998).

Nelson ED, Kavalali ET, Monteggia LM: Activity-dependent suppression of miniature neurotransmission through the regulation of DNA methylation. J Neurosci 28:395-406 (2008).

Neul JL, Fang P, Barrish J, Lane J, Caeg EB, Smith EO, Zoghbi H, Percy A, Glaze DG: Specific mutations in methyl-cpg-binding protein 2 confer different severity in rett syndrome. Neurology 70:1313-1321 (2008).

Neul JL, Kaufmann WE, Glaze DG, Christodoulou J, Clarke AJ, Bahi-Buisson N, Leonard H, Bailey ME, Schanen NC, Zappella M, Renieri A, Huppke P, Percy AK: Rett syndrome: Revised diagnostic criteria and nomenclature. Ann Neurol 68:944-950 (2010).

Nimmerjahn A, Kirchhoff F, Helmchen F: Resting microglial cells are highly dynamic surveillants of brain parenchyma in vivo. Science 308:1314-1318 (2005). 
Palmieri L, Pardo B, Lasorsa FM, del Arco A, Kobayashi K, Iijima M, Runswick MJ, Walker JE, Saheki T, Satrustegui J, Palmieri F: Citrin and aralar1 are ca(2+)-stimulated aspartate/glutamate transporters in mitochondria. Embo J 20:5060-5069 (2001).

Panayotis N, Pratte M, Borges-Correia A, Ghata A, Villard L, Roux JC: Morphological and functional alterations in the substantia nigra pars compacta of the mecp2-null mouse. Neurobiol Dis 41:385-397 (2011).

Percy AK, Lane JB, Childers J, Skinner S, Annese F, Barrish J, Caeg E, Glaze DG, MacLeod P: Rett syndrome: North american database. J Child Neurol 22:1338-1341 (2007).

Perova NV, Chebanov SM, Loginov AS, Oganov RG: [morphological approach to characterizing the heterogeneity of blood plasma lipoproteins in different types of pathology]. Biull Vsesoiuznogo Kardiol Nauchn Tsentra AMN SSSR 10:55-66 (1987).

Prescott TE, Rodningen OK, Bjornstad A, Stray-Pedersen A: Two brothers with a microduplication including the mecp2 gene: Rapid head growth in infancy and resolution of susceptibility to infection. Clin Dysmorphol 18:78-82 (2009).

Quaderi NA, Meehan RR, Tate PH, Cross SH, Bird AP, Chatterjee A, Herman GE, Brown SD: Genetic and physical mapping of a gene encoding a methyl cpg binding protein, mecp2, to the mouse $\mathrm{x}$ chromosome. Genomics 22:648-651 (1994).

Ramocki MB, Peters SU, Tavyev YJ, Zhang F, Carvalho CM, Schaaf CP, Richman R, Fang P, Glaze DG, Lupski JR, Zoghbi HY: Autism and other neuropsychiatric symptoms are prevalent in individuals with mecp2 duplication syndrome. Ann Neurol 66:771-782 (2009).

Ramocki MB, Tavyev YJ, Peters SU: The mecp2 duplication syndrome. Am J Med Genet A 152A:1079-1088 (2010).

Rett A: [on a unusual brain atrophy syndrome in hyperammonemia in childhood]. Wien Med Wochenschr 116:723-726 (1966).

Riikonen R: Neurotrophic factors in the pathogenesis of rett syndrome. J Child Neurol 18:693-697 (2003).

Robinson TE, Kolb B: Persistent structural modifications in nucleus accumbens and prefrontal cortex neurons produced by previous experience with amphetamine. J Neurosci 17:8491-8497 (1997).

Samaco RC, Mandel-Brehm C, McGraw CM, Shaw CA, McGill BE, Zoghbi HY: Crh and oprm1 mediate anxiety-related behavior and social approach in a mouse model of mecp2 duplication syndrome. Nat Genet 44:206-211 (2012).

Samaco RC, Mandel-Brehm C, McGraw CM, Shaw CA, McGill BE, Zoghbi HY: Crh and oprm1 mediate anxiety-related behavior and social approach in a mouse model of mecp2 duplication syndrome. Nat Genet 44:206-211 (2012).

Samaco RC, Neul JL: Complexities of rett syndrome and mecp2. J Neurosci 31:7951-7959 (2011). 
Santos M, Silva-Fernandes A, Oliveira P, Sousa N, Maciel P: Evidence for abnormal early development in a mouse model of rett syndrome. Genes Brain Behav 6:277-286 (2007).

Shahbazian M, Young J, Yuva-Paylor L, Spencer C, Antalffy B, Noebels J, Armstrong D, Paylor R, Zoghbi H: Mice with truncated mecp2 recapitulate many rett syndrome features and display hyperacetylation of histone h3. Neuron 35:243-254 (2002).

Shahbazian M, Young J, Yuva-Paylor L, Spencer C, Antalffy B, Noebels J, Armstrong D, Paylor R, Zoghbi H: Mice with truncated mecp2 recapitulate many rett syndrome features and display hyperacetylation of histone h3. Neuron 35:243-254 (2002).

Shahbazian MD, Antalffy B, Armstrong DL, Zoghbi HY: Insight into rett syndrome: Mecp2 levels display tissue- and cell-specific differences and correlate with neuronal maturation. Hum Mol Genet 11:115-124 (2002).

Skene PJ, Illingworth RS, Webb S, Kerr AR, James KD, Turner DJ, Andrews R, Bird AP: Neuronal mecp2 is expressed at near histone-octamer levels and globally alters the chromatin state. Mol Cell 37:457-468 (2010).

Urdinguio RG, Lopez-Serra L, Lopez-Nieva P, Alaminos M, Diaz-Uriarte R, Fernandez AF, Esteller M: Mecp2-null mice provide new neuronal targets for rett syndrome. PLoS One 3:e3669 (2008).

Van Esch H: Mecp2 duplication syndrome. Mol Syndromol 2:128-136 (2012).

Van Esch H, Bauters M, Ignatius J, Jansen M, Raynaud M, Hollanders K, Lugtenberg D, Bienvenu T, Jensen LR, Gecz J, Moraine C, Marynen P, Fryns JP, Froyen G: Duplication of the mecp2 region is a frequent cause of severe mental retardation and progressive neurological symptoms in males. Am J Hum Genet 77:442453 (2005).

Velinov M, Novelli A, Gu H, Fenko M, Dolzhanskaya N, Bernardini L, Capalbo A, Dallapiccola B, Jenkins EC, Brown WT: De-novo $2.15 \mathrm{mb}$ terminal xq duplication involving mecp2 but not 11cam gene in a male patient with mental retardation. Clin Dysmorphol 18:9-12 (2009).

Wan M, Lee SS, Zhang X, Houwink-Manville I, Song HR, Amir RE, Budden S, Naidu S, Pereira JL, Lo IF, Zoghbi HY, Schanen NC, Francke U: Rett syndrome and beyond: Recurrent spontaneous and familial mecp2 mutations at cpg hotspots. Am J Hum Genet 65:1520-1529 (1999).

Weng SM, Bailey ME, Cobb SR: Rett syndrome: From bed to bench. Pediatr Neonatol 52:309-316 (2011).

Yasui DH, Peddada S, Bieda MC, Vallero RO, Hogart A, Nagarajan RP, Thatcher KN, Farnham PJ, Lasalle JM: Integrated epigenomic analyses of neuronal mecp2 reveal a role for long-range interaction with active genes. Proc Natl Acad Sci U S A 104:19416-19421 (2007). 
Young JI, Hong EP, Castle JC, Crespo-Barreto J, Bowman AB, Rose MF, Kang D, Richman R, Johnson JM, Berget S, Zoghbi HY: Regulation of rna splicing by the methylation-dependent transcriptional repressor methyl-cpg binding protein 2. Proc Natl Acad Sci U S A 102:17551-17558 (2005).

Zappella M, Gillberg C, Ehlers S: The preserved speech variant: A subgroup of the rett complex: A clinical report of 30 cases. J Autism Dev Disord 28:519-526 (1998).

Zhang L, He J, Jugloff DG, Eubanks JH: The mecp2-null mouse hippocampus displays altered basal inhibitory rhythms and is prone to hyperexcitability. Hippocampus 18:294-309 (2008).

Zhou J, Damdimopoulos AE, Spyrou G, Brune B: Thioredoxin 1 and thioredoxin 2 have opposed regulatory functions on hypoxia-inducible factor-1alpha. J Biol Chem 282:7482-7490 (2007). 


\section{ABBREVIATIONS}

AP

Alkaline Phosphatase

BAC Bacteria Artificial Chromosome

BCIP 5-Bromo-4-chloro-3-indodyl Phosphate

Bp $\quad$ Base pair

BSA Bovine Serum Albumin

cDNA Complementary Deoxyribose Nucleic Acid

CNS Central nervous system

${ }^{0} \mathrm{C} \quad$ Degree Celsius

Cy3 indocarbocyanine

DAPI Diamidino-2-phenylindole dihydrochloride

ddH2O Double distilled water

DMF Dimethylformamide

DNA Deoxyribose Nucleic Acid

DNase Deoxiribonuclease

dNTP Deoxynucleotidetriphosphate

DTT Dithiothreitol

EAAT1 Excitatory amino acid transporter 1

EDTA Ethylene Diamine Tetraacetic Acid 


$\begin{array}{ll}\text { EGFP } & \text { Enhanced green fluorescent protein } \\ \text { EGTA } & \text { Ethylene Glycol Tetraacetic Acid } \\ \text { FITC } & \text { Fluorecein Isothiocyanate } \\ \text { FDR } & \text { False discovery rate } \\ \text { FBS } & \text { Fetal Bovine Serum } \\ \mathrm{g} & \text { Gram }\end{array}$

GFAP Glial fibrillary acidic protein

GO Gene Ontology

$\mu \mathrm{g} \quad$ Microgram

HEPES N-(-hydroxymethyl) piperazin, N'-3 propansulfoneacid

$\mathrm{kb} \quad$ Kilobase pairs

KI Knockin

KO Knockout

LC-MS/MS Liquid Chromatography-Mass Spectrometry/Mass or Liquid Chromatographytandem Mass Spectrometry

LFQ Label free quantification algorithms

$\log 2 \quad$ Binary logarithm

Log10 Base 10 logarithm

M Molarity 


\begin{tabular}{|c|c|}
\hline $\mathrm{mA}$ & Milliampere \\
\hline MECP2 & Methyl-CpG binding protein 2 \\
\hline $\mathrm{mg}$ & Milligram \\
\hline $\mathrm{ml}$ & Milliliter \\
\hline$\mu l$ & Microliter \\
\hline $\min$ & Minute \\
\hline $\mathrm{mM}$ & Millimolar \\
\hline $\mathrm{mm}$ & Millimeter \\
\hline mRNA & messenger Ribonucleic acid \\
\hline NBT & Nitro-blue tetrazolium \\
\hline NCBI & National Center for Biotechnology Information \\
\hline ng & Nanogram \\
\hline NLS & Nuclear Localization Signal \\
\hline PBS & Phosphate Buffer Saline \\
\hline PCR & Polymerase Chain Reaction \\
\hline PFA & Paraformaldehyde \\
\hline PIPES & Piperazine-N,N'-bis(2-ethanesulfonic acid) \\
\hline Pmol & Picomol \\
\hline PMSF & Phenylmethylsulfonyl Fluoride \\
\hline
\end{tabular}




\section{PNC Primary Neuronal Culture \\ RIPA Radio immunoprecipitation assay}

RNA Ribonucleic Acid

ROS reactive oxygen species

Rpm revolution per minute

RT Room Temperature

RTT Rett Syndrome

sec Second

SDS Sodium Dodecyl Sulphate

PAGE Polyacrylamide Gel Electrophoresis

Taq Thermus aquaticus

TBE Tris-Borate-ADTA-Electrophoresis

TBST Tris-Buffered Saline Tween-20

$\mathrm{TG}^{270} \quad$ Mecp $^{\text {R270_EGFP }}$ transgenic

Tris Trihydroxymethylaminomethane

TRITC Tetramethyl Rhodamine Isothiocyanate

UV Ultra Violet

V Voltage

WT Wild Type 
Weight/Volume 


\section{Acknowledgments}

It's a great honor to express my sincere gratitude to my Doctor Father Prof. Dr. med. h. c. Wolfgang Engel for his foresightful guidance with excellent discussions and wonderful feedback during my Ph.D studies. I am very grateful for his persistent support and critical reviewing of my work. I would like to gratefully express my gratitude and sincere thanks to my supervisor Dr. Ashraf-ul Mannan for his patience, notably knowledge and understanding. I am incredibly thankful for his personal attention, interest and expertise guidance during my Ph.D studies. I would like give my sincere thanks to Prof. Dr. Sigrid Hoyer-Fender for being my thesis co-referee and for opening excellent discussions and feedback during labhours. I would like to offer my sincere appreciation to the thesis examiners Prof. Dr. Dr. Hannelore Ehrenreich, Prof. Dr. Peter Burfeind, Prof. Dr. Jochen Reiß and Prof. Dr. Peter Schu for sparing their valuable time from their busy schedule to serve as my examiners. I do not have any words to express my deepest gratitude to my friend, boss and philosopher Prof. Dr. D.N. Rao (IISc, India) who introduced me to the scientific universe. I am indebted thankful to Krishna and Sarath for their abundant help, care and constant support during my $\mathrm{Ph} . \mathrm{D}$ and pre Doctoral time. I would like to express my special and warm thanks to my collaborators Prof. Dr. Dr. Hannelore Ehrenreich, Martesa, Dr. Sergej L. Mironov, Rustam and Ilian for their constant support. I cannot imagine myself staying in Göttingen without my friends especially Karolina, Eshita, Krishna and Vishnu who helped me and were with me during whole time, so I would like to express my deepest gratitude to them. I extended my heartful thanks to my friends Nagu, Suri, Sanju Phani and Sreedhar. My sincere thanks to Karolina, Mayur, Sabastien and Sunit for wonderful discussions. I am thankful to my IIsc friends Maddy, Visu, Biocore Madhu, Prashanth, Arun, Arathi, Ruchika, Sameera, Swayam, Shyamal, Saradhi and Sanjay who stand for me in all situations. I am thankful to my labmates/friends Belal, Kamila, Heike, Yvonne, Saskia, Marta, Manar, Ola, Sandra M \& L, Priya, Nadine, Jessica, Pawel, Krzysztof, Tan, Gunji, Christian and Arne for their support. I am thankful to all my friends 
Ajay, Suresh+Sathya, Sudhakar, Malli+Ganesh, Vijaya+Giri, Vijay+Pooja, Jyothi+Rajini, Padma+Satish, Renuka+Mahesh, Deepa+Sunil, Sailaja+Sridhar for their constant support. I would like to thank to my childhood friends Ramana, Srinu, YNV, Demullu, Adi, Baskhar, Bujji, Shanmukha, Madhuri, Rabbu, Raja, Giri and Anjali for their help. I would like to thank my animal care takers Lea, Stephan, Jenny, Filitz, Cristina and Axel for their anonymous help and dedication.

My deepest special acknowledgments and thanks to my family Suryanarayana Murthy, Vijaya, Sandhya, Bhagya, Narayana rao, Jashith, Vasu, Giri, Paddu, Abhi, Sailu and all my relatives for their encouragement and constant support.

Last but not least, I would like to bow and acknowledge my thanks to the Almighty God for be with me all the way. 


\section{Curriculum Vitae}

\section{Personal Details:}

Name: Chiranjeevi Bodda

Born on 16.08.1979 at Etikoppaka in India

Address: Gutenbergstrasse 24a/6,Göttingen, 37075,Germany

Telephone: $\quad 0176 / 62256999$

E-mail: $\quad$ chiru79@gmail.com

\section{Education:}

Master of Science: $\quad$ 2002-2004 J.K.C. College, Guntur, India.

(Acharya Nagarjuna University, Guntur, India)

2006 - 2008: Junior Research fellow (JRF), Department of Biochemistry, Indian Institute of Science (IISc), Bangalore, India. (under the supervision of Prof. D. N. Rao)

Promotion/PhD: $\quad$ since March 2009 Institute of Human Genetics,

Georg-August University, Goettingen

Thesis title: "Studying synaptopathies using MeCP2 transgenic mouse models" (under the supervision of Prof. Dr. Dr. W. Engel)

\section{CONFERENCES AND WORKSHOPS}

2010: $\quad$ Poster presentation at $7^{\text {th }}$ FENS forum of European Neuroscience, Amsterdam, Netherlands.

2011: $\quad$ Poster presentation at $8^{\text {th }}$ World congress of IBRO, Florence, Italy.

2011: Course attended on 'Statistical and dynamical models in biology and medicine', Göttingen, Germany.

2012: $\quad$ Poster presentation at $8^{\text {th }}$ FENS forum of Neuroscience, Barcelona, Spain. 


\section{List of Publications}

1. Bodda C*, Tantra M*, Mollajew R, Arunachalam JP, Can K, Mironov SL, Ehrenreich $\mathrm{H}$ and Mannan AU. Mild overexpression of Mecp2 in mice causes a higher susceptibility toward seizures (In Press, American Journal of Pathology) (2013)

2. Shoukier M*, Bodda C*, Mosalaganti S, Zerr I, Breithaupt M, Pilgram SM, Mannan AU. In-frame insertion mutation in the SPG11 gene causes autosomal recessive spastic paraplegia with thin corpus callosum in a Turkish family with late age of onset of the phenotype (Reviewing in Molecular Syndromology) (2013)

3. Pantakani DVK, Czyzewska MM, Sikorska A, Bodda C, Mannan AU (2011) Oligomerization of ZFYVE27 (Protrudin) Is Necessary to Promote Neurite Extension. PLoS ONE 6(12): e29584.

4. Kifayathullah LA*, Arunachalam JP*, Bodda C*, Agbemenyah HY, Laccone FA and Mannan AU. (2010) MeCP2 mutant protein is expressed in astrocytes as well as in neurons and localizes in the nucleus. Cytogenet Genome Res, 129, 290-297.

5. Duppatla V*, Bodda C*, Urbanke C, Friedhoff P and Rao DN (2009) The C-terminal domain is sufficient for endonuclease activity of Neisseria gonorrhoeae MutL. Biochem. J. 423, (265-277).

\section{(* equal first author contribution)}

